University of San Diego

Digital USD

2005-04-01

\title{
Reconciling Temporalities: A Substantive Explanation of the Origins of Difficulty in the Nurse Patient Encounter
}

Marilyn Theresa Macdonald PhD

University of San Diego

Follow this and additional works at: https://digital.sandiego.edu/dissertations

Part of the Nursing Commons

\section{Digital USD Citation}

Macdonald, Marilyn Theresa PhD, "Reconciling Temporalities: A Substantive Explanation of the Origins of Difficulty in the Nurse Patient Encounter" (2005). Dissertations. 324.

https://digital.sandiego.edu/dissertations/324

This Dissertation: Open Access is brought to you for free and open access by the Theses and Dissertations at Digital USD. It has been accepted for inclusion in Dissertations by an authorized administrator of Digital USD. For more information, please contact digital@sandiego.edu. 


\section{TITLE PAGE DISSERTATION}

UNIVERSITY OF SAN DIEGO

Hahn School of Nursing and Health Science

DOCTOR OF PHILOSOPHY IN NURSING

Reconciling Temporalities: A Substantive Explanation of the Origins of Difficulty in the Nurse Patient Encounter

by

Marilyn Theresa Macdonald

A dissertation presented to

FACULTY OF THE HAHN SCHOOL OF NURSING AND HEALTH SCIENCE

UNIVERSITY OF SAN DIEGO

In partial fulfilment of the

requirements for the degree

DOCTOR OF PHILOSOPHY IN NURSING

$04 / 2005$

Dissertation Committee

Diane Hatton, DNSc, RN, CS, Chairperson

Mary Rose Mueller, $\mathrm{PhD}, \mathrm{RN}$

Cynthia Baker, PhD, RN 


\begin{abstract}
Nurses describe patients as difficult on a regular basis. Nursing research to date has assumed the existence of this phenomenon. Most studies have listed descriptors of the difficult patient and offered interventions for nurses to use to alter patient behavior. Locating of difficulty within the individual and failure to consider the context of the nurse patient encounter is problematic. The practice of locating difficulty in the individual absolves organizations and society of responsibility to work to change factors that contribute to the construction of difficulty. The purpose of this research was to move beyond a focus on the patient as difficult to examine the context of the nurse patient encounter, and to generate a substantive explanation of the origins of difficulty in the encounter.
\end{abstract}

The grounded theory method was used from a constructivist approach. Data sources included (a) 120 hours of participant observation on a family medicine unit in a hospital in Atlantic Canada; (b) 12 formal interviews with former unit patients; (c) 10 formal interviews with unit nursing staff, and numerous informal interviews with nursing staff during participant observation.

Reconciling temporalities was the core category that emerged in this study and was the main concern for both nursing staff and patients. The degree of reconciliation required determined the degree of difficulty in the nurse patient encounter. Knowing the patient minimized difficulty in the nurse patient encounter. Reconciliation of time was inherent in getting to know the patient. When nurses did not have the time, and patients 
did not feel that care has been delivered in a timely manner the result was temporal incongruency. The greater the disparity between the time needed and the time available the greater the need for reconciliation in the encounter. The factors that contributed to temporal incongruencies, and necessitated reconciliation were: Families, availability of supplies and equipment, who is working, and care space changes. Contextual conditions that influenced the process of reconciliation were: Unit reputation and labor market structure changes. The strategies that nurses used to reconcile temporalities were controlling, working together, managing families, and employing geographies of place/bodies. The context of the delivery of nursing care is an important nursing research frontier. 


\section{ACKNOWLEDGEMENTS}

Writing a dissertation takes a village. I owe a debt of gratitude to the citizens of my village.

My dissertation committee helped me reach new places of understanding. The journey to understanding what to date had been obscure to me was not one to be missed. The path of this journey had many branch roads to new learning, and was surfaced with numerous dissertation drafts patiently reviewed and responded to.

Dr. Diane Hatton was first my teacher, then a member of my qualifying exam committee, then graciously accepted to chair my dissertation committee. Thank-you for encouraging me to publish my qualifying exam paper. That publication taught me I could write. Your careful questioning of my work let me know I had further to go when I thought I was there. You helped me see that it takes original thinking to be considered a scholar. Thank-you Diane for your knowledge, guidance, and respect.

I met Dr. Mary Rose Mueller, my second committee member when she guest lectured in one of Diane's classes. Her vast experience and understanding of field research impressed me. Dr. Mueller willingly shared this knowledge and experience in helping me enter the field for my study, and to carry out my study. Thank-you for your careful reading of my work, your guidance in making sense out of things and for all the encouragement, including making time to meet with me while vacationing in Atlantic, Canada. 
I have known Dr. Cynthia Baker, my third committee member for quite some time. Her work ethic and achievements have inspired me. Her ability to synthesize, revise and bring clarity to written work is impressive. Thank-you Cynthia for your timely and thorough review and feedback on the various drafts of this work.

I wish to thank my employer, the Southeast Regional Health Authority, in particular Carroll Ann O'Leary, Chief Nursing Officer (CNO) at the time I started my studies and Beverly Ring, current $\mathrm{CNO}$ for their support in giving me time off to attend summer classes, and to conduct and write this research. Beth Sparks, The Senior Advisor Nursing during most of my doctoral work was a valued source of friendship and support.

I am grateful to the study hospital who accepted me as a researcher, and to the patients and staff who participated in my research. Without you none of this would have happened.

I sincerely thank Dale Babineau my transcriptionist for the quality of her work, and efficiency in delivering my transcribed data.

I acknowledge the Hahn School of Nursing for the financial support awarded me, first in giving me the Hahn Scholarship, and secondly in awarding me the 2004-2005 Irene Sabelberg Palmer award to assist with my nursing research. This financial support meant a great deal to me.

I thank my husband Daniel for his unwavering support. Each summer you travelled to California to ease my loneliness, and reminded me to stop a minute and smell 
the roses. Your interest and involvement in my studies made them easier and more meaningful. I cherished your interest.

I thank McSheffery Industries for developing the floor plan illustrating the study setting. Finally I thank the many family members and friends who encouraged and supported me throughout this very worthwhile endeavour. 
TABLE OF CONTENTS

Acknowledgements

ii

Table of Contents

List of Appendices

CHAPTER I THE PHENOMENON OF INTRIGUE 1

Purpose 5

Theoretical Perspective 5

$\begin{array}{ll}\text { Significance } & 6\end{array}$

CHAPTER II REVIEW OF LITERATURE $\quad 8$

Perspectives on the Difficult Patient 9

The sick role $\quad 9$

The sick role/Consequences in medicine 10

$\begin{array}{ll}\text { Gomerism } & 12\end{array}$

$\begin{array}{ll}\text { Problematics of the sick role } & 14\end{array}$

$\begin{array}{ll}\text { Deviance and labeling } & 18\end{array}$

Non-compliance as deviant $\quad 20$

Oppression theory $\quad 21$

Organization as oppressor $\quad 22$

$\begin{array}{ll}\text { The stigma perspective } & 25\end{array}$

The Nursing Perspective $\quad 33$

Nursing interaction theory $\quad 41$

Summary of the Literature Review $\quad 42$

$\begin{array}{lll}\text { CHAPTER III METHOD } & 46\end{array}$

Overview of method $\quad 47$

Site selection $\quad 49$

Gaining entrée $\quad 51$

Sample $\quad 55$

$\begin{array}{ll}\text { Ethics } & 57\end{array}$

$\begin{array}{ll}\text { Risk management } & 60\end{array}$

Researcher's Role $\quad 60$

Data collection $\quad 62$

Trustworthiness $\quad 64$

$\begin{array}{ll}\text { Data analysis } & 65\end{array}$

Simultaneous collection, comparison and analysis of data $\quad 65$

Coding and comparisons 65

Memoing and theoretical sampling 66 
$\begin{array}{ll}\text { Participant observation data findings } & 69\end{array}$

$\begin{array}{ll}\text { Temporal incongruencies } & 70\end{array}$

Availability supplies and equipment $\quad 71$

Labor market structure changes $\quad 71$

$\begin{array}{ll}\text { Geographies of place } & 72\end{array}$

Experience/competence/values 73

Patient descriptors $\quad 73$

Nursing staff interview discoveries $\quad 74$

Time incongruency $\quad 75$

$\begin{array}{ll}\text { Knowing the patient } & 77\end{array}$

$\begin{array}{ll}\text { Availability supplies and equipment } & 78\end{array}$

$\begin{array}{ll}\text { Controlling } & 78\end{array}$

$\begin{array}{ll}\text { Families } & 79\end{array}$

$\begin{array}{ll}\text { Expectations/geographies of place } & 79\end{array}$

$\begin{array}{lr}\text { Environmental conditions } & 80\end{array}$

Unit reputation $\quad 81$

Who is working $\quad 81$

$\begin{array}{ll}\text { Care space changes } & 82\end{array}$

Labor market structure change $\quad 83$

Patient interview analysis $\quad 84$

Time incongruency $\quad 85$

Knowing the patient $\quad 86$

Care space changes $\quad 86$

Expectations/geographies of place $\quad 86$

$\begin{array}{ll}\text { Controlling } & 87\end{array}$

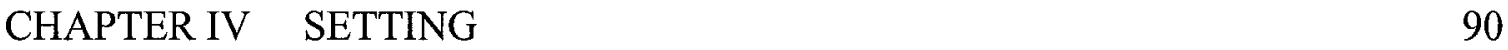

$\begin{array}{ll}\text { Patients } & 90\end{array}$

Staff $\quad 91$

$\begin{array}{ll}\text { Staff responsibilities } & 91\end{array}$

Medical care $\quad 93$

The Unit $\quad 93$

Geography 93

Unit flow 98

The context of the Canadian Health Care System 103

Atlantic Canadians and the Healthcare System 105

$\begin{array}{ll}\text { Diagram of research setting } & 108\end{array}$

$\begin{array}{lll}\text { CHAPTER V FINDINGS } & 109\end{array}$

Reconciling temporalities $\quad 110$

Knowing the patient 113

vi 
Temporal incongruencies $\quad 115$

Families $\quad 120$

Availability of supplies and equipment $\quad 121$

$\begin{array}{ll}\text { Who is working } & 124\end{array}$

Care space changes $\quad 126$

Unit reputation and history $\quad 129$

Labor market structure changes $\quad 131$

Controlling 133

Including families $\quad 135$

Geographies of place/bodies/expectations $\quad 136$

Summary

139

Diagram of findings 141

Case of the Harmonious Encounter, Temporalities Reconciled 142

Summary $\quad 144$

The Case of Irreconcilable Temporalities Leading to Difficulty 144

Summary 146

$\begin{array}{lll}\text { CHAPTER VI } & 148\end{array}$

A Review of The Substantive Explanation $\quad 148$

Knowing the patient $\quad 150$

Implications $\quad 151$

Temporal incongruencies $\quad 153$

Implications $\quad 154$

Families $\quad 156$

Implications $\quad 156$

Geographies of place and person $\quad 157$

Implications 158

$\begin{array}{ll}\text { Summary } & 159\end{array}$

REFERENCES

vii 


\section{LIST OF APPENDICES}

Appendix

Description

$\begin{array}{llr}\text { A } & \text { Consent Participant Observation } & 174 \\ \text { B } & \text { Consent Patient } & 175 \\ \text { C } & \text { Consent Nurse } & 176 \\ \text { D } & \text { Patient Recruitment Letter } & 177 \\ \text { E } & \text { Nurse Recruitment Flyer } & 178 \\ \text { F } & \text { Interview Guide } & 179 \\ \text { G } & \text { Patient Guide to Unit } & 180 \\ \text { H } & \text { IRB Approval } & \end{array}$

viii 


\section{Chapter I}

The Phenomenon of Interest

Difficult is a word that has a disturbing ring to it. When it is used to describe a patient it takes on a host of negative connotations. Nurses use this concept on a regular basis to describe some of their patients, and share a certain common understanding in describing a patient as difficult (Carveth, 1995). Concepts that become common parlance among nurses warrant exploration and description. Exploration of this phenomenon has lead to further knowledge and understanding of it. This knowledge will add to the discipline and raise consciousness regarding the effects of the widespread use of a stigmatizing term.

The literature concerning the difficult patient focused on describing characteristics that resulted in patients being labeled difficult. These characteristics included "demanding, complaining, frustrating, time-consuming, requesting often, calling frequently, manipulative, female, impolite, unreasonable and uncooperative" (Podrasky \& Sexton, 1988, p. 18). The concept of stigma appeared in the literature on difficult patients. For example, describing a patient as difficult is considered to be a stigmatizing act (Carveth, 1995; Carveth-Trexler, 1996; Johnson \& Webb, 1995; Juliana et al., 1997; Kus, 1990; Neuwirth, 1999; Podrasky \& Sexton, 1988).

The concept of the difficult patient is not new in the nursing literature. It has been the subject of at least two books by Ujhely (1963) and Stockwell (1972), and countless 
articles in the nursing, non-research literature. A recent review of the nursing, nonresearch literature confirmed the continuance of this trend (Cook, 2000; Fee, 2001; Fadiman, 1997; Gorman, 1996; Hirst, 1983; Morrison, Ramsey \& Synder 2000; Mystakidou \& Tsilika, 2000; Neuwirth, 1999; Nield-Anderson et al., 1999; Platt \& Gordon, 1999; Quan, 2000; Sohr, 1996). A common thread in this literature is the description of the characteristics of the difficult patient followed by suggestions on how to respond. In contrast, the nursing research literature in the past fifteen years included only nine studies of the concept. It would seem at first glance with so few studies that the subject is of little significance to nursing. The proliferation of articles in the non-research literature is an indication that the concept is ever present but generally seen as a problem that resides in the patient and that nurses already know the solution. Interventions suggested in the literature include: get to know the patient, listen, work on communication, admit negative feelings and get on with giving good care, set limits, allow the patient some control, do better assessments to uncover problems, acknowledge what the patient says, use contracting, and a consistent approach, reach out to the patient, and accept patients as they are (Cook, 2000; Fee, 2001; Gorman, 1996; Kus, 1990; Morrison, Ramsey \& Synder, 2000; Neuwrith, 1999; Nield-Anderson et al., 1999; Platt \& Gordon, 1999; Quan, 2000; Sohr, 1996). Despite the listing of these interventions there is almost no evidence in the difficult patient literature about whether or not they work.

The phenomenon of the difficult patient is also known to cause dissatisfaction for patients and nurses (Breeze \& Repper, 1998; Podrasky \& Sexton, 1988; Santamaria, 1996). A known relationship exists between patient satisfaction with nursing care and general patient satisfaction (Beck \& Larabee, 1996; Jacox, Bausell \& Mahrenholz, 1997). 
The present Registered Nurse (RN) shortage is the subject of numerous studies to determine strategies to retain nurses and recruit to the profession (Aiken, Havens \& Sloane, 2000; Aiken et al., 2001; Aiken, Clarke, Sloane, Sochalski \& Silber, 2002; Blegen, 1993, Cowin, 2002; Foley, Kee, Minick, Harvey \& Jennings, 2002; Ingersoll, Olsan, Drew-Cates, deVinney, \& Davis, 2002; Kangas, Kee, McKee-Waddle, 1999; Stienbrook, 2002). These studies found organizational variables that led to nurse satisfaction. Two of these factors were favourable nurse patient ratios and having control over practice. In contrast the variable with the highest predictor of nurse dissatisfaction was stress. The presence of the phenomenon of the difficult patient is known to leave nurses feeling stressed, frustrated, angry and helpless (Podrasky \& Sexton, 1988; Santamaria, 2000).

During the past twenty years of working as a nurse in a variety of settings this researcher has observed the phenomenon of nurses describing patients as difficult on a regular basis. Initially this seemed to be part of what was to be expected working as a nurse. Over time it became apparent that the phenomenon was not as simple as a patient presenting certain behaviors and the nurse reacting in a certain way to these behaviors. Little is known about what actually happens between nurses and patients in the "nurse to difficult patient" encounter. The exploration of "what all is going on here" is what gave wings to the idea of conducting this research. The perpetuation of this concept among nurses is troublesome. The belief by nurses that being difficult resides within the patient has placed thinking surrounding the concept in a cage.

As indicated above, the researcher was not only interested in the origins of the concept of the difficult patient but also how troublesome the perpetuation of the 
phenomenon is. In the process of defending this dissertation proposal the researcher was asked if studying the phenomenon of the difficult patient could be considered an act of perpetuation of the phenomenon. Initially this notion was rejected and the researcher persisted with the idea of studying the phenomenon of the difficult patient because that is how nurses described encounters that did not go well. During the process of preparation for data collection the desire to interrupt the perpetuation of the use of this term to describe patients was greater than the researcher's desire to use terms commonly understood by nurses. The decision was made to re-conceptualize the approach to the study and rather than conduct yet another study of the difficult patient the focus of this study became the origins of difficulty in the nurse patient encounter.

Among the studies reviewed about difficult patients, most persisted with the listing of the characteristics of the difficult patient, and tended to locate difficulty in the patient. There were two studies that suggested the researcher look beyond the patient to the context of care and that failure to take this broader view would result in yet more studies perpetuating current notions of the patient as the source of difficulty. This led the researcher to consider a wider conceptualization of the phenomenon. Rather than simply look for difficulty, and difficult patients, why not explore the nurse patient encounter. The exploration of encounters that went well was very instructional in explaining encounters that did not go well. In this study the focus was the nurse patient encounter. This focus made the perpetual describing of patients as difficult, problematic. This decision was validated on numerous occasions during participant observations for this research when staff engaged the researcher in conversation about encounters, not difficult patients. 
Purpose

The purpose of this ethnographic field study was to generate a substantive explanation of the origins of difficulty in the nurse patient encounter. A grounded theory approach was used to study the phenomenon. Data collection consisted of 120 hours of participant observation on a family medicine nursing unit, in-depth interviews with 12 former patients of the unit and 10 nursing staff from this unit in a hospital in Atlantic, Canada. The specific aims of the research were to answer the following questions: (a) How did nurses describe the origins of difficulty in the nurse patient encounter? (b) What were patient's perceptions of recent care encounters? (c) How did the context of care influence the nurse patient encounter? and (c) What were the consequences of difficult nurse patient encounters for patients and nurses?

Theoretical Perspective

The theoretical foundation of grounded theory is symbolic interactionism. This theory has three basic premises: (a) Individuals act toward things on the basis of the meanings things have for them; (b) meanings arise through social interaction among humans; (c) meaning fluctuates through the human self interaction, interpretive process (Blumer, 1969). Blumer saw social interaction itself as the creator, interpreter and constant re-definer of meaning for individuals. In other words every human act is an interpretation of what just happened and not a reaction to the way in which the world is organized.

This theory is congruent with the exploration of the problem at hand. To date, most of the research on the phenomenon of the difficult patient has focused on identifying patient behaviors that are problematic and recommending nursing 
interventions that will correct these behaviors. This approach situates the source of the problem in the socialization of the patient and in the attitudes, emotions and ideas of both the patient and the nurse. Rather than looking for simple cause and effect, understanding interaction is sought. The grounded theorist interviews participants and does participant observation to work toward an understanding of the problem. This understanding comes from the meanings regarding the phenomenon as described by the participants. Significance

This study contributes to nursing knowledge about what happens in the nurse patient encounter. Nurse patient encounters take place in a context and this study focused on context and explored how difficulty was socially constructed. This discovery revealed the contribution that micro and macro organizational factors make in the construction of difficulty and points to the need for Nursing Theory to have a more expanded view of the environment. Knowing that difficulty is constructed, and understanding how this happens can lead nurses to find new ways of being in the nurse patient encounter that interrupt the practice of locating difficulty solely within the individual.

Nursing interaction theorists, Orlando, Travelbee, Paterson and Zderad (Meleis, 1997), King (1971), Wiedenbach (1964) and Peplau (1952) considered the nurse patient relationship to be the essence of nursing and assumed the context of care allowed for the establishment of this relationship. Environment for these theorists was considered to be immediate to the patient. The theory generated in this study identified factors in both the micro (immediate) as well as the macro environment of the patient that contributed to the creation of difficulty. This finding points to the need for nursing theory to have a more expanded view of the environment. 
During three decades of nursing practice the researcher heard nursing colleagues use the term difficult patient and used the term at times herself. The discomfort the researcher felt in using this term and in hearing it used led to conducting this study. In order to broaden the focus for this study, a comprehensive review of the literature on the difficult patient was undertaken from a variety of perspectives. These perspectives are outlined and synthesized in the following chapter. 


\section{Chapter II}

\section{Review of Literature}

A comprehensive review of literature on the phenomenon of the difficult patient was undertaken from several perspectives. These perspectives included: The sick role, deviance and labeling, non-compliance, oppression, stigma and nursing. This review served to identify what research has been done and what is known about the phenomenon already. A substantial body of literature exists on patient's who are considered to be "good" "bad", "problem" and "difficult." This review of literature served to further situate the reader regarding what is known about the difficult patient in order for the researcher to design nursing research to interrupt existing discourses.

The literature reviewed here provided a backdrop of considerable depth regarding health-care provider understanding and construction of difficulty concerning the phenomenon of the "difficult" or "problem" patient. Several classic literatures were reviewed, compared and critiqued to enable the researcher to come to a fuller understanding of the phenomenon of the difficult patient. The review of these classic literatures will begin with Parson's sick role perspective developed from his Social Theory of the early 1950's. The problematics of this theory are illustrated in the studies described in Medical Men and their Work and in the literature on "gomerism." The 
construction of deviance and patients as deviant were reviewed using the works of Becker $(1966,1973)$ and Kleinman $(1988,1995)$. The work of Becker and Kleinman also explains how we, and the society in which we live construct phenomena. Noncompliance as deviance and its intersection with the phenomenon of the difficult patient are presented. The contribution of oppression theory in the construction of the difficult patient will be explored. The role played by the organization, and the organization of work, in doctors and nurses construction of difficulty were illustrated in the field studies by Zussman (1992) and Chambliss (1996). The contribution of the stigma perspective to understanding of the phenomenon was explored. Finally a detailed critique of one sociological study considered to be directly related to the proposed research and the nursing studies about the difficult patient are also presented here.

Perspectives On The Difficult Patient

The sick role.

Parsons, a structural functionalist, is credited with the development of social system theory to which he linked health and illness. In his social system theory, he explained that societies establish norms for how individuals are expected to act. From these norms flow the accepted roles of individuals. Norms are based on the beliefs and values of a society. According to Parsons, the key elements of the American value system are: (a) Mastery over the environment both physical and social, (b) economic productivity, (c) capacity for achievement and (d) necessity of achieving education and health. From these values Parsons (1979) developed what he called the sick role to which the following attributes were ascribed: (a) Normal individual capacity is temporarily interrupted and therapeutic assistance is needed, (b) this incapacity exempts the person 
from fulfilling usual roles, (c) the incapacity is considered by society as legitimate, the individual is not at fault; however, the individual must understand that incapacity is undesirable and must work to get well and (d) the individual is obliged to seek and accept qualified help to assist with return to normal capacity. Parsons alluded to those individuals who do not cooperate with treatment as deviant but did not elaborate on this. Parsons likened health which he defined as "the state of optimum capacity of the individual for the effective performance of the roles and tasks for which he has been socialized" (p.132) to capital in the economic system. The notion of the sick role does explain the findings in the nursing literature on the difficult patient and will be taken up in that section of the literature review.

\section{The sick role/ Consequences in medicine.}

Quint (1965) found the provider managed patients through a process referred to as "information control." Davis (1960), in a study of families of children with polio, found that families knew very little about the treatment and prognosis of the child. Likewise Shiloh (1965) found patients often knew the nature and cause of their problem but little about their treatment and prognosis. Medicine was seen as treating disease and neglecting the psychosocial aspects of care. Walsh and Elling (1968) hypothesized that as professional groups strive for increased power and prestige, group members may alter their commitments to members of lower socio-economic groups. They found nurses (believed by the researchers to be part of a group seeking to improve their professional status) distanced themselves from lower income patients. These researchers explained their findings in terms of class structure, the higher the socio-economic status of a group the greater the status and power. Groups such as nurses who strived for improved status, 
walked a tightrope. If a group altered its orientation to serve those with power and influence, then members of lower socio-economic groups would be even worse off. Walsh and Elling believed that one solution was to provide greater financial and professional recognition to those who dedicated themselves to working with lower income groups, however, they were very skeptical of the likelihood of this happening. This finding may also be due to nurses perceptions that lower income patients are perhaps at fault for their illness and are not working hard enough to get well, in keeping with the notion of the sick role.

How then are the attributes of the sick role manifested in the studies just presented? In these studies the patients were certainly considered legitimately ill. The patients or families sought legitimate medical care and were expected to accept that, having done so the medical provider was doing the right thing. Patients, however, began to encounter difficulty when the expected temporary nature of an illness was prolonged. The sick role norms are based on a curative model of disease where treatments tend to cure and patients return to normal productivity. When this does not happen and patients and families begin to ask questions, providers employed strategies such as information control. It was at this point that healthcare providers began to doubt the legitimacy of the patient's illness and saw the problem as residing within the patient. Findings revealed the expectations of the patient role were very unclear to patients and left them with the perception that power rests with physicians and nurses and patients were on an organizational conveyor belt never really knowing the schedule of the belt or how to interrupt the schedule. Further consequences for patients who did not fit the sick role 
expectations have been described by (George \& Dundes, 1978; Leiderman \& Grisso, 1985; Lorber, 1979; Mizrahi, 1985).

\section{Gomerism.}

The phenomenon of the difficult or problem patient has been explicitly described in sociological studies of physicians, particularly physicians in training. One pejorative term that has been used by physicians to describe the difficult patient is "gomer" (George \& Dundes, 1978; Leiderman \& Grisso, 1985). George and Dundes describe the person labelled as gomer to be: Male, older, dirty, debilitated, a chronic alcoholic, derelict, down and out, on welfare and having a history of multiple admissions to hospital. These authors developed a "gomer assessment" and considered patients with this label to be part of hospital folklore. George and Dundes clearly located the problem within the patient and saw no societal connection to this phenomenon. In contrast, Leiderman and Grisso take exception to the definition of George and Dundes. In their study of 18 patients they found these patients came from various races and classes and described them as having irreversible mental decline, no place to go to live and unable to care for themselves. These authors suggested in their study that the "gomer" was a reflection of problems in the health care system and society but did not elaborate on what problems they were referring to. The labeling of patients in both these papers as gomers reflected the sick role as previously described. These patients did not get well and go home as expected and were seen as a burden and labeled.

Mizrahi (1985) worked extensively with medical interns and residents and found them trained to: (a) Focus on diseases, not patients, (b) avoid patients and rely on chart details and (c) treat patients as non-persons. Mizrahi described physician behavior as 
classist and made explicit that this was a result of physician training that is steeped in the sick role tradition.

Lorber (1979) also described the patient role in a study conducted in a 600 bed hospital with patients scheduled for elective surgery $(n=103)$. Patients were interviewed upon admission to obtain their views on how they believed they should act while in hospital and were then observed postoperatively to see how they did act. Lorber predicted that patients who "felt a good patient was one who was cooperative, trusting, uncomplaining and undemanding would conform to these norms during their hospital stay" (p. 204) while patients who did not feel this way would be considered deviant by hospital staff. Findings did support this prediction, however, Lorber also found that hospital staff expected patients to make their needs known and that nurses and doctors were not unilateral in their labeling of patients as good or bad. This labeling was restricted to those staff who bore the brunt of the patient's wrath. Hospital staff expected to conduct their work with minimal disruption. Problem patients in this study fell into two groups, those who were seriously ill, complained a lot and required a lot of reassurance and those who were not seriously ill in the eyes of the staff and complained a lot. The second group were considered particularly problematic, were stigmatized and risked medical and nursing neglect. Lorber believed that "inpatient care imposes on patients a role characterized by submission to professional authority, enforced cooperation, and depersonalized status" (p. 203).

Tagliacozzo and Mauksch (1979) conducted 132 patient interviews, asking patients what they thought nurses and doctors expected of them. Patients responded with statements such as; physicians expected cooperation, trust and confidence. In addition, 
patients responded that being on good terms with doctors and nurses was essential to their well-being, and they felt helpless. The role imposed on patients as described by Lorber (1979) as well as Tagliacozzo and Mauksch does parallel the sick role. While patients are in the sick role the medical provider will decide who is legitimately ill, when and where they should seek care, that they comply with the medical plan of care and that medicine will decide when they are cured.

\section{Problematics of the sick role.}

Numerous authors have critiqued the sick role concepts over the years, one of whom was Gallagher (1979). Although respectful of the work of Parsons, Gallagher believed it completely negated the existence of chronic illness and of health maintenance and prevention. He believed Parsons sick role assumptions represented an acute illness model of disease only. In addition to this criticism, there is an absence of any consideration of the context from which patients come and return to. Patient care informed uniquely by the sick role perspective, thus perpetuates, the belief that the problem of the difficult patient resides within the patient.

Kleinman (1988), a psychiatrist, conducted clinical and ethnographic studies of the process by which meaning is created in the chronic illness experiences of patients in North America and China. In his work, he focused on the meanings that symptoms and behaviors had for patients. Kleinman illustrated the paradox of modern medical care, and the focus on the biological domain of care with the failure of the practitioner to understand the meaning of illness in the chronically ill patient. This has served to contribute to the exacerbation of chronic illness as well as the decline in medical practitioner satisfaction. Doctors learned to attend to disease not illness. Disease is just 
one dimension of illness. A medical intervention may improve or cure the disease. The illness however is embedded in the life world of the person and the care provider must gain some insight and understanding of the psychological meaning that illness has for for the person before them. Kleinman maintained that people's experience of chronic illness only makes sense when viewed within the context of their life world. Treating illness means meeting and getting to know the life world of the person. Kleinman proposed a new method for physicians to learn about the patient's life world. In addition to the typical physician patient interview, Kleinman called for the incorporation of an "ethnographic attitude" on the part of the practitioner. This attitude will enable the practitioner to learn to listen to the patient's story and to begin to understand what illness, not disease, means to the patient. This attitude will enable the practitioner to understand the patient's view by developing an explanatory model of the person's illness. A useful example of an explanatory model of a person's illness that operationalized much of what Kleinman said was elaborated by Tripp-Reimer (1984).

In viewing the health of individuals Tripp-Reimer (1984) proposed a grid with two axes, disease/nondisease, (horizontal) and illness/wellness (vertical). This model has four quadrants. In quadrant I the person feels well and no disease is present. In quadrant III the the person feels ill and the medical practitioner finds a disease process. In these two quadrants practitioners and patients are in agreement on the health status of the person. In quadrant II the person feels ill, however, the medical practitioner can find no disease present. In quadrant IV the person feels well and disease is found to be present. Tripp-Reimer maintained that nursing has an important role to play in quadrant's II and IV by seeking to further understand from a cultural perspective what illness and disease 
mean for the person. Further understanding of the meanings of disease and illness for patients allows nurses to provide information and explanations that foster self-care activities. Kleinman's commitment to ethnography in medicine is compelling. He readily acknowledged the usefulness of measurement of phenomena in patient care but insists measurement must then be related to "context, social process, and historical event" (Kleinman, 1995, p. 83).

Kleinman (1988) is provocative in his critique of existing health and social systems. The existing health care system with its biomedical focus on the cure for acute disease states totally disserves those people living with chronic illness "we have powerful techniques but no wisdom"(p. 142). The present health-care system contributes to the creation of further deterioration in patients living with chronic illness. When patients do not believe that practitioners are listening to them, they often seek complementary therapies that may at times exacerbate existing conditions. In order for a shift in medical care to occur, Kleinman maintained medical students need to learn the ethnographic interview. More importantly medicine needs to recognize the problems in the present paradigm of care and become activists for political change.

Kleinman (1995) manifested his activism through research and writing. In his examination of the recently popularized medical diagnosis of Post Traumatic Stress Disorder (PTSD) we discover how social problems are transformed into problems of the individual. In this instance, the problem is medicalized. Kleinman wants us to reflect on the social process and history that have led to the existence of PTSD. We are reminded that the psychological and physical responses of soldiers and civilians to war, terror, and violence are certainly real and should be anticipated. What he objects to is the assignment 
of a diagnosis that exonerates a society as the source of the suffering and points to the individual as the source.

Society values cure and financial solvency. The sick role is based on these values. Activities that cannot be measured to demonstrate this are not valued. Disease that is curable is legitimate and therefore makes the person legitimate. The chronically ill challenge and frustrate the system and the practitioners because they do not fit the model of cure. Kleinman (1988) likens the dysfunctionality of the interdisciplinary teams that discuss chronically ill patients as metaphors for the treatment these patients receive. The team usually experiences a constant jockeying for position among members for their point of view to be accepted which may have nothing to do with what the patient wants or needs.

Kleinman (1988) in his discussion of chronically ill patients referred to difficult and problem patients. Those who are chronic medical patients, have personality disorders, complex life situations, are hostile or angry are described as difficult. Additional factors that contributed to practitioners identifying patients as difficult included the inappropriate expectations of an acute care medical system and caregiver frustration. Kleinman asked, is pain the person's language of communication for a very difficult and complex life situation? Any chronic illness is deeply embedded in the social world of the person. Beginning practitioners copy all that is known from others and written by others. An experienced competent practitioner stops copying and begins to think originally. This original thinking interrupts acts of stereotyping and can help find healing ways. In the absence of original ways of thinking, existing discourses are relied 
upon. One of these discourses is to blame or to describe as deviant what is believed to be the object of immediate frustration, for the nurse this may be the patient.

\section{Deviance and labeling.}

Carveth (1995) framed her nursing research on the difficult patient using deviance and labeling theory. This led the researcher to the review of two classic works to understand deviance and its origins. Becker (1966) edited a book containing several sociological studies and essays that illustrated the departure from traditional early 20thcentury thinking surrounding deviance. Until the 1950 's, individual acts considered deviant from the norms of society were seen as inherent to the personality of the individual. It then became the duty of the professional to find a way to modify the behavior of the deviant individual. A description of deviance as an interactional process began in the 1950's. This approach examined the whole of the interaction between individuals and individuals and society, and is based on the premise that "deviance is a process of interaction" (Becker, 1966, p. 3). In the process there are at least two participants, the person who is said to be deviant and the person who is saying the other is deviant. Becker believed the process by which an individual comes to be called deviant is what is commonly referred to as labeling. This shift in the approach to studying deviance came about in part because sociologists noticed that acts described as deviant in one situation were not necessarily considered deviant in all situations. Society made rules regarding phenomena but also modified them based upon certain circumstances.

Examples of this variation in reaction to the acts of individuals based upon circumstances was found in the work of Winick (1966) who studied physician narcotic addicts and found physicians were rarely criminally charged when found to be in 
violation of the criminal code as were street addicts. The status a society ascribed to the physician shielded them from the usual process. Schwartz and Skolnick (1966) found the skilled laborer attempting to seek gainful employment after incarceration had a much more difficult task than the physician found guilty of malpractice who kept his/her job and was supported by the medical community.

These studies are among a large number that supported the construction of deviance as an interactional process. Becker (1966) believed it necessary to move away from the belief that deviance is a quality of the person. This leads members of society to believe that no matter what, if the person has the trait there is little to be done. The sociological approach advanced in the 1960's was "if we viewed deviance as something that arises in interaction with others, we realize that changes in interaction may produce significant changes in behavior " (Becker, 1966, p. 3).

Becker (1973) further elaborated this thinking on deviance in his classical work Outsiders: Studies in the sociology of deviance. Becker defined deviance as "the infraction of some agreed-upon rule" (p. 8). Deviance is described as a phenomenon and is made up of "the person who says an act is deviant, the process of arriving at the decision the act is deviant and the situation "(p. 8). Becker saw this phenomenon as much larger than any individual and believed as soon as the individual was judged as deviant we are prevented from seeing the act of judgment as part of the phenomenon.

In writing about outsiders, Becker (1973) was referring to two groups (a) the deviants, those who are judged by others as deviant and (b) the rulemakers, often viewed by the person labeled deviant as outsiders. Through this classical work Becker implored the reader to consider the whole process surrounding the use of the term deviant. He 
believed this process to be a dynamic one, that varies over time, and according to who the players are and what is at stake. Becker also maintained that individuals in their responses take their cues from the responses of others. Thus, the immediate interaction as well as the micro and macro context of the interaction must be considered to understand the phenomenon of deviance.

Non-compliance as deviant.

Healthcare providers apply the label of deviant to patients who are seen as noncompliant (Carveth, 1995; Juliana et al., 1997; Parsons, 1979). The concept of noncompliance with its origins in biomedical theory (Haynes, 1979) both parallels and intersects the concept of the difficult patient. Nurses label patients difficult, because the patients; (a) do not act as expected, (b) hold beliefs contrary to those of the nurse, and (c) challenge the nurses' competence. This labelling is paralleled in medicine when patients are labelled non-compliant because they fail to follow medical orders. The concepts intersect in that they share a common ideology. Many nurses and physicians consider the patient as the source of the problem.

Haynes (1979) defined non-compliance "as the extent to which a person's behavior (in terms of taking medications, following diets, or executing lifestyle changes) did not coincide with medical or health advice" (p. 2). This definition remains pertinent today, demonstrating the presence of sick role ideology. The professional is all knowing and the source of non-compliance is the patient. Fineman (1991) noticed this objective definition of non-compliance by medicine. Like his predecessors, Kleinman (1988) and Becker $(1966,1973)$, Fineman questioned the acceptance of the belief that the source of non-compliance is the patient. He conducted a field study using long-term observations 
and in-depth interviews with healthcare professionals. Fineman found the values, beliefs and expectations of healthcare providers were frequently incongruent with those of their patients. This incongruence becomes the source of healthcare provider construction of patient non-compliance. Fineman believed that greater healthcare provider understanding of patient's beliefs and values could remedy non-compliance.

Kleinman (1995) emphasized the importance of paying attention to context. He insisted our gaze be fixed on context, social process, and history surrounding all phenomena. The emphasis on context by Kleinman is instructive and if heeded prevents the use of frameworks that may create and perpetuate labels such as "deviant." Kleinman's suggestions called for inductive approaches to phenomena as opposed to deductive. Inductive approaches inherently pay attention to context. The context of care was central to this study. This context was the hospital and many hospitals have hierarchical structures that may be oppressive.

\section{Oppression theory.}

The nursing research literature on the difficult patient indicates that female nurses are likely to describe female patients as difficult (Podrasky \& Sexton, 1988). This is a manifestation of horizontal violence, a characteristic of oppressed group behavior. This led to the exploration of oppression theory and the possible role it may play in the construction of the phenomenon of the difficult patient

The following description of oppression theory was that described by Roberts (1983) adapted from the work of Friere. Individuals and groups are oppressed when dominated by forces external to themselves with greater power and status than they. The latter are the dominant group and the oppressed are the subordinate group. The norms of 
the dominant group are considered the "right" norms with respect to language, race, class, culture and identity. The subordinate group is seen as inferior in at least one if not all of the above characteristics. Over time the group who is oppressed gradually comes to internalize the beliefs about themselves held by the dominant group. This results in the oppressed having a negative view of self as well as feelings of low self-worth. The process of oppression is complete once a group has lost their language, culture and thus, their identity. At this point the oppressed have only the oppressor as a role model and they come to believe that being like the oppressor will lead them to success and entry into the dominant group. Oppression is manifested in a variety of ways. One of the most common is the submissive - aggressive or horizontal violence syndrome. This happens when the oppressed are unable to express aggression against the oppressor, a lot of complaining will occur within the group. This leads to frustration and self-deprecation. Members fear retaliation from the oppressor and continue with the inter-group conflict. The oppressor interprets this internal conflict as evidence that the group is inferior and incapable of self-governance.

Organization as oppressor.

Organizations have social structures. The hospital structure has already been described as having a hierarchical history. Hospitals of today are attempting to flatten those hierarchies but many of the employees in these hospitals with flattened organizational structures have been socialized to a hierarchical model and perpetuate behaviors that preserve domination. Brandi (2000) in her research with women hospital executives in southern California found participants described the healthcare environment as male-dominated, patriarchal and conservative. The majority of nurses continue to be 
employed in hospitals and, therefore, continue to experience at least some degree of dominance and "dominance is most complete, when it is not even recognized" (Cleland, 1971, p. 1543).

There are two important hospital field studies conducted by sociologists that involved doctors and nurses. These studies are important because the authors consider the organizations where doctors and nurses work as a factor in how these professionals come to act. The first study was by Zussman (1992) who conducted field studies in two intensive care units (ICU) to learn about the relationship between medical ethics and the practice of medicine. Zussman found, in general, ethics are guided by principles and rules. Physicians, however, in their day to day work make decisions on a case by case basis and not by general rules. Ethics reformulates technical problems into moral ones, physicians do the opposite. Traditionally, patient autonomy has been an alien concept to physicians because it threatens physician authority. The doctor patient relationship has seen a shift toward patient rights, primarily manifested through the use of informed consent. Medicine, however, continues to shape the choices of patients.

In terms of difficult patients, Zussman (1992) found that doctors and nurses were diligent in their care for all patients. Doctors and nurses were resigned to the fact that problem patients will always exist. The doctors and nurses in this study reduced the patient situation to the technical. The cause of the present problem was never addressed and the problem was seen as the patient. Zussman acknowledged that physicians were a product of their training and of the organizations in which they practice. He observed that nurses were valued for their technical expertise, they chose to work in the ICU to have 
less interpersonal patient contact, and they were subordinate to the rules of the organization and as such were unable to be patient advocates.

Zussman (1992) described hospitals as being organized to move patients through as quickly as possible. This does not allow for examination of the context that surrounds the patient. At the same time when the "difficult patient, gomer, frequent flyer, noncompliant person" returns to the hospital, blame is located within the individual. This happens for two reasons (a) systems of care are not organized to treat what is not measurable and (b) physicians learn how to cure known diseases. Physicians and administrators run hospitals and they have learned this is how health care is to be delivered. Zussman argued that nurses choose to work in ICU to have less patient contact as a consequence of the organizational valuing of technical expertise and following the rules. ICU nurses do have greater status and decision-making opportunities. Nurses often go to work in ICU because nurse to patient ratios on general units allow them so little time with patients (Aiken et al., 2002).

Chambliss (1996) conducted field work over a ten year period in which he interviewed nurses and observed them in their work to explore the moral geography of the hospital and what it meant to nurses to work in the organizations in which they worked. Chambliss observed that nurses in hospitals couldn't own their work. Nurses were subordinate to the rules and policies of the organization and to the orders of the physician. Chambliss wrote with respect for all of the nursing care delivered by nurses, he also noted they did not receive the respect they were owed for what they did. According to Chambliss hospitals are an abyss of routines and roles and patients are objectified in order to preserve hospital routine. Nurses are expected to learn the routines 
and roles and to remain within them. Nurses who became routinized accepted as normal what the non-nurse would consider to be an emergency. Some nurses were unable to be routinized, meaning they had limits to what they considered routine.

Chambliss (1996) noted the degree of frustration that nurses experienced with ethical dilemmas. The question ethics aimed to answer was, what should be done? This often meant medicine decided. Frequently what medicine decided was in opposition to what nursing thought was correct. This conflict had its origins in the basic philosophies of the two groups, medicine cures and nursing cares. Chambliss recommended nurses devote their energies to well designed organizational routines and acknowledged this necessitated nurses being a part of the organizational policy and decision making processes. He captured the importance of the role of the nurse in the hospital organisation, as well as the organisational dynamics that frustrated nurses, and made it difficult for nurses to be part of the policy and decision making process. Labeling patients as "difficult" maybe a manifestation of nurses" frustration. Describing patients as "difficult" was also identified as a stigmatizing act in Chapter 1. This review of literature will now consider the stigma perspective.

The stigma perspective.

Stigma is a theoretical perspective identified and described in the sociological literature. Both the sociological and the nursing literatures refer to labeling patients "difficult" as a stigmatizing act. The phenomenon of the difficult patient has not been examined from a stigma perspective until recently. In Macdonald (2003) the stigma perspective was employed as a lens to review the nursing research literature on the difficult patient. Excerpts from this paper are presented here including an overview of 
what the stigma perspective is and how this perspective contributes to further understanding of the difficult patient.

According to Charon (1998) Erving Goffman, sociologist and author of the book Stigma: Notes on the management of spoiled identity, was considered to be a symbolic interactionist. Charon described symbolic interactionism as a perspective. Informed by this perspective Goffman's (1963) research flowed from his observations of people in social interaction. He believed individuals become who they are from what they have learned in interaction with the people who constitute a society. Society in turn becomes what those individuals have internalized. He saw this interaction as dynamic.

Goffman (1963) began his essay on stigma by saying that stigma is "a deeply discrediting attribute" (p. 3). He immediately went on to say that in speaking about stigma what is really needed is a "language of relationships, not attributes" (p. 3). Relationships are developed through social interaction. Goffman explained that in society, identity norms have been established through social interaction and are internalized by its members as they grow and develop. The people a society sees as meeting these identity norms are described as "normals" and those who do not meet these norms are the "stigmatised." Keeping in mind the dynamic nature of social interaction Goffman saw normals and the stigmatised on a continuum and suggested the status of an individual can vary along the continuum. There are those who may be stigmatised due to a physical deformity. They may eventually be able to have this deformity corrected and thus be identified as normal. For others whom society identified as normal, some lifealtering event may occur that leaves them physically deformed or drug addicted and thus stigmatised. He discussed the degree of discomfort normals feel in interaction with the 
stigmatized. This uneasiness can stem from trying to establish a balance in social interaction between being overly sympathetic and ignoring the stigma to the point that impossible demands are made. Goffman also argued that normals might consciously or unconsciously use stigmatization as a means of formal social control. Normals in society expect the stigmatized to play their part, know their place and not test the limits. Goffman closed his essay by describing the consequences of being stigmatised. These consequences included self-derogation, self-hate, suspiciousness, depression, hostility, anxiety, defensiveness and bewilderment.

The stigma perspective moved the discussion of the difficult patient from a description of attributes to a discussion of relationships. Healthcare providers often saw the phenomenon of the difficult patient as residing within the patient. The stigma perspective with its emphasis on relationships makes it clear that the nature of the social interaction between nurses and patients is a contributing factor to the existence of the phenomenon. The problem does not reside within the patient nor does it reside within the nurse in its entirety. The manner in which both the nurse and the patient have been socialized lead them respectively in their social interactions.

There is an expectation on the part of the professional to know and understand the theories at work within social interaction and to act in such a way as to minimize social judgments leading to acts of labeling and stereotyping. The notion that the stigmatised and the normals are part of a continuum does expand thinking around the phenomenon of the difficult patient. Both patients and nurses have exhibited characteristics that were described as the consequences of stigma. If the origin of the phenomenon does not reside uniquely within the patient or the nurse then logically, organizational and societal 
contexts must be examined. Employing the stigma perspective to illuminate the phenomenon of the difficult patient has created possibility in furthering understanding of it.

The phenomenon of the difficult patient has been examined from the perspectives of the sick role, deviance and labeling, non-compliance, oppression and stigma. These perspectives contributed to the knowledge about this phenomenon but fall short of full illumination. There is a risk in the unilateral application of any single theory to phenomena. The unilateral application of theory results in "statements about universals rather than pluralities and diversities" (Scott as cited in Wuest, 1995, p.127). The intent here was not to arrive at a single theory that may explain the existence of the phenomenon but rather to explore theories to determine their utility in informing the phenomenon of the difficult patient.

The expedition into the world of these perspectives has been worthwhile. In the works reviewed, the sick role and oppression theory continue to be part of the life world of the healthcare provider and as a result providers stigmatize and label patients. Social scientists like Becker and Goffman for almost four decades have argued for a discourse of relationships. Until research on the context of care has the same status as measuring the outcomes of care, locating difficulty within the individual will persist.

Before departing this section of the literature review, there is one sociological study that has direct relevance to the proposed research. Fineman (1997) chose the difficult patient as his phenomenon of study. He did so because he noted research on the doctor-patient interaction as well as anecdotal literature maintained that difficult patients were easily identified by healthcare providers. These providers shared a common 
understanding of who the difficult patients were and the belief that the difficulty resided within the patient. Fineman could find no research to support these suppositions. He conducted an ethnographic study using what he described as an intrepretivist/constructivist approach. The study was conducted in a large western U.S. hospital on three different units over a period of 18 months. Informal interviews were held with interns, residents, doctors and nurses. Participant observation was also carried out during this study. Formal interviews were conducted with 31 doctors, 32 nurses and 15 patients whom doctors and nurses identified as difficult. During the initial four months of the study a list was developed of characteristics that doctors and nurses used to describe difficult patients. The list eventually had 34 characteristics categorized under three headings: (a) Circumstantial problems, (b) medical problems and (c) behavioural problems. This list was used as an instrument during the formal interviews. The study was guided by four research questions:

(1) How do doctors and nurses define and understand patients as difficult? (a) Are there differences in the ways in which doctors and nurses define and understand patients as being difficult? (b) do doctors in-training and doctors vary in the way they define and understand difficult patients? (c) do nurses in-training and Registered Nurses (R. N.'s) vary in the way they define and understand difficult patients (2) by what means do doctors and nurses construct their understandings of difficult patients? (a) what is the meaning making process? (3) what is the essence of doctor's experience of difficult patients? (a) how is this experience made known to them? Others? (b) what does doctor's experience 
reveal about their perceptions of their interactions with patients? (4) what if any social function do difficult patients serve? (Fineman, 1997, pp.7-8)

Fineman (1997) used quantitative methods to answer questions one and two. The type of quantitative design was not described. The previously mentioned instrument consisting of 34 characteristics grouped under three categories of difficulty; circumstantial, medical and behavioural was given to each nurse and doctor at a formal interview. Participants were asked to check off all characteristics that represented the difficult patient. Doctors and nurses were compared on each category of difficulty using $t$-tests, the strength of relationships among variables was measured using eta ${ }^{2}$. The category of behavioural difficulty was divided into eight sub-sets, Fisher's exact tests were used to compare sub-sets, the association between doctors and nurses and the numbers of each who cited factors as difficult. The Chi-square and phi coefficient were used to compare the association between providers expectations of behavior with their citations of behavioural difficulty.

In response to the first research question, no significant difference was found between doctors and nurses in their reports of difficulty. Doctor's descriptions of difficulty remained constant whether in training or completed. RN's indicated significantly more difficulties than nurses in-training $p=<.02$. Doctors reported significantly more difficulties than nurses in-training $\mathrm{p}=<.01$.

In response to the second research question about the means used by doctors and nurses to construct their understandings of difficult patients Fineman (1997) found doctors indicated significantly more total characteristics of behavioural difficulty than nurses $\mathrm{p}=<.05$. This significance was explained by comparing doctors and nurses 
behavioural expectations. A standard dictionary definition was used by the researcher to define expectations "anticipated, hoped for, supposed, or assumed with a high degree of certainty to the point of making preparations for or anticipating particular things, actions, or feelings" (Fineman, 1997, p. 231). Fineman maintained "doctors expect to form a relationship with patients, a relationship that depends on establishing good communications and rapport with patients, and on maintaining their own authority. In contrast, nurses expect merely that patients abide by rudimentary hospital rules and not disrupt daily nursing care routines"(p. 253). These expectations are the means by which doctors and nurses constructed their understanding of the difficult patient and the failure of patients to meet the expectations of doctors and nurses was described as the meaning making process.

The third research question, what is the essence of the doctor's experience of difficult patients was answered through a thoughtful content analysis of field notes and patient medical records. Fineman (1997) found "that doctors experienced behaviourally difficult patients as a hostile strike on and a threat to the very foundations of their professional identities" (p. 349). No evidence was found that physicians in any way altered their perceptions of themselves rather "in response to a perceived threat, rewrote the biographies of their patients, rendering the threat harmless and benign" (p. 350). This re-writing usually cast the patient in the light of being difficult because of age and the possibility of being demented. The fact that doctors needed to do such re-writing indicated their need for power and authority in the doctor-patient relationship. It was also a manifestation of medical practice informed by a sick role perspective. Fineman purposely asked doctors about their need to maintain control in the doctor-patient 
relationship and doctors denied this need; however, their actions contradicted their words. The asymmetry in the power relationship between patient and doctor was a glaring one. Some hope with regard to altering this asymmetry may be found in the answer to the fourth research question, what social function do difficult patients serve? Fineman maintained the fact that difficult patients exist challenged doctor's belief and insistence on control in the doctor-patient encounter. This group represented "la resistance" to medical domination.

This study held promise at the outset. Fineman (1997) professed to adhere to everyday life social theory, critiquing conventional structural/functional sociology and rejecting positivism, abstract empiricism and rational objectivism. The literature review included a brief overview of discourse analysis and a statement about how institutionalised power demonstrated itself in many ways one of which was language. "Language reflects, sustains and reproduces social structures of dominance" (p. 37). The importance of the social context in which medicine and nursing took place was emphasized as well as the asymmetry in power between doctors, nurses and patients. The theoretical and practical implications of the results could have been further explained. Fineman to some extent divorced data collection from data analysis. There was some analytic interpretation with respect to the doctor's interviews only. The patient interviews seemed to disappear. Important theory could have been generated from all of the interviews, however, more emphasis was placed on the understandings and experience of difficulty of doctors in this study and it seemed as though nurses were included for comparison purposes rather than to really discover their understandings and experience of difficulty. Nurses learned the nurse-patient relationship is central to nursing, yet Fineman 
found nurses cared only about making sure patients abided by hospital routines and rules. In contrast, the focus of this study was how difficulty was constructed in the context of the nurse patient encounter rather than describing difficulty. Fineman reported some of the strategies that nurses used when confronted with difficulty but did not examine how difficulty was constructed in the context of care.

To continue with the examination of the literature that had a direct bearing on the proposed study the nursing research literature on the difficult patient will now be reviewed and critiqued. This will be preceded by a brief report on the findings of a concept analysis of the phenomenon of the difficult patient.

The nursing perspective.

Part of the process of reviewing the nursing research and anecdotal literature included a concept analysis of the phenomenon of the difficult patient. The attributes reported from the literature on the difficult patient were: (a) The presence of certain behavioral characteristics in patients that conflicted with the expected patient role, (b) the presence of personal characteristics that conflicted with the beliefs and values of the nurse and (c) the presence of behaviors that nurses perceived as challenging their competence and control. These attributes were gleaned from the nursing research and non-research literature on the difficult patient and bear a striking resemblance to the elements of the sick role perspective that were discussed near the beginning of this chapter. In Parsons sick role perspective the patient's role is to work to get well and return to normal work. The norms of the sick role oblige patients to seek and accept qualified medical help; thus, behaviors that challenge the competence and control of the health care provider contravene sick role expectations. Researchers in many studies 
continue to use the sick role to inform their work and have failed to see this gestalt being reproduced in their findings. This has resulted in the perpetuation of listing behaviors that are not acceptable to healthcare providers and the ultimate labeling of patients displaying these behaviors as difficult.

The following review of the nursing research literature will reveal the presence of the elements of the perspectives and theories already discussed, the sick role, deviance and labeling, non-compliance, oppression and stigma theory. The nursing research literature contained nine studies on the subject of the difficult patient. Of these nine studies, only two have included patients as participants. The phenomenon being examined is the origins of difficulty in nurse patient encounters, yet the patient is almost invisible. These studies have positivist leanings meaning that the phenomenon is decontextualized, both the patient's and the nurse's contexts were discounted. With three exceptions, what was seen as important in these studies was primarily the opinion of the healthcare professional.

Juliana et al. (1997) conducted an exploratory descriptive study in an attempt to define effective practices for nurses who encounter difficult patients. These researchers accepted the assumption that certain difficult patient characteristics such as demanding, insulting, rule breaking and non-compliance existed. Seven focus groups were conducted with a total of 53 nurses who were asked three questions (a) what interventions do you use with difficult patients, (b) how do these interventions improve patient outcomes, and (c) what expected outcomes served as clues to the nurse that the interventions succeeded. Thematic analysis was used on the data. Findings included a list of interventions for nurses to use with difficult patients. 
Olsen (1997) used a convenience sample of 51 nurses who were given three clinical vignettes describing patients and asked participants to determine if the patients described were responsible for their situation and if so did this affect the nursing care of the patient. The patients in the vignettes were (a) a gay man with AIDS, (b) a cocainedependent woman, and (c) an alcoholic man. A thematic analysis of data found that "patient responsibility" affected the nurse-patient relationship. The more the nurse perceived the patient as responsible for his/her condition the more the nurse would distance him/herself from the patient.

Carveth (1995) conducted a quantitative study using a convenience sample of 52 female nurses on nine different medical surgical nursing units in a tertiary medical center in the United States. The purpose of the study was to examine nurses' perceptions of patient deviance and the relationship between these perceptions and avoidance behaviors. The method involved participation in a card sort procedure to identify patients as ideal, difficult or neutral. Nurses rated eight statements describing patients. The second instrument used in the study was the Slater Nursing Competencies, based on a five point Likert scale. Findings supported the hypothesis that the number of supportive nursing behaviors would be lower for difficult patients than for ideal or neutral patients. Post-hoc comparisons of the three groups showed significant differences at $p=.05$ among the groups for care received, with the difficult patient receiving the least supportive care. Podrasky and Sexton (1988) used an exploratory survey design with 73 nurses and 25 licensed practical nurses to identify patient characteristics that nurses labeled difficult and nurses' reactions to these patients. The instrument used was the Difficult Patient Assessment Tool (DPAT) developed for this study. The DPAT consisted of four 
sections (a) biographic data, (b) difficult patient vignette reaction inventory (four vignettes), (c) nurses response profile (NRP) four sentences, and (d) the unpopular behavior checklist (UBC), 69 items.

Study findings listed 69 difficult patient descriptors. Nurse's reports on what they would do when faced with patient situations as described in the vignettes varied from orientating the patients to hospital routines, to anger, avoidance, punishment, and promoting independence.

The (NRP) was summarized as follows: (54) nurses felt frustration, (14) felt inadequate, incompetent and helpless, and (64) felt angry. Nurses were generally described as coping poorly with difficult patients. The researchers attributed this to a lack of training and skill, the emotional tone on the unit and that nurses may have used the (DPAT) as a way of venting.

Santamaria (1996) developed the Difficult Patient Stress Scale (DPSS) to investigate nurses stress experiences in caring for difficult patients. Later, this same author, Santamaria (2000), conducted a study to determine the relationship between a nurse's personality and stress levels reported when caring for difficult patients. Nurses completed two instruments: a) The Basic Adlerian Scales for Interpersonal Success (BASIS-A), and b) the Difficult Patient Questionnaire (DPQ) adapted from the (DPSS) used in 1996. The researcher reported significant correlations between certain nurse personality profiles and stress levels. Nurses who reported high levels of stress differed significantly from those reporting low levels of stress in the psychological processes used in caring for difficult patients. Specifically it was the personality construct of lifestyle that was explored here. Lifestyle for the purposes of this study was defined as "the 
individual's life goals and the manner in which he/she attempts to achieve them" (Santamaria, 2000, p. 20). Those individuals experiencing less stress took a broader view of what was going on in the difficult patient situation. Santamaria, (2000) chose to study the effects of the concept of the difficult patient on the nurse. This is one approach; however, the danger inherent here is to focus only on the nurse as a subject of research. This locates difficulty once again within the individual rather then considering both the nurse and the patient. Nurses experiencing high levels of stress tended to exercise more control in the nurse-patient encounter that led to patients manifesting "difficult" behaviors. These results are similar to those of Laskowski (2001) who found that the degree of meaning the nurse was able to establish with the patient mediated the degree to which the patient was perceived as difficult. High stress levels resulted in nurses exerting control over patients. There were, however, nurses and patients who were able to establish collaborative relationships resulting in mutually respectful, productive nursepatient encounters.

English and Morse (1988) conducted a study using simultaneous triangulation to explore the problem of the "difficult patient." Triangulation consisted of employing three methods in their research (a) Ethnoscience to describe the nurses' perceptions of the difficult patient, (b) patients were interviewed to hear their perspective, and (c) a content analysis of 42 vignettes about difficult patients found in nursing journals was carried out. The aim of the study was to develop an explanatory model for difficult patient behavior.

The nurses reported their perceptions of the difficult patient as, one who is disruptive, rings a lot, is mentally ill, incontinent, violent, sexually aggressive, manipulative and uncooperative. Seven patients, three males and four females ranging in 
age from 64 to 81 years of age were interviewed. Nurses identified these patients as difficult. Patients reported a lack of control, and their needs were not met which led to anger, frustration and fear. Patients also reported the nursing units were controlled by nurses, and communication was poor, both among nurses and between nurses and patients. The content analysis of the 42 vignettes about difficult patients found the vignettes focused on reporting difficult behaviors and prescribing remedies.

Breeze and Repper (1998) in a study using ethnographic methodology conducted a focus group with nine mental health nurses from four acute admission wards, and interviews with six patients whom nurses had labeled as difficult. The aims of the study were (a) to identify who the difficult patients are, (b) explore their care experiences, and (c) to develop an understanding of the difficult patient-nurse relationship. Findings revealed that nurses identified difficult patients as those who were aggressive, violent, inflicted self-harm and were disruptive. Patients reported they felt controlled and this led to the difficult behaviors. In the nurse-patient relationship, patients felt it worked when they were listened to and respected. When nurses were able to relinquish some power to the patient they were perceived by patients to be effective in their actions and competent at the same time. The voices of the patients were heard in this study validating that when nurses surrender control and listen that competent caring can take place. These findings illustrated the possibility that exists if nurses and patients are open to interactionist approaches. Nurses who were open to listening to and working with the patient did achieve success. Nurses who believed they needed to control the patient no matter what, found themselves with a "difficult patient" on their hands. It should also be noted the research method (ethnographic) permitted a gaze into the life world of the participants 
and contributed to an understanding of what was going on in the nurse-patient encounter. Kleinman (1988) advocated an ethnographic attitude be incorporated into the provider interview in order that doctors may begin to understand what illness means to patients. Laskowski (2001) conducted a grounded theory study with twelve mental health clinical nurse specialists (CNS's) working in an outpatient treatment setting and functioning as nurse psychotherapists. The participants were asked (a) what they referred to as difficult behavior, (b) how they felt about working with difficult clients, (c) how they responded to difficult behavior, and (d) how their understanding of difficult behavior changed over time. The basic social process uncovered was "evolving meaning." This study situated the nurse-patient relationship at the center of the difficult patient phenomenon. The degree of meaning established in the relationship with patients mediated the degree of difficult behavior expressed. CNS's stressed the importance of the nurse-client relationship and that managing difficult behavior falls within that relationship. The relationship involved the construction of meaning between the nurse and patient. The better the balance achieved in social interaction between the nurse and the patient, the greater the degree of meaning established in the relationship and the less the likelihood of the patient being described as difficult. The environment in which these study participants worked was somewhat different from a hospital ward. The number of auxiliary departments and personnel competing for the patient's and the nurse's time were fewer. The degree of autonomy for both nurse and patient was potentially greater, and may have contributed to a more successful interaction. This autonomy was often missing in the work setting of staff nurses (Aiken et al., 2001). A notable limitation of this study was the failure to include patients as participants. This study although it did not 
include patients found that the more meaningful the nurse-patient relationship the less likely a patient was to display difficult behaviors. This is important because it demonstrated that when there is a sense of mutuality in the nurse-patient encounter progress can be achieved. The participants were all prepared at an advanced level of nursing education that may have enabled them to mutually engage in the nurse-patient encounter. It must be noted that once again an interactionist research method was employed and the context in which the nurse and patient were interacting was considered integral to the study. Nurses in this study worked in an environment described as enabling them to exercise autonomy in their practice, unlike many institutional environments.

Johnson and Webb (1995) conducted a study on a hospital ward in Great Britain. The purpose was to explore the moral climate in which nurses worked, using participant observation. In their findings these researchers noted frequent labelling of patients as "good" or "bad." Further exploration revealed that the source of labelling was not patient characteristics but "rather evaluations of people in the ward were socially constructed in relation to a complex web of powerful social influences" (p. 47). The labelling of patients as good or bad was negotiable and varied a great deal with what was going on with the nurse's day, the ward in general, and with forces external to the ward. These researchers concluded that the nature of the relationships among nurses on the unit and between the unit and other departments of the hospital determined the degree to which patients were labelled good or bad. This finding parallels the work of Lorber (1979) who found that nurses and doctors were not unilateral in their labeling of patients as good or bad. Labeling was restricted to staff who bore the brunt of the patient's wrath. 
Nursing interaction theory.

At the outset of this chapter, emphasis was placed on the fact that nursing theory was absent from nursing research on the difficult patient. Meleis (1997) classified nursing theories developed between 1950 and 1970 into three schools of thought; needs, interaction and outcomes. The interaction theorists are the focus here. The work of these theorists; King, Orlando, Paterson and Zderad, Peplau, Travelbee, and Wiedenbach was influenced by the philosophy of existentialism, symbolic interactionism and developmental theories. The focus of their work was "how do nurses do whatever it is they do"? (Meleis, 1997, p. 188).

The substantive components of the theories developed by this group included: (a) A focus on the nurse-patient interaction as intervention, (b) the need for the nurse to be able to clarify her/his personal values surrounding the interaction, (c) illness has meaning and the nurse helps the patient find that meaning through the nursing process, (d) the perspective of the patient is of value, and (e) the healthcare provider knows best. A noted contribution of the work of these theorists is their inclusion of the patient perspective (Meleis, 1997).

Meleis (1997) identified two areas not addressed by this group of theorists in their work. First this group of theorists had a limited view of the environment, meaning, environment was limited to that immediate to the patient. Kleffel (1994) also identified that nursings' present understanding of the environment was inadequate and set out to explicate an expanded nursing environmental domain. Kleffel challenged nurse theorists to develop the knowledge base to create this expanded environmental domain. This yet to 
be developed knowledge could contribute to a better understanding by nurses of the context of care. The rather narrow view of the environment and the patient that nurses have learned may perhaps have served to drive the nurse to consider only the patient in the nurse-patient interaction. This view has resulted in a neglect to consider the context of care. This may be a contributing factor to locating the problem within the patient.

Secondly, the biopsychocultural nature of the human being was not developed in this work. The literature reviewed, particularly that of Kleinman (1988) and Becker $(1966,1973)$ has demonstrated how social interaction constructs phenomena and that this interaction is contingent upon factors in the environment in which the interaction takes place. These factors are biopsychocultural and political.

Summary of the literature review.

The preceding literature review will now be summarized according to what was common to the research, how the studies differed and the gaps that existed. The most obvious commonality was the presence in both medicine and nursing of practice that was infused with elements of the sick role. It is reasonably safe to assume the hierarchical and paternalistic organizations within which most nurses work are a source of this learned behavior. Nurses also demonstrated elements of oppressed group behavior. Many nurses do not recognize the dimensions of their oppression and thus perpetuate it. Both physicians and nurses engaged in the labeling and stigmatizing of patients who did not behave in the way they expected and who were not seen to be adequately helping themselves get well. This persistent locating of the problem within the patient absolves providers from looking at the healthcare provider-patient interaction, the immediate context of the interaction, the organizational context, and the societal context. 
The most obvious differences were found in the work of social scientists (Becker, 1966, 1973; Fineman, 1991; Goffman, 1963; Johnson \& Webb, 1995; Kleinman, 1988, 1995; Schwartz \& Skolnick, 1966; Winick, 1966). These works demonstrate how social interaction constructs phenomena and how the labelling of patients as good or bad varies based upon what is happening on a unit and in departments external to the unit. These researchers locate the origin of the difficult patient label in a complex web of social forces within and external to the nursing unit and they look at a variety of theories to explain this.

Another noticeable difference was found in two studies that included patients (Breeze \& Repper, 1998; English \& Morse, 1988) and in the work of Laskowski (2001). Patients in these studies reported feeling controlled. This feeling led them to act in ways that resulted in their being described by nurses as difficult. Researchers in these three studies contributed to breaking the cycle perpetuating the belief that the problem resided uniquely within the patient. The final difference noted in the studies reviewed was in the work of Chambliss (1996), Gallagher (1979), Lorber (1979), and Zussman (1992). These researchers focused on systems of care, organizations and the organization of care, as factors in the construction of the difficult patient. It was clear in the works of these authors that a much broader view of the phenomenon of the difficult patient must be taken in order to move the discourse beyond blame.

The literature has obvious gaps, the most notable was the near absence of patients as participants and yet the concept studied was called the difficult patient. The nursepatient interaction takes place in an environmental context. This context was referred to in only one study. Kelly and May (1982) in a literature review and theoretical critique of 
the nursing, psychological, and sociological literature of the previous 20 years on good and bad patients noted the lack of consideration of the social structure and processes within which the phenomenon of the difficult patient was occurring and challenged researchers to explicate the complex social reality that nurses and patients interact within. Absent from the research was any discussion of race, gender, classism, androcentric and ethnocentric bias (Bunting \& Campbell, 1990; Kinchloe \& McLaren, 2000; Stevens \& Hall, 1992; Wuest, 1993; Wuest, 1994). Nursing theorists, Orlando, Travelbee, Paterson and Zderad (Meleis, 1997), King (1971), Wiedenbach (1964) and Peplau (1952) considered the nurse-patient relationship to be the essence of nursing (Meleis, 1997). Yet nursing theory was absent in framing the existing research on the difficult patient. The small number of studies concerning this concept that goes to the core of nursing must be noted.

This review of literature served to start the exploration of what all is going on within the nurse patient encounter. However, there seems to be more to discover. Kleinman (1995) implored us to stop copying what was learned and to start thinking originally. The source of the words "difficult patient" is the nurse and the physician who have judged the patient as difficult. The roots or origins of this phenomenon have been examined and partially explicated by the perspectives of the sick role, deviance and labeling, non-compliance stigma and oppression. The reliance on these perspectives may be serving to stifle original thinking about the origins of difficulty.

This research engaged patients and nurses in the context in which they interacted. Somehow in this context patients come to be described as difficult. The origins of difficulty needed to be explored, identified and described. The method used was 
grounded theory because it enabled exploration, identification and description of this phenomenon. The following chapter introduces the method for this study and explains how the study was conducted. 


\section{Chapter III}

Method

The purpose of this ethnographic field study was to generate a substantive explanation of the origins of difficulty in the nurse patient encounter. The specific aims of the research were to answer the following questions: (a) How did nurses describe the origins of difficulty in the nurse patient encounter? (b) What were patient's perceptions of recent care encounters? (c) How did the context of care influence the nurse patient encounter? and (d) What were the consequences of difficult nurse patient encounters for patients and nurses?

The site selected for this study was a 529 bed acute care hospital in Atlantic Canada. The setting was a 36 bed family medicine unit. Data collection was conducted over a nine month period form January through September 2004, and consisted of 120 hours of participant observation, 12 interviews with former patients from the setting and 10 interviews with nurses working in the setting. Grounded theory informed the method.

This chapter has two parts. Part one provides an overview of the grounded theory method, describes the study site, gaining entrée, sample, ethics, risk management, researcher's role, and data collection. Part II gives a detailed account of the data analysis process for this study. 


\section{Overview of Method}

The grounded theory method was used for this study because of the inchoate nature of what is known about the origins of difficulty in the nurse patient encounter. This method enabled exploration, identification and description of the origins of difficulty from the perspectives of the participants who experienced difficulty and led to theory development that was meaningful and understood by those involved (Charmaz, 2000; Chenitz \& Swanson, 1986; Glaser \& Strauss, 1967). This becomes clearer with the following description of method. "Grounded theories, because they are drawn from data, are likely to offer insight, enhance understanding, and provide a meaningful guide to action" (Strauss \& Corbin, 1998, p. 12).

Grounded theory as with any other research method has undergone considerable scrutiny and evolution. Developers of grounded theory (Glaser \& Strauss, 1967) must be recognized for their important work. This early work despite its challenge to the empiricist tradition was also informed by it. This led to a positivistic or prescriptive approach to grounded theory. An approach whereby the researcher maintained an objectivist stance that led to the discovery of reality and the development of theory believed to be "true, testable, and verifiable" (Charmaz, 2000, p. 524). In contrast, qualitative researchers today, accept and make explicit that they are central in the research process and that they influence all steps of the process (Finlay, 2002).

Charmaz (2000) proposed a constructivist approach to grounded theory. This approach recognizes the multiple realities of any context, that findings are co-created by researcher and participants and that these findings would be meaningful and understood 
by the participants. Charmaz moved away from the idea of a step-wise method of data collection and analysis to a guideline for grounded theory whereby the researcher:

"moves each step of the analytic process toward the development, refinement, and interrelationship of concepts. The strategies of grounded theory include: (a) Simultaneous collection and analysis of data, (b) a two-step data coding process, (c) comparative methods, (d) memo writing aimed at the construction of conceptual analysis, (e) sampling to refine the researchers emerging theoretical ideas, and (f) integration of the theoretical framework" (p. 511).

This process was followed in this study and will be described in detail in part II of this chapter. A constructivist type approach to grounded theory informed this research project. The constructivist approach generated data from the interactional process that occurred among researcher, participants, and context.

The review of nursing and some of the social science literature for this study revealed generally uni-dimensional thinking with regard to the origins of difficulty in the nurse patient encounter. This uni-dimensional thinking tended to locate difficulty incurred in encounters within the patient. The sociological literature reviewed revealed a perspective of phenomena as socially constructed. Grounded theory using a constructivist approach was done in the field where the phenomenon was occurring. The opaqueness of the phenomenon was diminished through the research process of conducting participant observations, interviews, and analysis. The analysis led to the development of concepts. The researcher checked emerging concepts with nursing and patient participants and found they could understand them and that the concepts made sense. The concepts were used to formulate an explanation of the origins of difficulty in the nurse patient 
encounter. This theoretical explanation represented new knowledge for nursing. This knowledge created the possibility of interrupting current uni-dimensional thinking that has located difficulty in the individual.

\section{Site Selection}

The site selected for this study was a 529 bed, acute care hospital in Atlantic Canada. The setting is a 36 bed family medicine unit. To minimize the effect of power in the researcher participant relationships, the researcher selected a site two hours away and had no affiliation with the site.

The researcher decided that the preferred setting for the study would be a family medicine unit. Family medicine units are not common sites for research. The research most often done in hospitals is medical research, specifically clinical trials, and these are usually conducted in specialty areas such as, cardiology, and oncology. "The modern hospital distributes among its wards whole persons according to afflicted parts and professionals according to knowledge of these parts" (Schatzman, 1979, p. 192). When patients exceed the expected length of stay for a specialty area, yet continue to need hospitalization they are usually transferred to a family medicine unit. Family medicine units do not get the glory of specialty areas despite the variety and complexity of patients they care for, and tend to be more family oriented. Nurses that work in family medicine need to know about a variety of medical conditions. The researcher also hypothesized this unit, as a more likely place to find holistic nursing care, a condition hoped would mediate difficulty in the nurse patient encounter.

The Chief Nursing Officer (CNO) was contacted to determine if this hospital would welcome the researcher and proposed project. The response was favourable and 
the $\mathrm{CNO}$ arranged a meeting with the nurse managers of the two family medicine units, myself and the chair of the Ethics Committee to hear about the proposed research. The CNO explained to the researcher that the two family medicine units varied in that one had a relatively new manager and an inexperienced staff and the other unit was the opposite. Both managers were enthusiastic about the project so it was up to the researcher to select. The unit with low attrition, experienced staff, and where the manager had been in place for a long time was chosen. Following this, the researcher attended a unit staff meeting to explain the study.

In addition to wanting to conduct research in a family medicine unit setting, this unit was purposely selected because of its leadership, low attrition, and experienced staff. It is often argued that unfavorable patient care experiences can be attributed to factors related to nurse dissatisfaction such as the nursing shortage leading to high turnover rates, large numbers of inexperienced staff, burnout and nurses leaving the profession (Aiken, Havens \& Sloane, 2000; Aiken et al., 2001). This unit was not immune to the nursing shortage, however, it had the advantages of leadership, low attrition, and experienced staff. These conditions were considered by the researcher to be favorable to exploring the origins of difficulty in nurse patient encounters. This setting was more ideal than most and may have facilitated the work of the researcher using a constructivist approach. It is the uniqueness of the setting being studied that was particularly valued as well as the context specific actions and interrelationships that influenced people's interpretations and gave the data meaning (Erlandson, Harris, Skipper \& Allen, 1993). The meaning uncovered from this data will not bear the burden imposed on participant's reality by unit contextual conditions of lack of leadership, high turnover rates and inexperienced staff. 
Two months after data collection started through the process of participant observation, and informal and formal interviewing of staff the researcher discovered how complimentary staff was of their unit. These comments included: "It is the best run unit in the hospital," "staff respect the manager," "staff are experienced," "unit staffing is stable," and "staff in general worked well together." The researcher prepared a memo regarding this at the time wondering if in fact this was the ideal place for this study. Upon reflection the decision was yes in fact as stated above these data would not bear the burden of contextual conditions related to leadership, and high turn over of staff. The researcher believed this setting was ideal for this study. Chapter IV contains a detailed description of the setting for this study.

\section{Gaining Entrée}

Entrée is a continuous process of establishing, developing and maintaining relationships (Schatzman \& Strauss, 1973). The researcher works as a Clinical Nurse Specialist (CNS) in an acute care hospital and doing research where the researcher works would have been convenient from the perspective of time and travel. The dissertation committee of the researcher recommended against this because the nature of the researcher's work takes her to all areas of the hospital and the researcher is perceived as part of administration in the hospital. This could mean that staff would not necessarily feel free to decide about their participation or to be as candid in their narratives as they are ordinarily. The other confounding factor is that when staff sees the researcher it would be unclear if the presence of the researcher was as CNS or researcher. As previously mentioned, to minimize the effect of power in the researcher participant 
relationship, the researcher selected a site two hours away and had no affiliation with the site.

The researcher met the Chief Nursing Officer (CNO) from the study site on several previous occasions at Nursing Association annual meetings and as a coinvestigator on a multi site nursing research project. This acquaintanceship motivated the researcher to approach the $\mathrm{CNO}$ and to explore the opportunity of going to this site. The CNO was enthusiastic about this possibility and offered to be of assistance to the researcher in facilitating the process. The other motivating factor was the fact that The University of San Diego (USD) Institutional Review Board (IRB) required a letter from proposed study sites indicating their support for proposed research. The CNO was pleased to provide this when appropriate. At this time, the researcher was given the name and coordinates of the chair of the potential IRB site. The researcher scheduled a meeting with the IRB chair to introduce herself and to gather information on the IRB process.

The chairperson reviewed the local process with the researcher and indicated that the proposed research would likely be considered minimal risk and, therefore, would not require full board review. It was recommended that once IRB approval was obtained from USD that contact be made with the chair of the study site IRB for detailed directions. This represented the paperwork process of gaining entrée, however there is also the actual on site entrée process that will now be described.

The researcher was apprehensive about participant observation and despite reading on the topic arrived for the first participant observation session at 7:10am feeling somewhat anxious. The researcher approached the nursing station was greeted by a staff member and immediately taken to the staff lounge so that personal effects could be 
deposited. The night nurse was taping report in the lounge. The researcher returned to the nursing station to begin observing. Several staff members who had attended the December staff meeting were present and this was comforting. The night nurse arrived from taping report and invited the researcher into the area where day report is listened to (inner sanctum) and told "come on in you are one of us now." The researcher realized it takes much more than this to be an insider; however, it was a comfort to hear this nurse's invitation.

In reflecting about entrée and hoping staff would participate fully in this study the researcher recalled the numbers of times new work situations had been encountered in the past either as a new employee or working with a new employee. New employees can demonstrate their ability to work among their colleagues but even with this it can take a number of months for the person to fully integrate into a new situation. The observer cannot gain entrée in this way. The degree of entrée gained will depend upon the nature and quality of social interaction the researcher is able to achieve in the setting.

The researcher dressed in street clothes and introduced herself as a nurse who was doing research. Institutions are places of structure and dress is included in this. Nurses wore scrubs in various patterns as did licensed practical nurses (LPN's). Staff members who worked in a consultant capacity such as pharmacy, physio, dietary, and discharge planning tended to wear white lab coats. The researcher did not fit any of these roles and, therefore, chose to wear blouses, slacks, and sweaters.

In reading about participant observation, Lofland and Lofland (1995) recommended to the observer to get as much description of a setting down as soon as possible because in no time it is no longer noticed. The researcher did not believe she 
would not be noticed after two or three visits but rather that staff would come to expect the presence of the researcher on a regular basis for awhile.

During the first few observation sessions it was so hard to observe. The staff was busy and call bells were always ringing and the urge to answer them was powerful. At this point the researcher e-mailed her committee for guidance and was advised not to answer call bells. This was good advice as the researcher came to realize that a big part of wanting to answer the bells was to feel more a part of the staff, thus fulfilling personal emotional and psychological needs (Allen, 2004). One discovery for the researcher was the importance of introducing staff to research and not apologizing for it. It is easy to get caught up in the busyness and want to be doing the nursing care when the purpose of the researcher was to do the research and perhaps mentor nurses to research in the process.

There is no doubt staff wondered about the presence of the researcher. On one occasion in the first two months staff were gathered having what seemed to be a social chat and when the researcher approached they disbanded. Any time a staff member was asked in the first few weeks how the day was going the response was always "busy and this is a busy unit." This made the researcher sense that staff was wondering if the presence of the researcher was really to find out if they were as busy as they say they said they were. On the third day of observation during rounds the doctor asked that one of the patients have a mini mental exam then turned to the researcher and said "you can do it if you know how." Before the researcher could respond the charge nurse and the care coordinator responded in unison that that was not the reason the researcher was here. This gave the researcher the sense that there was understanding and support for the presence of the researcher. 
One staff member made the following comments on two separate visits "are you making notes about me," and "oh you are back to spy on us." Following both of these comments the researcher explained the nature and purpose of the research. The comments were made laughingly, however, there was likely some true sentiment in them. This researcher did not become an insider because this is not possible unless one is. Over time the researcher did come to feel a connection with the staff. This came about through several strategies such as casual conversations during observations to clarify questions, participating in social exchanges before and after reports, going to breaks with staff and bringing the occasional treat such as muffins or trail mix. The process of conducting staff interviews also helped establish relationships with these staff members.

\section{Sample}

The sample was a convenience sample. The participants were former adult patients and nursing staff of the family medicine unit. Twelve former unit patients and 10 nursing staff, nine RN's and one licensed practical nurse (LPN) were formally interviewed. The patients were Caucasian, English-speaking, cognitively alert and ranged in age from 39 to 93 , the average age was 62 . They came from varied socio economic backgrounds and there were six males and six females. Fifty eight percent were retired, $41 \%$ had less than high school education, and the remainder had high school plus some type of additional studies beyond this. The nurses were female, Caucasian, Englishspeaking, and required a minimum of one year's experience of full-time nursing on an adult family practice nursing unit to be part of the study. Nursing participants ranged in age from 28 to 60 , the average age was 41 . The majority were diploma prepared nurses. The years of nursing experience ranged from 6-20 with an average of 12.8. The years of 
experience in the study setting ranged from 1-15 with an average of 8 . Only one nursing participant had less than four years nursing experience on the study unit. In the experience of the researcher the patient participants reflected those of family medicine units in Atlantic Canada. The nursing participants were also representative of the staff profiles of family medicine nursing units with the possible exception of the number of years in the study setting.

The recruitment of patients was discussed with the nurse manager who recommended the researcher approach the unit care coordinator to recruit patients. The unit care coordinator, coordinates the needs of patients related to discharge and gets to know most patients to some degree. The researcher asked the care coordinator if she was interested in recruiting patients for this study and she readily agreed. The researcher carefully discussed with the recruiter the focus of the research was the exploration of the origins of difficulty in the nurse patient encounter. Patients were told the nurse researcher was studying nurse patient encounters to find out what makes patients happy with their care or unhappy. No particular effort was made to recruit patients who may have been labeled as "difficult." The unit care coordinator approached patients upon discharge to explain the study to them. Patients that were interested in participating were given a letter of invitation to participate in the study (Appendix D). The care coordinator gave the researcher the patient's name and telephone number and interested patients were contacted within one week of their discharge from hospital. One interested participant was readmitted to hospital before the researcher called. Eventually contact was made. Eleven patients were interviewed within two weeks of discharge. The twelfth patient had 
a family emergency that necessitated the interview be delayed by one month following discharge.

Nursing staff members were recruited by posting letters of invitation on the staff bulletin board to participate in the study. These letters were posted about six weeks after participant observation commenced. A copy of the letter is included as Appendix F. Interested staff could contact the researcher by e-mail, telephone, or by simply approaching the researcher during participant observation sessions.

\section{Ethics}

USD IRB approval was granted on August 25, 2003 (Appendix H). In early September the IRB chair at the study site was contacted. The researcher was instructed to complete a research application form and forward it with the proposal to the chair. Part of the review process at the study site was to have the managers of proposed research setting areas sign off on the proposed research. The $\mathrm{CNO}$ offered to approach the managers of the two family medicine units and invite them to a presentation on the proposed research. This meeting was held on September 27, 2003. Both managers were enthusiastic about the project and the unit as earlier described was chosen. The nurse manager signed the research application form indicating support for the study and this was given to the chair of the IRB who attended the same presentation. The proposal was assigned to a member of the IRB for review. It is important to note here that the only reservation the reviewer had was a concern with the use of the term difficult patient in the patient consent forms (Appendices B \& C). The forms were revised to accommodate this request and approval was granted in November 2003. Because a change was made to the patient consent forms 
as approved by the USD IRB, the Associate Provost at USD was advised and these changes were approved November 24, 2003.

Once approval was received the nurse manager at the study site was contacted. The unit staff needed to know about the study and it was arranged that the researcher would attend the unit's December, 2003 staff meeting to explain the study. About one third of the unit staff was present at the meeting. The researcher explained the topic of the study was the nurse patient encounter specifically what makes encounters go well and not so well. It was also explained that these encounters take place within an environment or context and that the researcher would be paying particular attention to context during observation periods. In addition to observations the researcher would be recruiting nursing staff for interviews regarding their encounters and former patients to hear about their recent hospital care encounter experiences. The purpose in doing this research was to find out what leads to difficulty in the nurse patient encounter. The remainder of the staff received the explanation on a one to one basis as the researcher met them during participant observation sessions.

One detail that was completely overlooked during the proposal approval process was the preparation of a consent form for participant observation (PO) (Appendix A). This had been discussed with the dissertation committee and it was agreed consent would be obtained. The researcher realized this in preparation for the staff meeting knowing the approval would not happen before the meeting. The staff members were told that a consent form would be placed in their respective mail folders and upon completion they were to put the consents in an envelope with the researcher's name on it next to the mail 
folder. This consent also served as a summary of what the study was about (Schatzman \& Strauss, 1973; Chenitz \& Swanson, 1986).

This consent form was not part of the proposal approved by USD IRB or the study site IRB. The participant observation consent form was prepared and forwarded to the Associate Provost at USD. Approval was obtained on December 15, 2003. This approved participant observation consent form was sent to the IRB member at the study site who had approved the proposed research.

One month after commencing participant observation flyers were posted on the staff bulletin board inviting nursing staff to participate in formal tape recorded interviews (Appendix E). The charge nurse made announcements at day report times that the researcher was recruiting participants. The researcher scheduled formal interview dates and times with the nurses who agreed to participate, a review of the purpose of the study was also provided at this time. At the time of the interviews, the study was explained once again to the participants. The participants were assured that participation was voluntary and they may change their mind at any time about participation without any fear of reprisal. The participants signed the consent before the interview started and a copy of the consent was left with them. Interviews were tape recorded and transcribed verbatim. The tapes and transcriptions are in a locked file in the researcher's office and no actual names appear on the tapes or transcriptions, only pseudonyms. Participants were advised they could stop the interview at any time and this was completely acceptable. The questions used to guide both patient and nursing interviews are attached as (Appendix F). 


\section{Risk Management}

Potential risks for participants in this study were psychological, and maintaining confidentiality. Risk management included advising participants of the possibility of emotional distress during these interviews. None of the participants experienced emotional distress to the point that it appeared to effect their participation. If this had happened and they wanted to stop at this point and resume at a later time they were told this was acceptable. With respect to confidentiality, participants were informed that the transcribed interviews were assigned pseudonyms and kept in a locked-drawer in the researchers' office except when the researcher was doing data analysis.

Participants were advised that there were no immediate benefits to them except perhaps some therapeutic effect from participating in the interview. In the long term if the study can identify and describe processes that lead to difficulty in the nurse patient encounter this will be very meaningful for nurses and patients.

\section{Researcher's Role}

Data for this study were obtained from interviews with patients and nurses and from participant observation on a family medicine nursing unit. The researcher was the instrument in the study and was aware of the importance of making explicit, personal biases and subjectivity. The way in which the researcher worked to achieve this was through the practice of reflexivity. "Reflexivity can be defined as thoughtful, conscious self-awareness" (Finlay, 2002, p. 532). No qualitative researcher would argue that the researcher enters the field without bias. Every researcher comes from a context, has a degree of knowledge, and a set of values and attitudes (Schatzman \& Strauss, 1973). Researchers using a constructivist approach recognize that data are co-created by the 
researcher and the participants (Charmaz, 2000). As the researcher collected and analyzed data, and identified categories theoretical sampling was used to confirm these categories.

Theoretical sampling is a mechanism used by the grounded theory researcher to determine if the categories identified are relevant, adequate in number and if they explain what is happening in the data. Theoretical sampling is "sampling of incidents, events, activities, and making comparisons of these in the data" (Strauss, 1987, p. 21) it may involve further data comparisons, conducting further interviews or re-interviewing, and consulting the literature. An example of this from the participant observation data concerned the development of the category that eventually became availability of supplies and equipment. During the first week of participant observation the researcher heard nurses speak about missing pills and the time spent looking for missing pills. In comparing data from subsequent observation sessions this same frustration was recorded in most PO sessions data. Once the researcher began staff interviews if staff did not mention this concern then the question was asked and every nurse interviewed confirmed that they lived this frustration.

In addition, the researcher employed the following strategies to enhance understanding of the data as they were collected: (a) A journal was kept of personal responses to situations encountered during the research process, (b) monthly telephone talk sessions were held with committee members for discussion of processes and activities and (c) theoretical memos, observational notes, and methodological notes were kept for incorporation into data analysis (Olshansky, 1996). Theoretical sampling was particularly enhanced during the last eight weeks of participant observation when 
observations, patient interviews, and staff interviews were all happening in close proximity to one another. This allowed the researcher to check things out in moving among situations and contexts.

\section{Data Collection}

Data collection included 120 hours of participant observation and 22 formal interviews, ten with nursing staff and twelve with former patients of the study setting. Participant observation began January 15, 2004, four to six hours a day, four days a month. The nurse manager was notified before each visit of the dates and hours that the researcher would be present. The manager was away during the initial four visits but advised the day charge nurse. Data collection began with participant observation on the nursing unit. Initial observations were deemed very important because this rapidly became routine, "sensitivity to the common is lost to people who work anywhere for any length of time" (Schatzman \& Strauss, 1973, p. 53). The researcher watched for such things as the people, communication among people, the physical setting (noise, space, equipment), events, activities, arguments, discussions, and how work was organized. In this grounded theory study the researcher examined the phenomenon where it existed (Chenitz \& Swanson, 1986), and found that difficulty in the nurse patient encounter arose out of the interaction of nursing staff, patients' and the environment that surrounded them. Participant observation enabled the researcher to map the territory, decide where to observe, when to observe, and get to know the routines. During this period of observation the staff got to know the researcher to some extent and vice-versa.

Observations were done at key intervals on the nursing unit, such as, change of shift reports, during unit rounds and at varying times of the day. Outside of report and 
unit rounds the researcher moved about the unit looking and listening. The first eight observation sessions were done between $7 \mathrm{am}$ and $1 \mathrm{pm}$. The remainder were conducted between $3 \mathrm{pm}$ and midnight. The days of the week varied and observations were also done on two holidays. The focus of these observations was to listen to nurses descriptions of: Patients, families of patients, workload on the unit, unit atmosphere, relationships within the unit and with other units and departments. These were the moments when nurses revealed what they perceived the situation to be.

This prolonged engagement allowed the researcher to widen the blinders regarding nursing participants and context. The nursing participants also had an opportunity to informally interact with the researcher. The familiarity established among the researcher, the nursing participants, and the setting established a level of interactional meaning not achievable through interviews alone. Interviews are one method of data collection, however, researchers are reminded that interviews may provide just one snap shot of situations. Participant observations minimized the one snap shot effect.

Field notes of these observations were discretely kept during participant observation as well as following informal interviews and used for comparison purposes once interview data were collected. Field notes were organized into three packages, observational notes (ON's), theoretical notes (TN's) and methodological notes (MN's). Observational notes are just that, statements describing what the researcher observed with minimal interpretation. Theoretical notes represented what meaning the researcher derived from the observational notes, the ideas and concepts that the researcher was finding in the data. The writing of theoretical memos was a type of preliminary analysis of the data. Methodological notes were about the research process, and served as a form 
of critique to the researcher and as a reminder of strategies to employ or avoid in future (Schatzman \& Strauss, 1973).

One month after commencing participant observation flyers were posted on the staff bulletin board inviting nursing staff to participate in formal tape recorded interviews. The charge nurse made announcements at day report times that the researcher was recruiting participants.

In late February, the first formal nursing staff interviews were conducted. A series of interview questions were used to guide the staff and patient interviews. These questions are attached as (Appendix F). The interview process provided an opportunity for the researcher to get to know the staff and vice versa. This enhanced the feeling of connection to the unit for the researcher and made observation periods more meaningful. During observations the researcher jotted notes and following each session detailed transcriptions of the sessions were prepared. Patient participant interviews began in April, 2004. Participant observation transcriptions and the memos contained within became data as well as the transcriptions of the tape-recorded interviews with nursing staff and patients. Data collection and analysis were a simultaneous process, a process that was not linear but rather recursive. Part II of this chapter is devoted to elaborating this process in order that the reader may be better able to follow the path of the researcher and to add trustworthiness to the findings.

\section{Trustworthiness}

Trustworthiness amounts to an account of what the researcher does in carrying out the research to assist the reader to trust what the findings are stated to be. The strategies used in this study to gain trustworthiness were: (a) The systematic accounting 
of the processes used in data collection and analysis (Denzin \& Lincoln, 2000), (b) prolonged engagement in the study setting, and (c) multiple data sources to allow for triangulation (Lincoln \& Guba, 1985). The detail provided in part II on data analysis adds transparency to the interactional process that created the findings of this study.

\section{Data Analysis}

The researcher followed the strategies outlined in the guideline for data collection and analysis, Charmaz (2000). These strategies were used to frame the description of the analysis process and included:

(a) Simultaneous collection and analysis of data, (b) a two-step data coding process, (c) comparative methods, (d) memo writing aimed at the construction of conceptual analysis, (e) sampling to refine the researchers emerging theoretical ideas, and (f) integration of the theoretical framework" ( p. 511).

Simultaneous collection, comparison and analysis of data.

During participant observation session's notes were jotted down for incorporation into field notes. Following each observation session approximately four to six hours were spent typing field notes and at the same time reflection and analysis began. Six weeks after participant observation started formal interviews were begun. This resulted in the simultaneous collection, constant comparison, and analysis of data from three sources.

\section{Coding and comparisons.}

In keeping with the strategy of simultaneous data collection and analysis once data collection began they were coded as soon as possible following a coding paradigm indicating the relevance of the code assigned and whether the code represented a condition, an interaction, a strategy or a consequence (Strauss, 1987). The initial 
transcriptions of PO and staff interviews were coded sentence by sentence working toward the development of categories. Ultimately the researcher was looking to identify a central or core category. The coding of data and the assignment of categories represented the two-step data coding process. The assignment of categories contributed to conceptual development. The use of comparative methods began by comparing field notes from one session to another to see if observations were mostly similar or if they varied. Eventually once staff and patient interviews began data comparisons were made among observations and interviews.

\section{Memoing and theoretical sampling.}

Memo writing occurred after most observations and following coding sessions and interviews. These memos usually consisted of what was seen, heard, and thought, and about what seemed to be going on in the data. The process of memoing amounted to the recording of theoretical notions that the researcher formed in the process of reading and conducting the research. Theoretical memos represented a preliminary analysis and assisted the researcher to determine what data to collect next and perhaps where to look next in line with theoretical sampling. An example of this from field notes on day two of observations states "work on casual interviewing getting feedback from staff about their thoughts on topics such as availability of supplies" (FN2). Already the researcher had identified a category. Subsequently when interviews with staff began if they did not talk about missing supplies like medication then the researcher asked the question and every nursing interviewee confirmed this and a category with thick description was built. As other categories emerged the researcher constantly compared what was found in the interview transcripts with field notes gathered from participant observation and informal 
interviews. This in turn was compared with the theoretical memos to enable integration of the framework. As the evidence mounted confirming each category, a degree of density resulted, allowing a description of the category that was rich and trustworthy (Strauss \& Corbin, 1998). Memos accumulated and the researcher began to formulate hypotheses about what was going on, and these were checked out either in interviews, during observations or by consulting relevant literature. At times in the data the researcher encountered concepts that could not be fully comprehended. An example of this was "time." Theoretical sampling enabled the researcher to draw upon knowledge from the literature illustrating properties or dimensions that helped to more fully describe the concept. The researcher then was able either to confirm the category or to establish a new one. The building of categories led to examining the circumstances that favored the existence of the category. The researcher looked at how this category was created, the factors that led to its existence, the consequences of the category, and how it related to other categories.

The researcher also remained alert to the emergence of what are known as negative cases (Becker, 1998). These cases diverge from what has been emerging from most of the data and serve as an opportunity to interrogate findings to date and to send the researcher back to the field to ask further questions or make additional observations. Negative cases are a good example of variation (Strauss \& Corbin, 1998). These cases contribute to the trustworthiness of findings by forcing the researcher to further analyze existing data and to additional data collection to explain the negative cases. The researcher did not discover any purely negative cases. The divergence in the data came from those participants who expressed time challenges but felt these were mediated by 
working as a team and helping each other out. Working together, for them minimized the likelihood of difficulty in their encounters.

As the analysis proceeded, incidents in the interviews and from participant observations began to repeat themselves, when no new data emerged from the interviews or from participant observation, the categories were considered saturated and data collection ceased. There were areas of commonality as well as divergence in the data. For example all nursing staff expressed the desire to have more time to provide patient care. Some staff expressed that by working as a team it was easier to give the care needed. This sentiment was not expressed by all participants.

The generation of theory came from the categories that emerged from the data. Eventually as the categories became saturated a theory of what was going on emerged and this theory represented the core category. It related easily to all other categories, it appeared frequently in the data, it generally was able to provide explanation for what all was going on in the data (Schatzman \& Strauss, 1973; Strauss, 1987). The goal of grounded theory is to generate a theory. In a constructivist grounded theory "data do not provide a window on reality. Rather, the discovered reality arises from the interactive process and its temporal, cultural, and structural contexts" (Charmaz, 2000, p. 523-524).

The core category that emerged from the data for this study was reconciling temporalities. Nursing staff and patients regularly found themselves at odds with one another with respect to time. Nursing staff members were searching for the time needed to deliver the care they wanted to give and patients wanted the care they needed delivered in a timely fashion. The degree to which reconciliation was achieved determined how difficult the nurse patient encounter became. Knowing the patient almost always meant 
that reconciliation was not needed. Getting to know the patient takes time. When nurses found they did not have the time to get to know the patient and when patients did not feel like they had received the care they required in a timely fashion this led to the development of the category known as temporal incongruencies. The greater the degree of temporal incongruence the more reconciliation was required. The situational conditions that contributed to temporal incongruencies and influenced the amount of reconciliation needed were: Families, availability of supplies and equipment, who is working, and geographies of place. There were also environmental or contextual conditions that affected reconciliation and these were: Unit reputation, labor market structure changes. The strategies that staff used to reconcile temporalities were: Controlling, working together, managing families, and employing geographies of place/bodies. The ordering of categories as listed here did not automatically happen. The analysis process as outlined below is intended to reveal to the reader the evolution of concepts and how the ordering of categories unfolded.

\section{Participant Observation Data Findings}

This section illustrates the building of categories and the initial stages of integrating the framework. This process was not a linear one but rather a process that involved all of the elements of the guideline more or less simultaneously. The first data collected were from participant observation sessions and the categories identified in the context of care were: temporal incongruence, availability of supplies and equipment, labor market structure changes, geographies of place, staff experience/competence/values and patient descriptors. Examples of codes that contributed to the building of these categories are provided in the description of the categories. 


\section{Temporal incongruencies.}

Temporal incongruence meant that the researcher observed or heard about conditions on the unit that interfered in some way with staff delivering and patients receiving care in a timely fashion. The choice of the term was the researchers and came from staff constantly making reference to lateness of tray times, test times, and not enough time. Incongruence came from observing that when staff and patients desired a certain activity to happen it often did not as evidenced by tray time arrival. Examples of codes in this category are: variation in food tray time arrival, time of day admissions arrived, $\mathrm{RN}$ taking time to go to pharmacy for medications, $\mathrm{RN}$ doing non $\mathrm{RN}$ work, and patient toileting decisions (diapering vs taking to toilet which takes more time). The nursing staff began each shift with a list of tasks to be performed for each patient and a general timeframe in which to perform these tasks. From the very first participant observation session staff spoke about busyness and not having time to do what needed to be done. The researcher identified the concept of time early on but started by focusing on the staff ability to manage time and not relating this to the context of care.

It was only once the interviews with nursing staff began and staff were asked to describe nurse patient encounters that did not go well every participant answered qualified the description with the fact that they did not have enough time to give to the patient and that this led to difficulty in the nurse patient encounter. Subsequently in patient interviews when patients were asked what made patients unhappy with their care they responded by saying they did not get the care they felt they needed in a timely fashion. It was only by comparing data across observations and interviews that the researcher was able to identify and confirm the category of temporal incongruence. The 
notion of time was easy to see but what was actually going on with time was the challenging part.

Availability supplies and equipment.

The second category called availability of supplies and equipment is relatively self-explanatory. Staff experienced delays in provision of supplies as well as malfunctioning of equipment. Examples in this category were, patient medications not available when needed, waiting for tube feeding solutions, and the vital sign machine repeatedly not working. The most notable delays came from constantly missing patient medications. Missing pills was noted at the very first observation session and eventually confirmed in every nursing interview.

\section{Labor market structure changes.}

The next category, labor market structure changes is one that was coined from the literature. Early on in data collection the researcher noted how often nurses spoke about the nursing shortage and that when RN's were sick they were often replaced by LPN's and that this meant more work for the $\mathrm{RN}$ who was already time challenged. The concept of time kept appearing in the lives of nursing staff in the study setting. In discussion with committee members it was suggested the researcher consult some of the recent literature on space, place, and time in healthcare. In this literature, specifically in the work of Cartier (2003) economic restructuring in healthcare was discussed using similar terminology to describe trends in minimizing the numbers of high cost professionals in healthcare delivery. This terminology seemed appropriate for codes such as increased hiring of Licensed Practical Nurses (LPN's), fewer RN's and the introduction of Patient Service Workers (PSW's) to the study setting. 


\section{Geographies (of place).}

This category was initially called geographic placement of patients and seemed reasonably straightforward for the researcher and simply referred to the fact patients were separated according to gender, if isolated they were naturally in single rooms and if their clinical status was precarious they were placed closer to the nursing station. The other aspect of location of patients concerned staff comments about patients that should not be on this unit. In discussing this category with committee members the researcher was asked if patients who are noisy or who are demented were located in any particular area. The short response to this from participant observation was no, however, committee members asked that the researcher write a memo about geography. The researcher was thinking only about the map aspect of geography. In order to write a memo about geography it was necessary first to define what was meant by geography besides the typical map aspect and geography when used here refers to "the arrangement of features of any complex entity" (Webster's, 1991).

Going to the literature on geography was most instructive. All places have geographies and these places have expectations (Holloway \& Hubbard, 2001). A good timely example of this is the ban on smoking in public places. The public now have the expectation that public places where these bans are in place are smoke free. Another geography is known as moral geography. Moral geographies are judgements people make about what behaviors and practices are acceptable in what settings. Hospitals traditionally have been considered to be places of care and comfort. Patients did voice this expectation in their interviews as well as the belief that they should not necessarily be housed with crying patients, moaning patients and cognitively impaired patients. Nurses also talked 
about patients particularly brain injured patients as not being appropriate candidates for a family medicine unit or not being in the "right place." Nursing staff also felt that palliative care patients should be on the palliative care unit to better meet their care needs. This is an excellent example of the evolution of a concept from the beginning where it seemed to be a simple matter of asking why a certain patient is located in a certain place to the realization that everyone has mental geographies of person and place and if a person is not in the place where it is expected they should be then this can contribute to the process of the construction of difficulty in the nurse patient encounter. Experience/competence/values

The category of experience/competence/values was used to encompass comments staff made about each other in general conversation about their work. The codes in this category were good to work with, working as a team, on top of things, communication, by the book, bends the rules, who is working and smart. Following the coding of nursing interviews this category was renamed "who is working." This was an in vivo code and was used by several nurses at interview and through the comparative process was found to better describe what was happening in the context of care. The last category that emerged from the participant observation data was patient descriptors.

\section{Patient descriptors.}

These were terms the researcher heard or overheard nurses use usually before reports or during reports. Some examples included: non-compliant, pleasant man, rings a lot, drug seeking, placement problem, needy family. The use of these terms was often associated with situations in which some nurse patient encounter difficulty had occurred or was anticipated to occur. Eventually this category was subsumed under the category of 
controlling. During nursing interviews when staff were asked to describe encounters that did not go well they began by saying they did not have enough time to be with the patient, this led to listing patient descriptors and for some listing controlling strategies that were sometimes employed.

This represented the results of the initial coding of the participant observations and the categories that emerged from this part of the analysis. The categories identified were: Time incongruence, availability of equipment and supplies, labor market structure changes, geographies of place/bodies, staff experience/competence/values, and patient descriptors. Two months after participant observation started the first three nursing staff interviews were conducted.

Nursing Staff Interview Discoveries

The categories retained from the coding of the nursing staff interviews were: Time incongruencies, knowing the patient, controlling, families, geographies of place, and expectations. Categories that were originally believed to be context dependent and that determined the amount of reconciling of time that staff had to do in the provision of patient care were also discovered in the data and these were: Unit reputation, availability of supplies and equipment, who is working, care space changes, and labor market structure changes.

As soon as the interviews were transcribed coding commenced and was conducted sentence by sentence. The researcher was very much aware of the categories that emerged from participant observation data and knew that these categories would influence the coding of the nursing staff interviews. As a way of mediating this influence questions were inserted into the staff interviews to verify what the researcher was 
observing. An example of this was to ask nursing staff about the availability of medications and other supplies and equipment on the unit when needed. The confirmation of this in the interviews gave the researcher confidence in the category. The interviews provided the researcher with the opportunity to verify everything that was being observed and this constant comparison and theoretical sampling added to the trustworthiness of the data. At varying intervals staff would ask what the researcher was finding. This gave the researcher an opening to check out categories. This helped the researcher to come up with the category of time incongruency. Staff members were asked to talk about time since the researcher was hearing the term over and over again. It was in informal conversation the researcher noticed how conflicted staff members were in making decisions about apportioning time.

Time incongruency.

The coding of the first three nursing interviews was memorable for the researcher in that the overwhelming first impression from the data was of a plea from nurses for more time to do everything. This led to an initial reaction on the part of the researcher to write a memo about how nurses could perhaps save time in their work through better individual organization of time and the travel time it takes to get around the nursing unit as a result of design. The researcher was locating the problem of time shortage within the staff. Following this memo writing the data and codes were reviewed once again and a category that was rapidly noticed was one that the participants had identified, the in vivo code of knowing the patient, however, this was contingent upon having the time to get to know the patient. 
The ubiquity of the concept of time led the researcher to discuss this with committee members. The recommendation was to consult the literature on time. This was a good example of theoretical sampling of the literature to better understand what was appearing in the data.

The literature on time was instructive to the researcher in more fully conceptualizing time. The researcher's ideas about time were quite linear and this is not uncommon for most people. In fact most organizations in society operate in a linear fashion. By this what is meant is that a certain amount of work can be expected to be completed within a certain period of time as if human interactions can be apportioned that way. Nurse's work is caring for patients and this takes place in a context shaped by the needs and demands of other patients, co-workers, and the organization. The point to be made here is the meeting of the psycho-social care needs of patients cannot be neatly packaged into 0-5 minute frames and this is nicely summarized by Davies (2001) with "care and caring have to be given and cannot be temporally or spatially confined" (p. 143). It became clear to the researcher at this point that nursing staff delivered care in a context of linear time when there was a great deal of nursing work that was complex and non linear. Jones (2001) argued there was no single time but rather "a multitude of times" (p. 151) that everyone operates within and competes for at any given moment.

This theoretical sampling of the literature enabled the researcher to begin to understand what it was that nurses were doing in their work faced with time incongruencies. The researcher initially called what was going on "adjusting their sails." This meant the nurses were constantly altering what they set out to do in order to meet patient needs/demands and their own time imperatives. Adjusting their sails eventually 
became reconciling temporalities since reconciling means putting up with that which is not desired and this best described what was heard from nursing staff and patients when they talked about encounters that did not go as well as desired. On the other hand when nursing staff talked about encounters that went well the in vivo category into which all codes easily fit was knowing the patient.

\section{Knowing the patient.}

Knowing the patient was the category with the thickest description and this should not be surprising since this is central to becoming a nurse. Nursing staff talked about what they did to get to know the patient and included: Establishing rapport, accommodating, spending time, explaining, accepting, showing compassion, individualizing care, and listening to name a few. This category related easily to the core category since getting to know the patient was contingent upon having the time to do so. Since having the time to do all it takes to get to know the patient is usually not possible then nurses reconciled the care required with the time they had. Knowing the patient is a concept well documented in the nursing literature. Fisher (1989) in her study on how nurses came to define patients as dangerous found mental health nurses evaluated patients as more dangerous when they were unknown, and were more understanding of patients when they knew them. Tanner (1993), in a phenomenological study of nurse's development of expertise in critical care nursing, found the recurring theme of knowing the patient. Knowing the patient meant "both knowing the patient's typical pattern of responses and knowing the patient as a person. Knowing the patient is central to skilled clinical judgement, requires involvement, and sets up the possibility for patient advocacy and for learning about patient populations" (p. 273). Allen (2001), in her study of nursing 
practice, found nurses expected they should know the patient, doctors, families and the institution expected them to, however, the care setting nurses found themselves working within often did not foster this.

When staff members were asked to describe encounters that did not go well most descriptions were prefaced with not having enough time. Another source of time loss for staff came from the frustration they experienced with the availability of supplies and equipment.

\section{Availability supplies and equipment.}

One particular source of frustration for staff was what they referred to as "missing pills." Nurses who were giving medication were always short pills and spent a great deal of time looking for pills or going to pharmacy. The unit had obtained a vital sign monitoring unit that was to be a time saver. Staff liked it when it worked, however, it was often out of service and this was frustrating for staff when it was sent for repair the answer was always that nothing was wrong. When nurses found themselves really pressed for time one of the strategies they resorted to was using controlling behaviors.

\section{Controlling.}

As staff described encounters that did not go well the category controlling was identified. Staff talked about the following: Sticking to routines, doing it by the book, expecting patients to fall in line, enforcing the rules, not giving explanations to patients and families, and hurrying patients. During these descriptions of encounters that did not go well patient descriptors also emerged and included bell ringer, combative, super demanding, wanting to be waited on, loud, overbearing, and manipulative. Another 
category that emerged from the staff member interview data was families and the time that staff felt families needed.

\section{Families.}

Most of the patients on this family medicine unit are elderly, meaning 70 and older. Many of their children are of the baby boomer generation. Generally speaking these families are larger, their members are working people with families of their own and if a parent or family member is in failing health it adds to their sphere of responsibility. If an elderly family member is hospitalized the family balance is disturbed and its members want to know the details and need to plan based on how everyone will be affected. This means families will be asking questions and the baby boomers are generally more educated and expect to be kept informed and will not hesitate to challenge healthcare providers for answers. These facts were weighed out by nursing staff all of whom spoke about how much time families take and if they were not given the time they felt they needed relationships deteriorated. This led to staff talking about expectations and how unrealistic patient and family expectations were with respect to hospital care.

\section{Expectations/geographies of place.}

When nursing staff talked about patient and family expectations they described their expectations as unrealistic with respect to time. Early on in the data collection process when the researcher initially identified the ubiquity of the concept of time and was focused on how many steps nurses take just to deliver care the geographical layout of the unit was focused on. This led to the literature on geography and the discovery of the geographies of place, that places have expectations. Traditionally hospitals have been known as places of care and comfort and people have come to expect just that. The 
restructuring of hospitals and the shifting of convalescence to home care, other institutions and the needs of families have changed the landscape of hospital care (Cartier, 2003). Hospitals are redefining themselves as places of bio-technological wizardry and are becoming "no care zones" (Casey, 2003). This could be one reason nurses are finding patients expectations unrealistic. As care providers they may not be fully cognizant of the effects on patients of the displacement of nursing time in favor of the performance of bio-medical tasks.

This prioritizing of the completion of medical orders before considering the psychosocial needs of the patient is not new. Schatzman (1979) described this predominance of the medical model to treat the somatic and the psychosocial was only attended to if it interfered with medical treatment or the functioning of the ward. The predominance of the medical model has evolved in the form of redefining hospitals as places of biomedicine and reifies the location of power in these places.

This summarizes the categories that contributed to the degree to which nurses were able to reconcile temporality in the delivery of patient care. The reconciling of temporalities was also influenced by environmental conditions of: Unit reputation, who is working, care space changes, and labor market structure changes.

\section{Environmental Conditions}

Two conditions that contributed favourably to reconciling temporalities were the unit reputation, and who is working. The unit reputation was described in part one of this chapter. 


\section{Unit reputation.}

This unit has had the same manager for a long time and the manager is known for her leadership, inclusion of families in care, and de-escalating sources of potential conflict. These attributes were easily articulated by staff who believed that this contributed to minimizing the possibilities of difficult encounters and to the palliation of difficult encounters when they occurred. This was observed during participant observation sessions and one intervention in particular was noted when the nurse manager came to report and let staff know she was available to support them with a new admission. The patient was known to staff who had encountered difficulty with a family member of the patient on a previous admission. In describing the factors that contributed to encounters that go well or not so well some staff used the expression "who is working." The researcher found this to be an apt description and used it as a category.

Who is working.

Who is working meant that if the staff on a particular shift worked well together and helped each other out as needed then no matter what everything got done and the shift went okay. Part of this is also related to a generally experienced staff on this unit and a staff that does not turn over regularly. Staff when short of time may not have given the patients the time required, however, they explained the situation to patients and by working as a team were each able to do a bit more for each patient. This compared to staff that preferred to work independently and each get their own work done. This often led to one or several staff falling behind if the status of one or two patients deteriorated or if there were several new admissions. When staff fell behind this contributed to patients waiting longer for their care and generally increased frustration for staff and patients. As 
staff described factors that negatively affected encounters with patients they also talked about the complexity of their patients and how short the length of stay of patients was. This led to the development of the category called care space changes.

\section{Care space changes.}

Care space change refers to descriptions nursing staff gave of the care environment. They spoke of how most of the patients were elderly and this is reflected in many healthcare settings. Patients are living longer and with a host of chronic illnesses for which they take numerous medications. Nurses described patients having pages and pages of medications. Despite how ill many patients were there was a constant push to reduce lengths of stay and to admit elective surgery patients only on the day of surgery.

The setting for participant observation was a family medicine unit with a hospitalist program. Atlantic Canada has been experiencing a shortage of family medicine physicians, leaving a number of citizens without a family physician. The family physicians were experiencing particularly heavy workloads. The hospitalist program was created to: (a) Ensure a standardized consistent approach to the delivery of in-hospital care to family practice patients, (b) to provide access to physician care to all residents of the area, and (c) to reduce the length of stay of hospital patients. These imperatives were met, however, many patients preferred to see their own doctor and this program served medicine and the organization more so than the patient. Two family medicine physicians were present on the unit every morning, and one was available each afternoon, as well as evenings, nights and week-ends for two week periods. After two weeks two more would rotate through and so on. 
Nurses had ready access to a physician, however, the rhythm at which the physician worked to process orders now regulated the admission and discharge process for the unit. If discharges were not entered until after rounds near noon or later then admissions from ER arrived later. More admissions on evenings made the unit busier at a time when the staffing complement drops. Nurses felt the effect of these care space changes. The elderly who were dependent for their care and who were on a lot of medications needed more care time. Shorter lengths of stay reduced the number of contacts staff had with patients and reduced the opportunity to get to know the patient. This situation contributed to the need for nurses to reconcile temporalities. One additional environmental condition that further contributed to the need for nurses to reconcile time was labor market structure changes.

\section{Labor market structure change.}

The development of this category was described above and came to mind immediately as nursing staff spoke about the increasing numbers of LPN's and the shortage of RN's. They also spoke about the dwindling numbers of other professionals such as physiotherapists. Nurses know there is a shortage of RN's and noted when nursing workload could not find an RN to send to a unit an LPN was sent. RN's wondered how long it would take for these RN positions to disappear in favor of LPN's. Their fears were well founded in reading the work of (Cartier, 2003) who noted the current structure of the labor market favors minimizing the numbers of highly paid professionals.

Nurses described the introduction of Patient Service Workers (PSW's) to the nursing unit in late 2003. These workers were primarily cleaners and replaced the 
services previously done by housekeeping staff and ward aides. Staff has been going through a process of adaptation with this change since they have actually had to take on some of the functions previously done by ward aides that Patient Service Workers (PSW's) do not do. It is interesting to note the introduction of the PSW's was stated to contribute to more patient focused care. The PSW's would be on the unit at all times, there would be fewer people going in and out of patient rooms and the patients would get to know them. These arguments are all legitimate. The irony of it all is that the nurse needs to get to know the patient and to spend more time with patients.

The initial summary of the analysis of the nursing staff interviews led to the discovery of the core category of reconciling temporalities. The degree to which staff were able to reconcile time demands with time resources was determined by the situational conditions of time incongruencies, knowing the patient, controlling, families, and the expectations/geographies of place. Factors in the environment that influenced the reconciling of temporalities were: unit reputation, who is working, care space changes, and labor market structure changes. Now follows a description of the process of analysis of patient interviews.

\section{Patient Interview Analysis}

Approximately six weeks after beginning nursing staff interviews, the interviews with the former patients from the setting for participant observations began. There was a period of ten weeks where participant observations, nursing staff interviews and patient interviews were all overlapping one another. This permitted the researcher to be inundated with data from three sources simultaneously and to check out ideas and hunches as data collection unfolded. For patients what was important in the nurse patient 
interaction was to be listened to, respected, and to receive the attention required within a reasonable period of time. Most patients particularly those who were dependent for their care spoke of experiencing some type of care delay and this dovetails with the nursing staff repeatedly searching for time to do patient care and was observed by the researcher during participant observation. All of the codes in the patient data fit into one of the existing categories. This was very surprising to the researcher because at the beginning of the study the thought of having three sets of data plus all of the memos it seemed almost impossible that the categories that emerged in one set of data would be such good repositories for incoming data.

The categories that saturated the most completely in the patient interview data were time incongruency, and knowing the patient. The other categories that replicated themselves in the patient data were: Care space changes, expectations/geographies of place, and being controlled.

Time incongruency.

Patients all acknowledged that they believed nurses were too busy. They did however, all want to have the amount of care time necessary to get their needs met. This was expressed most poignantly by patients who had to wait to be toileted, and once toileted had to wait for extended periods of time to finish the toileting process. Patients wanted to be allowed to be patients to be listened to, to get the information they needed in a timely fashion. They explained that their call bells were initially responded to reasonably quickly but once their request was placed it often took quite some time to have it fulfilled. Patients also spoke about needing time with the nurse and this data was placed in the category knowing the patient. 


\section{Knowing the patient.}

One patient said "I need for someone to hear my story, being in hospital is about me and I needed to tell the nurse about it and to know I am heard" (P12, p. 1). Patients spoke about being worried, frightened, and shocked during hospital experiences and how being able to communicate with staff helped this. Patients looked for compassion in their care providers, they expected staff to find out about their routines and what they liked and disliked and basically to get to know them and be there for them because when they were sick they did not feel like they could defend themselves like they did when they felt well. Patients noticed the changes and the challenges the hospital and the nursing staff were experiencing.

\section{Care space changes.}

Patients spoke about how long they waited in the ER for a bed. Some patients noted that most of the patients on the unit were elderly and some objected to the fact that there were patients there who were confused, crying, moaning, and even violent. The objection was not to these patients having care but rather to the fact there are not designated units for patients with varying cognitive challenges. Patients felt they were discharged too quickly and that some aspects of the discharge were not attended to. Patients attributed these to gaps in medical care, particularly communication between specialists that saw them in hospital and their family doctors. Patients do have certain expectations when they go to hospital.

\section{Expectations/geographies of place.}

Patients articulated the findings that created this category more clearly than staff. Patients expected to get the care and attention they needed in a timely fashion. They 
expected to recover in hospital and held out hope that more money will enable hospitals to be places of care and recovery. They know staff are busy but still felt they should get the care they were due. When care was not what patients felt it should be they spoke about being controlled by staff.

\section{Controlling.}

Patients who were dependent for care felt they were controlled. They felt that when they needed to go to the bathroom it was expected this should happen when staff were present rather than having to call them back. Patients who used a bedpan felt they were left too long on the bedpan. Patients who had urinary catheters felt this worked fine and fit with the routine but when the catheter came out, the patient then had a personal routine that did not fit with the ward routine. Patients who were dependent for toileting felt controlled as to when they could go. Patients who were independent in their care of course had no problem with toileting routines but most of them spoke about their fear of becoming dependent because they observed that toileting and feeding needs were not met on the patient schedule but rather that of the ward. In summary the conditions patients experienced that determined the degree of reconciliation of temporalities required were: time incongruency, knowing the patient, care space changes, expectations/geographies of place, and being controlled.

This summary of the process of data analysis and concept evolution was intended to make as explicit as possible the relationship between the researcher and the data in order to enhance the trustworthiness of the findings. Trustworthiness was described earlier in this chapter. The initial summary of the findings revealed that the core category in this study was reconciling temporalities. Nursing staff and patients regularly found 
themselves at odds with one another with respect to time. Nursing staff were searching for the time needed to deliver the care they wanted to give and patients just wanted the care they needed delivered in a timely fashion. The degree to which reconciliation was achieved influenced how difficult the nurse patient encounter became. The situational conditions that led to the need for reconciliation of temporalities were: knowing the patient, controlling, families, equipment and supplies, who is working, and expectations. Contextual conditions that affected reconciliation were: Unit reputation, labor market structure changes, care space changes.

The ordering of these findings changed as concepts evolved and the eventual ordering as presented in the findings chapter became: The core category that emerged from the data for this study was reconciling temporalities. The nursing staff unilaterally agreed that knowing the patient minimized difficulty in the nurse patient encounter and that reconciliation of time was inherent in getting to know the patient. When nurses did not have the time, and patients did not feel that care has been delivered in a timely manner this resulted in temporal incongruencies. The greater the incongruence the more reconciliation was required in the encounter. The factors that contributed to temporal incongruencies, and necessitated reconciliation were: Families, availability of supplies and equipment, who is working, and care space changes. Contextual conditions that influenced the process of reconciliation were: Unit reputation, and labor market structure changes. The strategies that nurses used to reconcile temporalities were controlling, working together, managing families, and employing geographies of place/bodies.

The prolonged engagement in the field was an important aspect of this study. The level of familiarity the researcher had with the context and with the nursing staff 
enhanced the meaning of the findings. In appreciation of the opportunity to conduct participant observation and to provide the reader with a window into the setting a detailed description of the setting will now be provided in Chapter IV. Chapters III and IV set the stage for the detailed presentation of the findings in Chapter V. 


\section{Chapter IV}

\section{Setting}

This chapter provides a description of the important elements of the family medicine unit selected as the study setting. These include: Patient population, staff and their responsibilities, medical care, geography, and unit flow.

A diagram of the unit is included at the end of this chapter. The micro environmental context of the unit was described in Chapter III with respect to unit history and leadership. The unit is also affected by factors in the macro environmental context of the Canadian healthcare system and this is addressed at the end of this chapter.

\section{Patients}

The patient population on this unit was generally older, over 65 years of age. Most patients had acute medical conditions such as respiratory, gastrointestinal, infectious, and cardiovascular diseases. These patients were either newly diagnosed or had an acute episode of a chronic illness. Palliative care patients were also admitted if the palliative care unit was fully occupied. Family medicine units also admit patients who do not meet the criteria for any acute specialty area. Patients were provided with a patient guide to this family medicine unit. The guide is included as Appendix G. 
Staff

The unit staffing complement is measured in full time equivalencies. There were 23.5 RN FTE's, 4.2 LPN, 1 care coordinator, 3.2 ward clerks, and 2.5 Patient Service Workers (PSW). The care team was made up of the nurse manager, charge nurse, nursing staff, doctor, dietician, care coordinator, pharmacist, pastoral care, PSW, respiratory therapist, social worker, physiotherapist, and ward clerk. There was no unit budget for physiotherapy, respiratory, or dietary. These care providers saw patients on this unit when they were consulted to do so. Care delivery followed a combination of functional/team nursing. Most staff worked twelve - hour shifts 7:30-7:30, however, there were also staff that work eight hour shifts.

\section{Staff responsibilities.}

The regular charge nurse worked Monday to Friday from 7:30-3:30. On weekends a staff nurse was the charge nurse. On all other shifts the charge nurse also administered medications for all patients.

The unit had a care coordinator who made rounds each day. Her primary responsibility was to make plans for the continuing care of patients including discharge.

This unit had a medication nurse who administered all scheduled medications including intravenous medications for all patients. Patients on insulin or patients requiring medications stat received them from their assigned nurse. If the patient was assigned an LPN, the nurse covering the LPN administered the insulin and the stat medications. The medication nurse was responsible to carry out the narcotic count with another RN at the end of each shift. 
The nursing staff provided patient care according to a care plan initiated electronically on admission and updated as medical orders and patient status changed. These care plans were printed each morning by the night staff and placed in care plan books by room and bed number and outlined the technical care needed.

The orientation checklist for new staff to this unit indicated that RN's are responsible for covering the LPN's for PRN medications, insulins, admissions, preparing the medication list for discharged patients, contacting the doctor for orders when the clinical status of the patient deteriorated and performing these orders if the LPN was not qualified, administering blood products, and caring for chest tubes. Two (2) RN s checked insulins, potassium chloride, heparin boluses, blood products, and the medication list made for the patients when they were being discharged. Stat Orders were the responsibility of the nurse who had the patient. The nurse signed off on the order indicating it has been carried out avoiding the possibility of someone else carrying out the same order.

LPN's completed admissions, however, the RN did the physical assessment, medication list and entered this information into the electronic record and checked to see that all orders had been entered. During completion of the admission database if the patient answered yes to the questions about Methicillin Resistant Staphlococcus Aureaus (MRSA) the nurse obtained a verbal consent recorded this in the nurse's notes and entered the order for the swabs to be taken. Contacting a doctor about a patient was the responsibility of the nurse for that patient except on the 7:30-3:30 shift when there was a charge nurse. Nurses were responsible for restocking the medication room, and nurses gave scheduled ointments and creams to patients. 
LPN's carried out unit admission procedures except the physical assessment. They also performed capillary blood glucose checks, urinary catheterizations, dressings, tube feedings, care of drains, and applied scheduled ointments and creams.

PSW's cleaned patient's rooms including the bathroom. They collected the trash, answered patient call bells and delivered food trays. They prepared linen and equipment supply carts used by the nursing staff.

\section{Medical Care}

Medical care was provided by doctors participating in a hospitalist program (HP). Most patients admitted to this unit either did not have a family doctor or had a family doctor who was part of the HP. The doctors who worked in this program changed every two weeks. Two physicians were present every morning on the unit Monday to Friday. One was available in the hospital each afternoon. Weekend coverage was also provided. Atlantic Canada has been experiencing a physician shortage for some time and a number of citizens were without a family doctor. If these people were admitted to hospital then the hospitalist served as their physician. Patients with a family physician were followed by the hospitalist if their family doctor was part of the HP.

\section{The Unit}

\section{Geography.}

Access to the horseshoe shaped unit is through one of two sets of double doors, one set at each end of the horseshoe. The patient rooms are along the outside of the horseshoe and all patient rooms have windows. A corridor separates patient rooms from the nurse's station and utility areas. In the center of the horseshoe is a counter style area with several computer terminals (4), (2) telephones, and a printer. There is lots of counter 
space. Behind this counter at the head of the horseshoe is the secretarial space. This space has a telephone, the intercom to patient rooms, an addressograph stamper, and numerous under counter drawers containing paper supplies and forms. Patient charts can usually be found here on one of two mobile carts. One tall cart can hold all 36 charts or one shorter cart for fewer charts. These can be wheeled about for patient rounds or for nurses to bring to the inner sanctum for documenting. Nested within the countered area is a smaller room where nurses listen to morning report. On my first visit I was invited to come into the (inner sanctum). Morning report was held in this room and nurses did most of their documentation throughout the day here. This room has a door at each end, counters on both sides, and the walls are solid on the bottom half and windowed on the top half. This room has two of the 4 computer terminals, recording equipment for the doctors, a telephone as well as four or five blue office style chairs. On the window ledge above this counter thank-you notes and cards are displayed. Doctors also used this area for order entry and reviewing electronic patient data. There were another five to seven of these chairs at the outside counter. Several manuals were located on one of the counters including the unit orientation manual, the workload measurement manual, hospitalist program manual, nursing competencies manual. Hospital policies and procedures were accessed via the hospital intranet. On one wall is a cork bulletin board covered with staff family pictures. Beneath the cork board on the counter was an accordion file where staff pay stubs and mail were filed. On the end walls leading to the medication room were bulletin boards one is for posting memos, minutes of staff meetings, and clinical literature. The other often had staff reminders regarding re-certifications, or vacations. 
Paper supplies and forms were located behind the outside counter on the kitchenette side of the horseshoe. In addition to paper supplies and forms, there were patient teaching booklets on topics such as influenza, MRSA, C-difficile. There were also some clinical nursing textbooks, some recent and some old. On the counter opposite the bookcase with the nursing texts sits the photocopier, printer and fax machine. Also located in this area was a file with a variety of clinical titles. The clinical titles corresponded with those diagnoses commonly encountered on the unit and under each title was an article or two on the topic. This was the project of a pharmacy student in 1998 and has not been updated since that time. Near this file is a computer terminal primarily used to view patient medical imaging results. On the opposite side of the horseshoe is a cart with intravenous supplies, a sink, over the sink a cupboard with skin and wound care supplies. Beside the sink is the emergency cart with an emergency drug box and a respiratory support basket. Opposite the emergency cart were the staff locker cubicles. These cubicles measured about 10"h, 8"w and 12"in depth. Staff were overheard saying there were not enough for everyone. Most lockers had combination locks on them. Next to the lockers was a black board and usually during each of the researchers periods of observation a quote of some sort was written on the board. These quotes were included in participant observation notes. The quotes had a general inspirational tone and the researcher was told that one of the Patient Service Workers was the source. On the other side of the lockers in the nurse's station was a counter and a third telephone. The unit had three telephones.

Next to the inner sanctum was a hallway with access to either side of the horseshoe then there was the medication room. There were three bulletin boards in this 
hallway. One had the staff rotation, another union information and miscellaneous information, the third was for writing notes on and that can be erased. The medication room had three solid enclosed walls and the fourth opened wide to the hallway between it and the inner sanctum and gave access to the corridors on either side of the horseshoe. The wall opposite the entrance had cupboards top and bottom, a sink and a fridge. The unit narcotic locked area was in these cupboards. The remaining space held medication related supplies. One solid wall was the storage area for the two unit medication carts. These carts were refilled by pharmacy on Monday, Wednesday, and Friday at approximately 10:30. Ward restock was on Wednesday, and narcotic restock was daily around 10:30. The other wall had a caddy with multiple pockets containing syringe and needle supplies. There was also a large diagram of the chest tube set up the hospital used. This room also housed the electronic thermometers, blood glucose testing machines and the portable (buddy). The buddy was a mobile unit that was equipped to check temperature, pulse, blood pressure, and oxygen saturation.

After the medication room was a thruway providing passage to both sides of the unit. In this passageway the following items were stored; general supply cart, linen cart, and a cabinet with all previous charts of unit in-patients. Next to the passageway in the center of the horseshoe on one side was the unit kitchenette. This space was galley style and could only be accessed from one side of the unit. Upon entry on the right were cupboards both up and down, a sink, a boiling water tap and a microwave oven. Supplies for making tea, toast and coffee were provided for patients. On the left of the room were the fridge, ice machine and the trash bin. Continuing along the center of the horseshoe adjacent to the kitchenette was the staff lounge. The room was small and rectangular with 
no windows. On the right were a coffee machine, an old two-seater couch, a desk, microwave oven, and a two-cubicle locker. On the left was the same type of couch plus 1970's end tables, lamps and a refrigerator. Next was the soiled utility room were linens and equipment were kept for pick up. Equipment such as intravenous pumps and poles that needed to be cleaned were left here for the PSW's. Items needing sterilization were also left here for pick up. This room opened to both sides of the horseshoe. It also had a washer and dryer. Next to this area was a second passageway opening to both sides of the horseshoe, off this passageway were the nurse manager's office, staff bathroom, patient shower room, tub room and bathroom and a small storage room for patients lifts, IV poles and McGill chairs. After this on one side of the shoe was the locked storage and resident's lounge, and the patient/ family lounge. The family lounge had two comfortable chairs, a wall mounted TV, a small bookcase with some books and magazines, a floor lamp and a couch. The colors were pinks and greens. On the other side of the shoe at this end was the fourth floor kitchen.

There was a collection of art on the walls along the corridor access to patient rooms. Pieces of the collection were done by former patients or by family members of patients. The walls were painted in pale colors. Here and there were bits of information on topics such as latex allergies and the closed - circuit TV channel. There were three wall clocks, one on each side of the horseshoe and one at the top. There were wall mounted hand antiseptic dispensers outside each patient room. Rooms were either single, double, or four bed wards. Each patient area had a bedside table and an over bed table. All rooms had double windows. Curtains were suspended from the ceiling and could be drawn around beds for patient privacy as needed. The curtain tracks did not always allow 
the curtain to be pulled freely. There was a bathroom with toilet and sink for every two patients. Of course single rooms had bathrooms. Also noted propped on the counter that surrounded the nursing station was the poem "what a smile is." There were eight laundry hampers located outside patient rooms. The hampers had pedal operated lids. Staff placed laundry in them and several times a day a large trolley came by and collected it. Hallways were cleaned by a person driven battery - powered machine that made a lot of noise as it washed the floors. A diagram of the unit is located at the end of this chapter.

\section{Unit flow.}

The day began with staff arriving one by one. They gradually gathered in the nurse's station (inner sanctum). Most staff arrived about ten minutes before their shift started and they checked their assignment that was kept at the front desk just outside the inner sanctum where the unit secretary was located. Day staff $(7: 30-3: 30)$ included the Unit Manager, charge nurse, five RN's and two LPN's. Staff then went to the care plan books and checked the plans and wrote down their assigned tasks for the day. Staff sick calls had been received by now and this would trigger frustration for staff. The frustration often voiced was that the office of nursing workload frequently could not find $\mathrm{RN}$ replacement and if replacement was found it would most likely be an LPN. Staff came to work anticipating a certain staffing level.

Short staffing situations played out in two ways, staff assignments were rearranged and staff reprioritized to complete the essential or staff attempted to complete care as usual for more patients. Either way it took time and energy to make this adjustment and presented staff with a certain psychological burden to start the day. In the next chapter "who is working" will be discussed in terms of the extent to which staffing 
affected unit equilibrium. The other scenario that happened at this time was the unit was full staffed and because of staffing situations on other units the office of workload called requesting that a staff member float elsewhere. Despite the frequency with which either of these events happened and that staff knew this could happen it still caused considerable frustration.

During this time there was also an exchange among staff on various topics from community events, to family events, movies, vacations, catching up on what happened with certain patients on their days off, and general socializing. By 7:30 the charge nurse and the unit manager arrived and the taped report began to roll. All nursing staff usually listened to the entire report. Listening to report usually took 20-30 minutes. During report if patient call bells rang, the Patient Service Workers were expected to respond. There were three Patient Service Workers on days, one began at 0700, another at 0900, and the third arrived at $11 \mathrm{am}$. Following report the charge nurse reminded staff of the tests and procedures that patients were going for and what patients needed to have something to make their bowels move.

If students were present, the charge nurse listed the patients they had, the care they would be performing and introduced the student to the RN/LPN assigned to the patient. Students were usually most welcome and were a help to staff. If there were replacement staff they were welcomed as were people like myself, the nurse researcher. Staff joined their patients to begin giving baths and treatments. Capillary blood glucose testing was done on a scheduled basis for patients who were diabetic. Patients on Insulin coverage were tested at $7 \mathrm{am}, 11 \mathrm{am}, 5 \mathrm{pm}$, and $10 \mathrm{pm}$. Patients on scheduled as well as 
coverage were tested at $8 \mathrm{am}$, noon, $5 \mathrm{pm}$, and $10 \mathrm{pm}$. This was to assure the patient only received one insulin injection.

At $8 \mathrm{am}$ the unit secretary arrived and worked until $4 \mathrm{pm}$. There was also a secretary from $4 \mathrm{pm}$ until $11 \mathrm{pm}$. Around 0800 the doctors arrived. On this unit, rounds were made daily Monday to Friday by the rounds team consisting of the charge nurse, doctor, pharmacist, and care coordinator. This group went from room to room to visit most every patient. This process took most of the morning. The charge nurse often returned to the nursing station during rounds as orders changed and entered these orders electronically, she would also inform the nurse right away of the change if the nurse was present. Nurses were expected to check the new order board after breaks and before the end of their shift to keep up with order changes.

The morning was a time of lots of activity, bathing patients, ambulating patients, giving medications, meals, patients coming and going for tests, and lots of people external to the unit coming and going. A modest estimate of the daily number of arrivals to the unit was 100 . This number came from estimating that each patient had one visitor (36), staff (20), doctors (10), care coordinator (1), pharmacist (1), physio (2), IV team (10), enterostomal therapist (1), laundry pick up (6), and other (12). During periods of observation, the researcher never experienced a slow day, meaning the unit having a full complement of staff and several empty beds allowing staff to sit around and socialize. The unit was busy and the degree of busyness varied. When it was extremely busy, staff were in constant motion and one felt that one should not interrupt them as it would give them one more thing to deal with. The degree of busyness escalated when there was an increase in the number of confused patients, dying patients, incontinent patients and 
patients who "go bad" that is, their clinical status deteriorated. On the other hand, when it was less busy, staff would hesitate more readily when passing a patient room, passing the researcher, or passing a visitor and one felt like one could interrupt them.

Patient meals arrived around 0800 , noon, and $5 \mathrm{pm}$. The patient information guide listed mealtimes as $8: 15 \mathrm{am}, 12: 10 \mathrm{pm}$, and 5:10pm. If trays had not arrived by these times staff were heard complaining about where the trays were. Patients would also wonder about where the trays were. They had these times in their minds and organized care around them so that when meal trays were later than expected they had to rethink what to do next. Blood work on general units was done by the intravenous team staff and in a timely manner. This enabled patients to be able to eat as planned and relieved the staff from wondering if fasting bloods had been done. Staff set up their respective patients then helped all those requiring feeding assistance. Breaks and meals were as follows:

$$
\begin{aligned}
& 1^{\text {st }} \text { break }-0900 \\
& 2^{\text {nd }} \text { break }-09: 30 \\
& \text { Evening break }-8: 30 \\
& \text { Night break }-10: 15 \\
& 1^{\text {st }} \text { lunch }-11: 30 \\
& 2^{\text {nd }} \text { lunch }-12: 15 \\
& 1^{\text {st }} \text { supper }-4: 30 \\
& 2^{\text {nd }} \text { supper }-5: 15
\end{aligned}
$$

The doctors began to enter orders and prepare consults about noon and were often around most of the afternoon. Between 1:30pm and 3:pm, the unit hallway lights were turned off to signal this was a rest period for patients. When staff returned from lunch 
they checked in with their patients, completed needed care and then sat down to begin documentation. Some documentation was electronic and some was manual. The software did not provide vital signs in graph format, therefore, staff documented these manually because the doctors wanted vital signs graphed. All staff had to return to the nurse's station to retrieve patient information and to document. Around three pm, the charge nurse taped the day report on all patients. The unit had a status report that all nurses filled in 45 minutes before the end of the shift to enable the charge nurse to tape report.

At 3:30pm, the charge nurse for evenings also became the medication nurse and any staff arriving for the evening listened to the day report. If the unit had more than one empty bed at this time of the day, the staff braced themselves for the inevitable admissions. Assignment changes often happened at shift change and nurses checked the assignment sheet for these changes. In the late afternoon and early evening there was a noticeable change in the number of visitors. The hospital had a visiting hours policy covering the period from $3 \mathrm{pm}$ until $8 \mathrm{pm}$. This unit was very flexible with visitors and accepted them almost anytime unless they became disruptive.

During the evening, the unit was generally quieter with less traffic from other departments. Discharges were frequently not written before noon leading to more admissions late afternoon and during the evening. The nurse-in-charge from $3: 30 \mathrm{pm}$ taped an updated report at $7 \mathrm{pm}$. Twelve hour night staff arrived and listened to the combined day and $3 \mathrm{pm}$ to $7 \mathrm{pm}$ updated report. Evening patient care rounds continued until about 10:30pm when staff liked to have patients settled. Staff then began to document. Late in the evening, the night staff completed the workload measurement forms online for each patient. Overnight the unit was usually staffed with two RN's and 
one LPN. Rounds were made hourly with major rounds shortly after midnight and early am. Staff worked together to provide the care the patients needed.

A 36 bed family medicine unit was chosen as the setting for this research. The patient population, staff and staff responsibilities, medical care, geography and the general flow of work have been described. Of equal importance is the context of care. Important conditions in the micro-environment of the unit such as leadership, stable staffing and an experienced staff were described in Chapter III. The micro-environment of the nursing unit is part of the macro environment of the Canadian Health Care System (CHCS).

\section{The Context of The Canadian Health Care System}

This country enacted the National Medical Care Bill in 1966 and implemented it in 1968. Gradually over the next four years, the provinces and territories joined this plan. Universal hospital and medical insurance was provided by the provinces and territories and supported with matching funds from the federal government. In order to receive the matched funding provinces and territories had to meet four criteria. "The coverage had to be comprehensive, universally available, portable between jurisdictions, and operated on a nonprofit basis and publicly administered" (Baumgart \& Larsen, 1992). The delivery of healthcare to the citizens is a provincial responsibility. The system is an illness care system and primarily medically driven.

Until 1977 the federal government reimbursed provinces for approximately 50\% of costs. Today the federal contribution is $16 \%$ (Healthy Futures, 2004, p.15). Provinces and territories are experiencing challenges to deliver the care and services the population expects. Compounding this issue are factors such as the increase in the number of 
elderly, the explosion in the number and cost of new medications, new technology availability and cost, shortages of health care professionals and a rising population that is generally unfit. This has led to emergency room backlogs of patients waiting for a bed, waiting lists for tests and surgeries and access to basic medical care. Media reports of these events are a regular occurrence.

How have Canadians arrived at a place whereby so much illness care is necessary? A brief summary of global mortality is instructive. "In 2000, 55.7 million people died around the world from a range of illnesses and conditions. Cardiovascular diseases led killing 16.7 million. Second were infectious diseases taking 14.4 million and third were cancers at 6.9 million" (Vital Signs, 2003 p. 108). The majority of deaths from infectious diseases were in developing countries whereas cardiovascular diseases and cancers predominated in developed nations among those "who consume too many unhealthy foods, tobacco, alcohol, and drugs, and who lead sedentary lifestyles. Developed nations account for only $28 \%$ of the world's population" (p.108).

The major chronic illnesses affecting Canadians are cardiovascular diseases, cancer, diabetes, and respiratory diseases. Canadians cherish their health care system and generally believe that more money is the answer. In every provincial and federal election increased funding of the healthcare system was either number one or two among the issues. The most recent federal election was in June 2004 and in early September, the Prime Minister and the provincial Premiers met for three days to reach agreement on a new plan to increase federal healthcare funding to the provinces. 


\section{Atlantic Canadians and the Healthcare System}

Atlantic Canadians also suffer from the same chronic illnesses as the remainder of Canadians but have higher mortality rates. The reasons for this relate to a number of social and economic inequities. "The region has a generally poorer health profile, lower incomes, higher rates of unemployment, and a smaller proportionate share of the national wealth than the rest of Canada" (Hayward \& Colman, 2003). www.pph-atlantic.ca

The plan to address the above challenges includes negotiating with the federal government for increased funding. The deal struck on September 16, 2004 called for the federal government to "inject $\$ 18$ billion into provincial health systems over the next six years and for automatic increases of 6\% a year that will last until 2015" (Laghi, Clark \& Fagan, 2004, p. A1, A9, A11).

The population is informed on a regular basis by the media of the scarcity of health care and health human resources and this generates fear and anxiety for those who are ill and who may become ill. People have a heightened anxiety at the prospect of needing healthcare and they watch the situation closely as consumers or relatives of consumers. Nursing staff in the hospital system see a constant increase in the number of patients presenting for care and the complexity of the conditions patients present with. Knowing that hospital beds will continue to be reduced is creating anxiety among healthcare workers because they are living with acute bed shortages on a daily basis. This anxiety was palpable and in combination with $\mathrm{RN}$ shortages contributed to a local context of anxiety on the part of the population as to whether there will be hospital beds and staff if and when they need care. Nursing staff believed their patients were older, sicker, and needed more time than they had to give. They also believed the chronic $\mathrm{RN}$ shortage will 
result in the disappearance of $\mathrm{RN}$ positions in favor of hiring more lower cost less skilled workers.

Some areas of Canada are experiencing $\mathrm{RN}$ shortages, however, the area where this study was done had few vacancies. Prior to beginning data collection the study site had introduced Patient Service Workers, initially to replace aides and housekeepers and eventually to assist with patient care. This represents what (O’Brien-Pallas, et al., 2001) described as substitution potential. O'Brien-Pallas in studies forecasting supply estimates for RN's found that vacancy rates were not a reliable predictor because of the numbers of lower cost less skilled workers that have been introduced to assist RN's with patient care.

The lives of patients and nursing staff and their encounters unfolded in a context that was influenced locally, provincially, and federally. A concise summary of these contexts revealed a population with growing numbers of elderly suffering from a variety of chronic illnesses and a generally unfit younger segment of the population. These factors added up to needing more money unless the younger segment suddenly becomes healthier. A number of initiatives are under way to promote wellness, however, these initiatives do not address the here and now. The participants in this study were living with present conditions.

Economic restructuring of the healthcare system has significant consequences for nursing practice and patient care. Hospitals were focusing budgets on being centers of biotechnology. In order to do this economies needed to be realized elsewhere. One area targeted was nursing hours. Hospitals want to reduce these hours. The strategies to achieve this were: (a) Shortened hospital lengths of stay, (b) shift as much basic care as 
possible to lower paid caregivers, and (c) relegate nursing care to families, homecare agencies or another type of care facilities (Malone, 2003).

The most important consequence for nursing was the distancing of nursing from the patient (Malone, 2003). Malone argued that the nurse patient relationship was central to nursing and the establishment of this relationship takes time. This relationship cannot develop and flourish if the role of the nurse becomes that of care manager minimizing the amount of time the nurse has with the patient. Nurses were experiencing frustration in their attempts to provide the care they knew the patient needed in an environment that wanted to process patients rather than care for them.

Patients were also frustrated. They expected to have their needs understood and met in a timely fashion by nurses and to be able to recover in a hospital. The hospital of today wants to limit itself to medical care (Cartier, 2003). As soon as a patient's needs are deemed to be that of nursing care or custodial care then this must happen elsewhere. Hospitals traditionally were known as places of care, comfort, and convalescence. This shift has left patients worried about the prospect of present and future care needs.

Both nursing staff and patients were experiencing anxiety about the adequacy of physical and health human resources. The findings of this study about the origins of difficulty in the nurse patient encounter were influenced by the context of healthcare delivery. These findings, examples from the data to support these findings, and the environmental conditions that influenced these findings are presented in detail in the following chapter. 
DIAGRAM OF RESEARCH SETTING

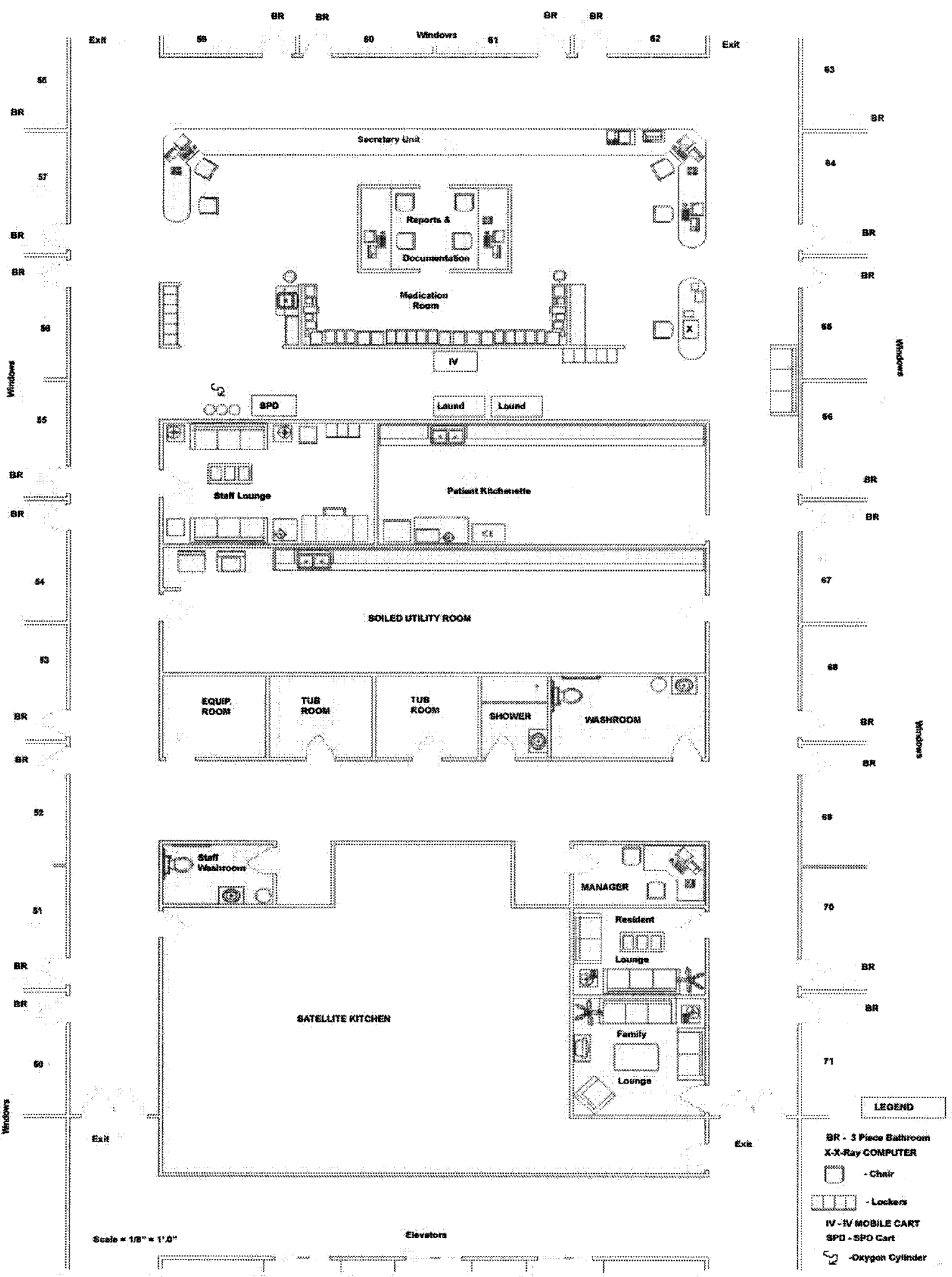




\section{Chapter V}

Findings

The purpose of this ethnographic field study was to generate a substantive explanation of the origins of difficulty in the nurse patient encounter. The specific aims of the research were to answer the following questions: (a) How did nurses describe the origins of difficulty in the nurse patient encounter? (b) What were patient's perceptions of recent care encounters? (c) How did the context of care influence the nurse patient encounter? and (d) What were the consequences of difficult nurse patient encounters for patients and nurses?

The site selected for this study was a 529 bed, acute care hospital in Atlantic Canada. The setting was a 36 bed family medicine unit. Data consisted of 120 hours of participant observation, 12 interviews with former patients from the setting and 10 interviews with nurses working in the setting. The research method was grounded theory.

In this chapter the findings of this ethnographic field study are presented beginning with a brief synopsis. The synopsis is followed with a detailed presentation of situational and contextual concepts that constituted the theory along with illustrations from the data to support and link these concepts to one another and to the core category. The findings are diagrammed followed by two case studies. The case studies illustrate the theoretical points. The first case study depicts the ideal nurse patient encounter, and the 
second case study an encounter that resulted in the creation of difficulty. The data illustrations were referenced with $\mathrm{N}$ for nursing followed with the number of the interview. $\mathrm{P}$ indicates data came from a patient interview, followed by the number of the interview. FN indicates the data came from field notes, followed by the number of the observational session. The consequences of the categories were also incorporated with the presentation of each category and in the case studies.

\section{Reconciling Temporalities}

Reconciling temporalities was the core category that emerged in this study and was the main concern for both nursing staff and patients. The degree of reconciliation required determined the degree of difficulty in the nurse patient encounter. Nursing staff and patients regularly found themselves at odds with one another with respect to time. Nursing staff were searching for the time needed to deliver the care they wanted to give and patients just wanted the care they needed delivered in a timely fashion. The degree of reconciliation required varied and this variation was time bound. The origins of difficulty were socially and contextually bound on the basis of a number of factors in both the micro, and macro environments of patient care. The nursing staff unilaterally agreed that knowing the patient minimized difficulty in the nurse patient encounter and that reconciliation of time was inherent in getting to know the patient. Temporal incongruencies occurred when nurses did not have the time, and patients did not feel that care had been delivered in a timely manner. The greater the incongruency the more reconciliation was required in the encounter. The factors that contributed to temporal incongruencies, and necessitated reconciliation were: Families, availability of supplies and equipment, who is working, and care space changes. Contextual conditions that 
influenced the process of reconciliation were: Unit reputation, and labor market structure changes. The strategies that nurses used to reconcile temporalities were controlling, working together, managing families, and employing geographies of place/bodies. These findings demonstrate how difficulty was constructed in the nurse patient encounter. Finding how difficulty was socially constructed and not an innate characteristic of an individual has created the possibility of interrupting current uni-dimensional thinking that locates difficulty and or blame uniquely within the patient when nurse patient encounters did not go well.

These findings point to a number of factors within both the micro and the macro contexts of healthcare that have a direct or indirect bearing on whether or not the nurse patient encounter will be a happy or an unhappy experience. Overall, patient satisfaction with the nursing care they received was based upon the time they perceived that the nursing staff had. Patients believed that the nurses were overworked, but, they also believed that they should get the attention they needed in a timely and compassionate manner.

The nursing staff in this study believed that most nurse patient encounters went well. Nurses also believed that when encounters did not go well it was primarily due to not having enough time to give to patients, and to the teamwork and attitudes among those who were working. The details of how these factors contributed to the construction of difficulty are now presented.

The presentation of the findings from this study begins with a definition of the core category reconciling temporalities, and a description of how this concept achieved its core status. Reconciliation means "to restore to friendship or harmony; to cause to 
submit to or accept something unpleasant" (Merriam Webster, 2004). This definition captures the process that patients and nurses experienced in getting and delivering care. If the nurse had the time to get to know the patient then reconciliation was naturally achieved in the nurse patient encounter. Reconciliation was always present, however, when nursing staff did not have the time to give to patients, and when patients did not feel they were receiving care in a timely manner the process of reconciliation became visible and palpable. The degree of incongruency between the time the patient needed and the time staff had or found to give determined the variation in the degree of reconciliation that took place for both patients and nurses. Often there was a restoration of harmony, however, at times both nursing staff and patients found themselves so time deprived that they put up with the unpleasant, or as staff and patients said respectively, "they just didn't have it to give, and you don't get that attention."

The only time I think may be, um, it wouldn't go so well is if you don't have the time to give somebody that clearly requires a lot of time, and-in their estimation, um, that's the only thing that I would say-like, I-I can pick numerous patients that I have not had adequate time - I would have loved to have had more time with. And that's fair-a fair comment on their part. They felt they were needy patients and required that extra time but I just didn't have it to give. Um, I don't think there were any - you know, complaints made, but just, I felt inadequate in that respect (N4).

I mean when you're sick, you just need a little bit of attention. Most times they're so busy that you don't get that attention (P2).

In instances where the staff were able to provide the care they wanted to and patients felt their needs had been met, encounters were usually harmonious and required little reconciliation. As soon as nursing staff were asked what contributes to good nurse patient encounters everyone replied, knowing the patient. Reconciliation was carried out in various ways. The most common approach used by the nurses was to explain to 
patients why they were unable to get to them in a timely manner. Patients could see how pressed for time the nurses were and would patiently wait and bundle their requests for when the nurse did arrive.

\section{Knowing the Patient}

Knowing the patient minimized difficulty and set the stage for the ideal nurse patient encounter. Reconciliation naturally occurred in these encounters. Nursing staff repeatedly spoke of the importance of knowing the patient and how well everything went, when they knew what was going on with their patients and how hard it was to find the time to do this. The concept of knowing the patient is a cornerstone of nursing education (Carper, 1978). The nursing staff expected to achieve this in their work and described the variation they experienced in being able to get to know their patients and the consequences.

Nursing staff spoke with feelings of pride and satisfaction in describing encounters that went well. They not only spoke about knowing the patient but the family. For some staff, positive feelings resulted from one encounter within a shift, for others it was over the course of a shift or over several shifts with a patient and family. Nursing staff reported that they made a difference in the lives of patients and families by knowing them. "They knew I knew how to treat him, and just the whole interaction, you were able to not only nurse him but the family as well" (N2). They explained that they were able to help families come to terms with devastating news about a loved one, "I felt in the end, that I helped them a little more because they were not accepting of her diagnoses at all" (N10). 
These feelings and beliefs about the care they gave when they knew the patient and family were tempered with infusions of what it was like to have eight patients. One of the eight may be on twelve medications, and have several medical conditions, another may be severely cognitively impaired, another dying with twelve family members present, and everyone needs the nurse at the same time. In today's context of shortened lengths of stay and $\mathrm{RN}$ shortages, getting to know patients was described as almost impossible at times. Nursing staff commented on how they should know their patients but the reality of the workload they carried and the number of hours in a shift meant they had to reconcile how they spent their time. This usually meant doctor's orders would be carried out, medications administered, emergencies managed, breaks and meals taken and covered, in-service attended, and then if any time remained consider spending it with patients and families.

When nursing staff talked about encounters that went well the category that emerged from the data was knowing the patient. Every act a staff member performed to get to know the patient better required time. One important act was doing a good admission. This meant the nurse had time to be present with the patient during the admission and during subsequent interventions. Nurses commented that taking the time to do a good admission led to more complete nursing care plans and to patients sensing that the nursing staff members were more likely to know them. When nursing staff had the time they believed they needed to carry out patient care and when patients felt their care needs were met, temporalities were reconciled. This meant that as any concerns arose either with staff or with patients if time permitted these to be addressed in a timely fashion then temporalities were reconciled. 
Time spent listening, um, and rapport with them. You have a good rapport with them, everybody does well (N3).

Patients wanted to feel the care provider knew who they were and they wanted healthcare providers to take a little bit of time to get to know them.

And you don't know them when they come in, and they don't know you. So it's sort of breaking the ice and getting to know them (P8).

In the above illustrations there was agreement that knowing the patient was important to staff and patients, however, finding the time to get to know the patient was often a challenge for the staff. Nursing staff readily described all the strategies that were involved in getting to know the patient such as listening, establishing rapport, accommodating, spending time, explaining, accepting, showing compassion, individualizing care. When time permitted staff to employ these strategies, the nurse patient encounter was a good one requiring minimal reconciliation. The consequences for staff when they had the time to get to know the patient was a feeling of satisfaction and a good feeling about the care they provided. Patients also felt satisfied when they felt that the staff knew them and gave them the time they needed. These feelings of satisfaction allowed for staff and patients to establish relationships of trust. As soon as staff were asked what contributed to nurse patient encounters not going well, the first comment was always not having the time that patients needed. So there was a palpable divide in what staff wanted to do and the time they had available. This divide was also expressed by the patients in this study and was assigned the category name of temporal incongruencies.

\section{Temporal Incongruencies}

The term time was used over and over again in the narrative accounts of nursing staff and patients and it was clearly the category that was the most easily identified and 
saturated. The greater the incongruence in the time requirements between patients and nurses the more likely there would be difficulty in the nurse patient encounter and the more likely reconciliation would be necessary on both sides. Nurses and patients eloquently articulated the degree to which both felt pressed for time and this varied. There were many explicit wrenching accounts from both nurses and patients describing care time challenges and waiting for care. Temporal incongruencies arose within the nurse patient encounter and within the context of care. The incongruencies within the encounter will be discussed first followed by those within the context of care.

Nursing staff began each shift with a particular assignment. RN's covered the LPN assigned patients for care beyond the scope of practice of the LPN. Predicting that a patient will develop a problem such as diarrhea is not part of the assignment, nor is predicting that the RN and LPN will each have a patient in crises at the same moment. These situations did arise and resulted in considerable temporal incongruency necessitating maximum reconciliation between nursing staff and patients and between nurses and LPN's.

Patients who needed help with toileting usually had limited mobility. Getting this person to the bathroom took time and sometimes required more than one person. The bedpan or diapering became the solution. Patients hated to ask for the bedpan and did not like being left on it or in a diaper any longer than necessary. If this situation was complicated by diarrhea then getting the patient on and off the bedpan or changed in a timely manner led to considerable incongruency and the need for reconciliation.

When you know you have two admissions coming up------- somebody's going bad, you know, things like that are going on, and you get someone who needs you to give them the bed pan every half hour, or, you know, who has diarrhea and you 
have to wash them up -- it's hard to keep your patience that way. It's a fight to get to them -------(N5).

Well, I had tubes for awhile----- that was fine. And the nurses would dash in and empty the container. But after I got the tubes out, I rang for a nurse to get me to the bathroom. She says, "I can't do it." I said, "Well I've got to go." When you've got to go, you've got to go. She says, "You've got to reprogram your kidneys." At 2 o'clock in the morning? ------- So anyway, she put me on the bed pan and left me all night (P2).

Frequently nursing staff talked about how much toileting patients needed and how patients felt their toileting needs were not met in a timely manner. Hospitals are organized according to linear time. Nursing staff attempted to organize work to comply with linear time. If a patient had a urinary catheter then catheter care was managed on a schedule. When the patient is dependent for toileting, the rhythm of bodily function does not follow the rhythm of ward rounds. Staff moved from room to room and soon after leaving a patient room the patient may experience the need for toileting. The patient calls for help and the timing of staff arrival varied. This incongruence resulted in loss of patient autonomy over a basic bodily function (Inglis \& Holmes, 2004) and the linear organization of hospital time contributed to this.

RN's and LPN's generally worked well together. RN staff were frustrated at times when they had critically ill patients that they did not want to leave yet a crisis with a patient of an LPN meant they had to. The replacement of an RN who was sick with an LPN was a source of frustration as was the fact that RN's found they were the last stop for everything including, explaining what the doctor said, fielding complaints about the telephone, television, and the food.

Nursing staff knew that patients waited for care. They knew they did not always give the time to patients that the patients believed they needed. Despite this, nursing staff 
felt the care they were able to give was good. One of the reasons nurses arrived at this conclusion was because they rarely had patient complaints about their care. Patients clearly recognized how overworked the nurses were and they believed more nursing staff was required. This did not change the fact that they wanted to have the care they believed they needed and that care be given in a compassionate manner.

As temporal incongruencies mounted, reconciliation was ever present. Nurses and patients wanted things to go well. When things did not do well and adequate reconciliation could not be achieved there were consequences for both staff and patients. Nurses felt stressed, and torn in trying to do their best. They felt that they were judged by patients and families as not being compassionate.

She said, well she doesn't want you around her because she feels you're not very compassionate. And I never heard that in my career before because I think I am fairly compassionate (N7).

Nurses also were more likely to judge patients as difficult when they were very pressed for time and could not take the time to get to know a patient. It was interesting to note that when nursing staff were asked about encounters that did not go well they began their reply by saying they did not have adequate time for patients in these situations and then they would use patient descriptors commonly found in the difficult patient literature such as elderly, alcoholic, swears, and super demanding.

Sometimes patients when they come into hospital - especially the elderly, it's almost like, okay, I'm here now and I'm going to be waited upon. Or you have four, five or six patients that are super-demanding (N7). Alright, um, an encounter that didn't go so well for myself and a patient, um, was because I couldn't stand this patient. And, I had seen him many times through the years, he would come in and he'd get well and he'd go home again, he'd come in, you might ------ another year --- six months. And he was a heavy drinker, he would drink himself into stupors 'til he was sick and then he-he'd come in and he' $d$ be really bad for a few days, and then once he got out of his, um, alcoholic state and 
the DT's, he would be just back to himself - really nasty and swear a lot-- ring the bell continuously (N5).

Labeling of patients as super-demanding and swearing a lot emerged as consequences of nursing staff not having enough time for patients and patients not getting the care time they needed. This finding supports the work of Becker (1966) who described labeling as the process by which a person comes to be called deviant. The meaning that deviance has for many is to avoid deviant activities or persons. Staff need to know that the process of labeling results in the construction of the person as deviant. Understanding this can interrupt the process of labeling and potentially interrupt locating difficulty within individuals.

Patients who were dependent for toileting were the most upset and some feared having to return to hospital and be dependent for toileting. Patients who were independent with toileting feared the day they would be dependent.

The lady in the bed next to me was a senior, on oxygen, probably her last month of her life is going to be spent there, whatever. But, uh, I seen one day when she rang the buzzer at five after three that she needed, and the nurse came in, and she told the nurse she had dirtied her diaper, you know. She said, 'I need to be changed." She said "I dirtied myself." And you could smell it in the room. And the nurse said, okay, I will be right back. But nobody came for that woman until her daughter showed up at 7:30 that night (P10).

Patients wanted to receive the care they felt they needed in a timely fashion.

In their struggles to have things go well, there were factors at work in the context of the nurse patient encounter that contributed to temporal incongruities and had a direct 
bearing on the creation of difficulty that necessitated reconciliation. These factors were: Families, availability of supplies and equipment, who is working, and care space changes. Families

Most people who become patients are part of a family unit, traditional or otherwise. The degree of family involvement among members varied widely. Some patients had family members who were constantly present and contributed as much as they could to the care of the patient. Other patients had family members who were constantly present but uncomfortable with participating in the care, although, they knew what care they wanted a family member to have and advocated for this.

Nurses found that in order to maintain harmony with families they needed to spend a great deal of time explaining situations to them, listening to them, supporting them, and also acting as a go between the family members and the patient. Many nurses said that it was not uncommon to have more difficulty in the encounter with the family than with the patient. Nursing staff also experienced a certain amount of ambiguity regarding where their responsibilities lay with regard to the family. Some nursing staff saw the patient and family as one. Others believed the patient was their responsibility and would only give time to families once they felt they had given the patient the time needed.

I've learned how to nurse those families rather than the patient-because the patient gets all they need (N10).

In this statement made by a nurse there is a great deal of information. The nurse explained that she has learned how to nurse families and this may not have been something learned in nursing school. The nurse has, however, through practice discovered families cannot be ignored. There is also the patient family dichotomy. The 
nurse by stating the patient gets all they need confirmed the approach of focusing on the patient and getting to the family if time permitted.

The researcher noted during observations that families regularly came to the nursing station and called the nursing station to speak with staff. Family members would wait outside patient rooms where staff members were to speak with them as they left a room. Getting to know the patient takes time, finding the time to give the care the staff wanted to give and the time that patients and families wanted required a constant reconciling of demands for time versus resources. The consequences for nurses in their reconciling efforts to make time for families was exhaustion and feeling like one patient with a family needing a lot of time was like having three or four patients. Because the time for patient care was so limited it felt at times as though staff were forced to choose patient over family (as if they could be divided) in deciding the care to give. There were other processes in the context of the nurse patient encounter that encroached upon the valuable time that nursing staff needed for patient care. One such process was the availability of supplies and equipment. Availability of Supplies and Equipment

Nurses described over and over again how often they were "missing pills" when they were needed and the time spent in going to pharmacy to get these pills. Patients when interviewed did talk about the timing of getting their medications but they spoke about it in passing and it was not a need that was focused on.

The frustration with missing pills and constantly looking for pills and reordering of pills was noted at almost every participant observation session and staff freely shared this frustration with the researcher. The pharmacy department had acquired a new 
computer interface over the past year but were very disappointed with the result. The system was slower and required more pharmacists to operate.

This left pharmacy in a situation of trying to make the best of a less than satisfactory situation. The hospital was also recruiting to fill pharmacy vacancies. A measure of the time spent obtaining medications would be instructive in demonstrating how many valuable nursing hours were spent on this task that could have been spent with patients. Nurses were continually explaining to patients why their pills were not available and what they were doing about it. This reconciliation took time as well but was usually accepted by patients. It also demonstrated how interdependent hospital departments are for the timely delivery of patient care. It must be noted that although nurses regularly spoke about the time spent looking for and obtaining missing pills they did not link this to time taken away from patient care until it was pointed out. The fact that the unit had a medication nurse may explain this. During the time the research was being conducted a second medication nurse was added on days. This supports the staff reports of the numbers of medications to be given and the time spent looking for pills to give.

Overall staff felt that equipment needs were well met with the exception of one piece of equipment obtained for the unit to assist staff with patient care. This was a mobile vital sign unit called the "buddy." This unit could be wheeled to the bedside and used to measure temperature, pulse, blood pressure and oxygen saturation. When it worked staff loved it, but, it was very unreliable. Whenever staff reported to bio-medical engineering technicians that it was not working, it would be checked out and staff were told there was no problem leaving them completely frustrated. The researcher frequently 
heard staff complain about the unreliability of this piece of equipment during participant observation sessions.

Nurses experienced time loss due to problems incurred with computerization. Many aspects of patient care delivery were computerized and when the computer systems failed or required downtime, nursing care was affected. Returning to manual functions sporadically required considerable time remembering how to do this.

The nursing care plan was described as a list of tasks to be done for the patient but did not portray the clinical picture of the patient, which frustrated nurses at times. The care plan was task and check box driven and nurses found they knew what the task list for the patient was but did not have a clinical picture of the patient. This is a symptom of a care plan built to interface with workload measurement, a task driven application. This system determined the staffing required for the unit, but as the clinical picture of the patient was not portrayed the nursing staff needed for patient care was not always accurately portrayed.

Nurses described other passing episodes with services like laundry and how frustrating it was not to have such basic supplies as face cloths and towels when one needs them. This occurred as a result of a change in the delivery of laundry supplies to the hospital. In the process of making this change, a number of problems resulted in nurses having to scramble and find linen elsewhere in the building. It also led them to prepare a contingency supply for future (a secret stash on the unit) because no staff member wanted to be left without the most basic of supplies. The consequences for staff as a result of missing supplies and equipment were, lost time for patient care and frustration. This contributed to illustrating the degree to which units and departments are 
interconnected in the care of patients as well as to the resourcefulness of nursing staff. Nursing staff are key to care delivery on any nursing unit and the staff in the study setting readily acknowledged this and spoke to the importance of who is working in terms of how well the care process on a unit will flow.

\section{Who is Working}

This category was an in vivo code and came from the nursing staff in this study. In using this terminology they were referring to teamwork. The nursing staff study participants all described how limited their patient care time was. A number of them described how working together and having a positive attitude enabled them to get through the shift, deliver enough care to patients to reconcile nursing time available with patient needs, and minimize difficulty in their encounters. Working together meant checking with each other regularly to find out how everyone was doing and if anyone fell behind then the others pitched in to help out without any questions asked. A positive attitude meant believing the work could be done and finding the way to do it. Working together involved explaining to patients at the beginning of the shift what the particular time challenges for the shift were. This helped patients understand what was happening, on the unit. Patients, in particular, spoke about the attitude of the staff and what a difference it made for them when staff seemed happy, pleased to be at work and positive in their approach.

I find, the patients can read the stress level (N2).

Nurses reported that when they arrived at work, who they would be working with would make all the difference. Some said that no matter what happened or how busy the unit was if everyone pulled together, checked in with one another, helped one another out 
then everything would be alright. Staff would not be able to give every patient the care he or she wanted but every patient would receive some care.

So, you know, we work really well together that way, so that nobody is hung out to dry, nobody is in a situation by themselves, and everybody gets looked after (N8).

The above illustration spoke to what nursing staff believed could be achieved under challenging circumstances when staff worked well together. It is also important to note how patients picked up on this and how they were affected by staff attitude. During participant observation sessions there was no explicit evidence of staff not working as a team in terms of verbal discord. The manifestations came in the form of staff members appearing overwhelmed with their workload and exasperated. This generated the sense of a certain level of unit chaos.

There are staff working that I have not met before and some that I have. The regular unit secretary is off. I moved about the unit, most of the time there is a bell ringing somewhere. I noticed a female visitor in the hallway looking anxiously about for a staff person The light over the door of the room where she came from is lit. She wonders why no one has come. I realized from report this is likely the daughter of the patient referred to in report. Soon both daughters are in the hall anxiously looking for a staff member. One makes the comment that her dad could be having a heart attack (I overheard this) the comment was not made directly to me. I told one of the daughters what room I had seen the nurses enter. The daughter says likely there's someone in greater need but you can tell she really wants the nurse. Some of the staff are on break including the Secretary. At the same time the funeral home has arrived to remove the body of the man who died earlier. The hospital supervisor is on the unit and closes all the doors to patient rooms so the patients cannot see the removal. The medication nurse helps with what is needed for the patient who has died and is a bit annoyed trying to find one of the mortuary kits. I walk through the nurses station and one of the nurses engages me in conversation about my research. She tells me she works part-time and lately the unit has been so hectic. There has been a lot of deaths and dealing with families has been so overwhelming. She says families are important but they are just so needy (FN13).

The consequence for staff who worked well together was a feeling of being 
able to manage no matter what. Staff who worked well together felt supported and in general felt that all patients got the best care that the time available permitted. Staff who did not work well together felt overwhelmed and patients sensed when staff members were pulling together and when they were not. Patients felt upbeat if staff were upbeat.

The fourth factor that contributed to temporal incongruency was care space change. The hospital landscape as a place for care has changed.

\section{Care Space Changes}

The category of care space change emerged from the data and encompasses how nursing staff and patients described the care environment today compared to ten or twenty years ago. These changes included; a population who is living longer with a host of chronic illnesses taking numerous medications, shortened lengths of hospital stay, and changes to medical care delivery such as the hospitalist program.

We have a population that it's nothing to have most of our patients being in their eighties and nineties. We're seeing people with more numerous problems, you know, multi-diseases, you're patching them up basically, you know, you're putting a band-aid on the biggest problem and maybe sending them home. (N9)

"And I mean, obviously in family medicine, there is nobody who's on one or two medications. They're all on 15 at least." (N6)

You're used to a certain Doc, you feel comfortable, and all of a sudden this new young doctor goes popping in, $\mathrm{Hi}, \mathrm{I}$ 'm doctor so and so and you don't even get their name. You feel better with your own family doctor." (P8) 
The setting for participant observation has a hospitalist program in place ostensibly to make sure patients were seen by a doctor each day and to provide medical services for those without a physician. These imperatives were met, however, many patients preferred to see their own doctor and this program served medicine and the organization more so than the patient. Most patients did not see their family physician. This resulted in some patients going home and not being sure what the next step was. The hospitalist was to communicate with family physicians, but, communication around specialist consults seemed murkier. This service made sure that patients were medically managed in a timely fashion but patients were not always certain about what was going on and some really would have preferred their family physician to visit them in hospital.

Nurses reported that patients frequently had questions for them after the doctor left and following up on these questions took additional nursing time. During participant observation it was apparent that at times patients did not understand what the doctor was saying. This was confirmed during interviews.

This doctor explains some things quite clearly and at other times does lapse into medical jargon like INR and some drug names that I wonder sometimes how much the patients really understand (FN5).

Here are the comments of one nurse with respect to this.

But they still are still in awe of the doctor. Like he goes in with his team and it's like "gasp"- - you know, and then they wait for the nurse four hours later to ask these questions, but the doctor's gone, he left at 12:30, you know. So that's the one thing, um, with patients (N10).

Nurses had ready access to a physician, however, the rhythm at which the physician worked to process orders regulated the admission and discharge process for the unit. If discharges were not entered until after rounds near noon or later then admissions 
from the emergency room arrived later. More admissions on evenings made the unit busier at a time when the staffing complement dropped. Nursing staff had less time to spend with new admissions which meant they did not get to know them, did not enter as much data on the patient record as they ordinarily would have, and did not have as much time to provide patients with the explanations they believed to be important. Explaining to patients the rhythm of the unit and the time for patient rounds was important because staff wanted patients to ask the doctor their questions in order to save them time later on in looking for answers.

The elderly who were dependent for their care and who were on a lot of medications needed more care time. Nurses confirmed that patients did not recover while in hospital as they were discharged as soon as the medical crisis was stabilized. Shorter lengths of stay reduced the number of contacts staff had with patients and reduced the opportunity to get to know the patient. When nurses were carrying out the discharge process with patients, they often commented on how little they actually knew about many of the patients but followed this with a statement that they were likely to get to know them better because they had probably been discharged too soon and would be readmitted. Nurses acutely felt how old patients were, how ill they were, how complex their medication regimes were and all this at a time when nursing staff had the least amount of time to give to their patients. This shift in recovery time from hospital to community left this nursing staff with a certain level of apprehension as their patients left.

These care space changes had consequences for staff and patients. Nursing staff felt the possibility of getting to know their patients had been reduced in the current 
context. The deepest sense of satisfaction expressed by nurses came from knowing they had nursed a patient well. Nursing opportunities to experience this satisfaction, however, were becoming limited in the hospital as care space. Patients expressed deep appreciation for getting the care and attention they believed they needed. The changes to the hospital as a space for care limited opportunities for both nurses and patients to achieve satisfaction.

In summary nursing staff and patients were time bound. Staff wanted to deliver a certain amount of care to patients and patients wanted to have the care they believed they needed delivered in a timely fashion. In order for this to happen there was an ongoing process of reconciliation on the parts of both nursing staff and patients. The degree of reconciliation required and the degree achieved contributed to explaining the origins of difficulty in the nurse patient encounter. The reconciliation process was immediately affected by knowing the patient, and the temporal incongruencies in the context of care. In addition to these conditions, there were environmental conditions that contributed to how nurse patient encounters unfolded. These conditions were: Unit reputation, and labor market structure changes.

\section{Unit Reputation and History}

During formal and informal interviewing of staff they were complimentary of this unit. Comments included; "it was the best run unit in the hospital," "staff respected the nurse manager," "staff was experienced," "unit staffing was stable and staff in general worked well together." This information was important to this study. It is often argued that unfavorable patient care experiences can be attributed to factors related to nurse dissatisfaction such as the nursing shortage leading to high turnover rates, large numbers 
of inexperienced staff, burnout and nurses leaving the profession (Aiken, Havens \& Sloane, 2000; Aiken et al., 2001). This unit was not immune to the nursing shortage, however, it had the advantages of leadership, low attrition, and experienced staff. These conditions were considered by the researcher to be favorable to exploring the origins of difficulty in nurse patient encounters. In the absence of factors that units commonly experienced contributing to staff and patient dissatisfaction if difficulty presented itself in the nurse patient encounter then this study would get a cleaner look at the processes that contributed to the construction of difficulty.

Near the end of the participant observation sessions, a job was posted for a position on the unit and the conversation was about the long list of applicants rather than the shortage of nurses to fill the vacancy. This study was valuable in that it explored the origins of difficulty in the nurse patient encounter in a setting known for leadership, experienced staff, and staff that have worked together for a long time.

A lot of the girls on the floor have been there for years so they've formed like their own little family and they know how each other works, um. So there's a sense of security that you can pretty much know that if something's going wrong for somebody there's a, usually a justified reason behind it, and we try to get to the bottom of it and try to get the best outcome for the patient and their family unit (N2).

When difficulty arose in the nurse patient encounter in this setting, the impact of the contextual factors that contributed to the construction of difficulty were more readily noted and described. In the immediate context of care, despite the good reputation of the unit nurses still strived to find the care time they so prized for their patients. In order to do this, they constantly juggled the work that needed to be done with the time available 
and with what the patients wanted in a dynamic process of reconciling the time imperatives of patients, the organization and themselves.

The consequences were positive for staff and patients on this unit that had leadership, an experienced staff and staff that knew each other well and worked well together. The materials for the construction of difficulty were limited on a unit with these strengths.

In addition to the unit environment one other environmental factor was identified from the data that related to the reconciling of temporalities. This factor was labor market structure changes and it existed in the immediate patient care environment as well as in national and international care environments.

\section{Labor Market Structure Changes}

This category was created because nursing staff spoke about the increasing numbers of LPN's and the shortage of RN's. They also spoke about the dwindling numbers of other professionals such as physiotherapists. Nurses know there is a shortage of RN's and noted when nursing workload cannot find an RN to send to a unit an LPN is sent. RN's wondered how long it would take for RN positions to disappear in favor of LPN's. Their fears were well founded in reading the work of (Cartier, 2003) who noted the current structure of the labor market favors minimizing the numbers of highly paid professionals.

Nurses described the introduction of Patient Service Workers (PSW's) to the nursing unit late in 2003 . These workers were primarily cleaners and provided the services previously done by housekeeping staff and ward aides. Staff members were going through a process of adaptation with this change since they have had to take on 
some of the functions previously done by ward aides that Patient Service Workers do not do. It was interesting to note the argument for introduction of the Patient Service Workers was to contribute to more patient focused care. The Patient Service Workers would be on the unit at all times, there would be fewer people going in and out of patient rooms and the patients would get to know them. These arguments were all legitimate. The irony of it all was that the nurse needed to get to know the patient better and spend more time with patients. Patients in general were accepting of the Patient Service Workers. The only criticism was an objection to having their meal delivered by the same person that cleaned the toilets.

And then they changed it over so that PSW's were mostly focused towards the patient, but then they also had to do all the cleaning as well. So, um, their focus initially was mostly on cleaning. You'd get a patient out of bed, and sit them in their chair, and the PSW worker would not do their bed 'til they had all their cleaning done. To me that's not patient-focused, that's, let's get the floor cleaned and then we'll deal with the patient. They're not allowed to walk patients, they're not allowed to help patients -------- the unit, go have a cigarette, go down for a test, --------- So, that's a role change again. And then they were setting out evening snacks before they left, and it was decided that 6:30 was too early to bring the snacks, and the nurses were left to pass the snacks out (N5).

Nursing staff and patients talked readily and frequently about the shortages of nursing staff. Patients all believed the nurses had too many patients to care for. Nurses were in a fight to get to patients and patients found they were continually waiting to see the nurse.

Just more nurses that they're- they're-yeah, that they're not-they don't have so many patients to deal with. They have a little bit more time to do the one on one without being rushed (P7).

The labor market structure changes were evident in the introduction of Patient Service Workers and the increase in numbers of LPN's. Unfortunately the existing nursing shortage lends legitimacy to the introduction of less skilled workers. The 
consequences for nurses were increased workload, fears of the erosion of RN positions, and less time with patients. The consequence for patients was worry that they would not be able to get the care they needed. Some patients also feared returning to hospital if they did not believe they would be able to get the care they needed.

The environmental conditions of unit reputation, and labor market structure changes affected the time that nurses had to deliver care and consequently the amount of care patients received. This unit had an experienced staff and one that did not change over rapidly. Staff valued the leadership of their manager. Staff at the same time recognized that not all staff worked as a team to maximize the time available for patient care. RN shortages and the proliferation of LPN's and Patient Service Workers added to the workload and the responsibilities of the $\mathrm{RN}$ and resulted in nurses feeling less patient proximity. In addition the patient population was elderly, necessitating more time with patients at a time when hospital lengths of stay are shorter and less overall time is available to patients. Faced with these time challenges nurses employed a number of strategies to reconcile or to attempt to reconcile temporalities. It must be noted that some strategies facilitated reconciliation and others did not. These strategies were: controlling, including families, imposing geographies of place/bodies, and working together.

\section{Controlling}

As staff described encounters that did not go well, the category controlling was identified. Staff talked about the following: Sticking to routines, doing it by the book, expecting patients to fall in line, enforcing the rules, not giving explanations to patients and families, and hurrying patients. During descriptions of encounters that did not go well, patient descriptors were used and included bell ringer, combative, wanting to be 
waited on, loud, and super demanding. Controlling described a number of responses and reactions that nursing staff used when they found themselves pressed for time. Interestingly enough patients also engaged in the strategy of controlling when they could not get the care time they desired. Controlling led to confrontation. Once the point of confrontation was reached, a maximum amount of reconciliation was required and if time did not permit reconciliation then difficulty arose in the encounter. The following illustrations demonstrated how both nursing staff and patients employed the strategy of controlling.

I remember washing her up and she was okay with all of that, and then I was getting her into the chair and she just, all of a sudden she said "you're hurrying me," and it really kind of made me feel really awful and guilty and I thought, yes I am, and I thought, this is not a very nice way to treat this gal, because, you know, she in a way didn't even want to get up in the chair. I was pushing my-- sort of-- I've got to get this all done so fast and, and I thought, gee, I wasn't very respectful of her wishes, and I was hurrying her, and that wasn't right $(\mathrm{N} 1)$.

And I said I didn't want to move. "Well, you don't have a choice." And I said, "What do you mean don't have a choice?" And that's why I saw red. I told them, I said I have as much right here as anybody else in the room. I'll pay for the room and so on. And she says, 'You don't have that right." So- this is a bad experience I had this time (P8).

Nurses knew that when they stuck to routines, and enforced rules, there would be a backlash from some patients. The urge to resort to controlling behaviors according to nursing staff comes from feeling pressed for time. Although this might result in needing more time later to reconcile encounter difficulties they got results often enough to make such behaviors worthwhile in a time crunch. Patients talked about feeling too sick at first to speak up for themselves but as time went by and they felt stronger they would be more assertive in trying to get their needs met. When nurses recognized they were controlling 
patients, they felt guilty about it. Patients usually expressed feelings of anger when given ultimatums.

The reconciliation of time in the nurse patient encounter was not limited to the patient. Most patients had families and nurses spoke at length about the time demands that families required in the process of their care. Of particular interest here was that patients did not make reference to any concerns encountered by their families. This may well be because an important part of the philosophy of this unit was the inclusion of family. The presence of families and the time that nurses needed to spend with families was previously described as a factor that contributed to temporal incongruencies in the nurse patient encounter. The data illustrations of the time spent with families also illustrated how nurses included families as a strategy to reconcile time. The nursing staff clearly recognized that patients and families were a unit and the struggle to include the family is illustrated by this nurse:

\section{Including Families}

Families are, uh, I never really believed how important families were ... they are ... we treat the families as much as the patients, and I think sometimes we spend more time giving care to the families than the patients. And some families help us, and are very helpful, others are very needy, more needy-- they need the care, they need the reassurance, they need the education, um ... so a big part of our care ... we're not strict about visiting hours (N1).

The importance of family in the care of a patient is presently learned in becoming a nurse. Including families in care giving is not a belief held by all nursing staff, however, and the literature bears this out. In hospitals, the status accorded the family is ambiguous (Levine \& Zuckerman, 2000). If family members are needed to continue with care following hospitalisation, they become very important, if not, their importance decreases considerably. Nursing leadership on this unit promoted inclusion of family and 
staff worked hard to accomplish this. Systems of nursing workload measurement do not necessarily favor building units of patient care for the families of patients. Nursing workload measurement is a good example of what Kleinman (1995) was referring to when he stated that the measurement of phenomena is important but the context within which the phenomena exists must also be considered.

Another strategy identified in the data that had an important effect on reconciliation was initially categorized as expectations and later changed to geographies of place. This change was described in the data analysis process in Chapter III. Geographies of Place/Bodies/Expectations

Nursing staff verbalized expectations they had about patients and patients verbalized expectations they had for their care experiences. Holloway and Hubbard (2001) carefully described the geographies of place, how social order and discipline are instilled in places, and that all places have expectations. Classic examples of such expectations are: Inner cities are places of crime, and suburbia is a place for families. These authors also described the human body as place and argue that how individuals treat their bodies is a social construction. For example "good complete citizens are generally considered to be those who look after their bodies" (Holloway \& Hubbard, 2001, p. 194). They talk about moral geographies and how certain bodies are seen as out of place in certain places. This can refer to judgments that are made about patients who smell, crying patients, moaning patients, or Alzheimer patients. The expectations of place were evidenced during participant observations and during both patient and nursing staff interviews. 
When nursing staff were asked if they had expectations about how patients should act, they initially responded that they did not really have an overall expectation, however, on further reflection they would say yes, in fact they did have expectations about how patients should act. Patients more readily replied that they had expectations of getting the care and the explanations they needed. During participant observations there was evidence that staff believed certain patients should be cared for on certain units, and that patients should comply with what was ordered and with unit routines. Nursing staff often discussed terminally ill patients and once these patients reached a stage that necessitated a lot of care and support the belief was the patient should be transferred to palliative care. Nursing staff was cognizant of the geography of the work place that expected they accomplish the patient care required within their shift. Most workload measurement instruments are developed for types of units rather than patients. This could have been one reason why staff wanted some patients transferred who's care requirements were not accommodated in the workload measurement. In order to care for these patients staff often found themselves pressed for time.

The pressure to find time makes the geographies of certain patients in place more explicit. If staff were pressed for time it was more difficult to rationalize giving time to patient's who were judged as not having taken care of their body, such as alcoholics or the life long smoker. It was easier for the nurse to reconcile time by giving the time they had to deserving patients. Geographies of place are socially constructed. Nursing staff and patients through their life experiences and education learned to expect certain things in certain places. Consequently, nurses experienced feelings of frustration and 
inadequacy when they had patients to care for who they believed did not belong on their unit or were not deserving of care.

You know they don't understand diseases, um, and don't understand that sometimes there's nothing we can do about certain diseases maybe, but yet they expect everything is curable, I guess. Most people-sometimes-but honestly, they expect you to make things go away. And I think the biggest instance where I can think of would either be drinkers or smokers that have damaged their body all their life-get to the point where the liver is shot or the lungs are shot, and they expect it to be taken away from them. Like -------- they expect not to have cancer, they expect not to have liver problems (N9).

Patients did not express any feelings of being out of "place" in the research setting, however, they believed that certain patient types should not have been housed with them and this left them feeling afraid and at risk while a patient.

I had a roommate who was drug crazed and who was tied down. People in such a state should not be mixed in with people like me. They should be on a locked ward (P11).

Reconciliation by nursing staff here came in the form of rationalizing that the good citizen should get care first. Patients felt that certain patient types should not be cared for in the same space where they were. The fourth strategy employed by staff when pressed for time was to work together as a team.

Earlier in this chapter, who is working was presented as one factor contributing to the temporal incongruencies that were experienced by both patients and nurses. Nursing staff when interviewed acknowledged that having the time they desired for patient care was not a common occurrence. Despite this when certain staff (who worked well together) were working, patient care was delivered, every patient received some care, staff were able to leave together on time, and with a sense that they had done a decent job. 
Finding that working together benefits a group is a well known fact. Finding that the failure to work together can contribute to the construction of difficulty in the nurse patient encounter is a little known fact and adds to nursing knowledge. Finding that nursing staff used controlling, including families, geographies of place, and working as a team to reconcile temporal incongruencies in the context of care has added knowledge to this discipline. These findings will enable nursing staff to more clearly comprehend the factors at work in the context of care delivery.

\section{Summary}

The purpose of this ethnographic field study was to generate a substantive explanation of the origins of difficulty in the nurse patient encounter. The specific aims of the research were to answer the following questions: (a) How did nurses describe the origins of difficulty in the nurse patient encounter? (b) What were patient's perceptions of recent care encounters? (c) How did the context of care influence the nurse patient encounter? and (d) What were the consequences of difficult nurse patient encounters for patients and nurses?

The core category that emerged from the data for this study was reconciling temporalities. Nursing staff and patients regularly found themselves at odds with one another with respect to time. Nursing staff searched for the time needed to deliver the care they wanted to give and patients just wanted the care they needed delivered in a timely fashion. The extent to which reconciliation was required and achieved influenced how difficult the nurse patient encounter became. The degree of reconciliation required varied and this variation was time bound. The origins of difficulty were socially 
constructed on the basis of a number of factors in both the micro, and macro environments of patient care.

The nursing staff unilaterally agreed that knowing the patient minimized difficulty in the nurse patient encounter and that reconciliation was inherent in getting to know the patient. When nurses did not have the time, and patients did not feel that care has been delivered in a timely manner this resulted in temporal incongruencies. The greater the incongruency the more reconciliation was required in the encounter. The factors that contributed to temporal incongruencies, and necessitated reconciliation were: Families, availability of supplies and equipment, who is working, and care space changes. Contextual conditions that influenced the process of reconciliation were: Unit reputation, and labor market structure changes. The strategies that nurses used to reconcile temporalities were controlling, working together, managing families, and employing geographies of place/bodies. These findings are important and demonstrated how difficulty was constructed in the nurse patient encounter. Finding how difficulty was constructed served to unseat the tradition of locating difficulty and or blame within the patient when nurse patient encounters did not go well.

The conditions in the context of patient care delivery contributed to the construction of difficulty in the nurse patient encounter. All of the contextual and environmental factors that emerged from the data were in some way time bound and therefore affected the time available to staff to deliver care to their patients. Patients wanted to have the care and attention they believed they needed in a timely fashion, however, they found in most cases they had to wait for that care and that nurses were overworked. The following diagram depicts the findings of this study. 


\section{Diagram of Findings}

CONTEXT

Unit Reputation and History

Labour Market Structure Changes

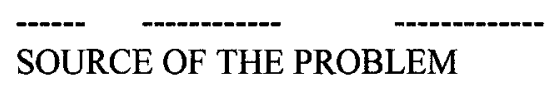

STRATEGIES
TO MANAGE
THE PROBLEM

CONSEQUENCES

OF USING

DIFFERENT

STRATEGIES

Who is Families

Working $\downarrow$ Care Space Changes

TEMPORAL

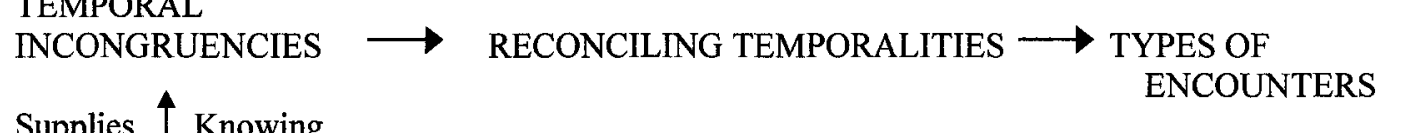

Supplies $\uparrow$ Knowing

Equipment the Patient

Including Families

Harmonious

Working Together

Controlling

Employing

Geographies of Place and Person

Difficult

Unit Reputation and History

Labour Market Structure Changes

CONTEXT 
In addition to the above diagram depicting the findings of this study two case studies will now be presented to illustrate how factors in the context of care construct harmonious or difficult nurse patient encounters. Case studies are commonly developed from a case that depicts the ideas the author wishes to portray. In this instance the substantive explanation generated came from the analysis and constant comparison of data from numerous observations and interviews and the two cases are a product of this (Stake, 2000). These two case studies "consist mainly of highly selected descriptive detail put together to illustrate the points of the theory" (Strauss, 1987, p. 219). The first case is that of the harmonious encounter, and the second case depicts the factors that construct difficulty in the nurse patient encounter,

\section{The Case of The Harmonious Encounter, Temporalities Reconciled}

Alyson RN, arrived on the nursing unit to begin a day shift and heard co-workers say "the unit has a full complement of staff and five third year nursing students." Alyson checked the assignment, had six patients and was covering three patients for an LPN for medications and treatments outside the scope of practice of the LPN. Two of Alyson's patients were assigned to a student nurse. The tape-recorded night report begins. The night nurse reported on a 90 year old woman admitted last evening in Congestive Heart Failure, taking numerous medications at home, spent a poor night, was confused and calling out for someone, and required a lot of time.

Alyson checked all the patient care plans, collected a previously stocked supply cart and began rounds by seeing the 90 year old woman first. She was in tears. Alyson sat down and asked "how may I help you?" The woman asked for the bedpan, and I said "okay, sure, no problem." And she looked at me and said "is it ever nice for someone to 
say, yeah, okay, no problem, and give me the bedpan with a smile on your face." You know, things that are just so minute to me as a nurse were so important to her (N5). Alyson later remarked to the researcher how much more cognitively capable this woman was in person compared to the report and the care plan. Alyson explained the unit routine to the woman as well as how often rounds were made and that in the meantime the woman could ring her bell as needed.

Alyson continued rounds, four patients were relatively self sufficient and reported to the nurse that all was okay at the moment. The fifth patient required complete care and was assigned to one of the students. Alyson and the student discussed the plan of care and explained it to the patient.

This patient he couldn't communicate and when we did his care he would get very agitated. I contacted his next of kin, his mother, and found out he was a huge country music lover. So I got a tape recorder and played his music, and during his care he made eye contact with us. He would not look so afraid and he would be a lot more relaxed and the care would go a lot better (N6).

At the end of rounds Alyson felt as though each patient had what was needed at the moment and checked with co-workers to see if anyone needed immediate help. Staff in general felt they were meeting their respective patient's needs. Alyson returned to check on the 90 year old woman and found a family member present who had many questions. Alyson explained that medications and treatments had to be done now for other patients and scheduled a time to come back and speak with the family member. Alyson's day continued in a pattern of administering medications, treatments, and spending time with patients and families as needed. "A nurse that is compassionate, the 
patient is different. You know, that nurse would bring life back to that woman's eyes (P10). "I think it's the communication, talking to nurses, that they can sit down for five minutes and just even hear somebody, because it really helps (P3).

Alyson checked regularly with co-workers to make sure all was well with them and at the end of the shift had a good feeling about the care delivered today. Alyson had the time to get to know the patients, encounters were harmonious and temporalities were reconciled.

\section{Summary.}

This case depicted the contextual factors necessary for the nurse patient encounter to be a harmonious one. Alyson worked a shift on an adequately staffed nursing unit, had time to get to know the patients and families, worked as a team member checking with other staff, and supplies were available as needed. This unit was also reported as having strong nursing leadership.

\section{The case of Irreconcilable Temporalities Leading to Difficulty}

McKenzie RN, arrived on the nursing unit to begin a day shift, it was snowing that morning and the drive to work was stressful. The first thing overheard was, we will be working one RN short today. This meant "we all had one extra patient so that sets you off on the wrong foot"(N1). There were two floating RN's sent to replace sick calls, the third sick call was not replaced due to a shortage of RN's and McKenzie was covering the medications and treatments of an inexperienced LPN. The tape-recorded night report began and McKenzie was wondering how all of the work was going to get done. The night nurse reported that a terminally ill patient was to be admitted momentarily coming from the Emergency Department and the patient had a large extended family that wanted 
the best care possible. Before report ended the patient arrived and McKenzie went to greet her.

I had a patient who was dying that had just come from Emerg. That was kind of all new for the family, so you're trying to spend time with them. I was covering the patients of the LPN. A patient of the LPN was having difficulty breathing. The LPN came and got me to help her. So I went in the room and she was choky, anxious, I set up the suction, I kept reassuring her. I was being hauled in two different directions. About ten minutes later a relative of the patient who was short of breath came along and said she doesn't want you around because she feels you are not very compassionate (N7).

McKenzie was devastated by the criticism and knew that somehow time was needed to go and listen to this patient and family and to try to explain the situation, but when? For the moment the situation was not reconciled and a difficult encounter was constructed.

McKenzie finished rounds on the assigned patients and feeling pressed for time decided that some baths must be started in order to get through the work today. The first patient chosen for bathing was an elderly woman. "I remember washing her up, getting her into the chair, all of a sudden she said "you're hurrying me." She didn't even want to get up. I was pushing to get all this done so fast" (N1). McKenzie realized how upset the patient was and apologized to the patient for hurrying her and not listening to her.

McKenzie now returned to check on the woman who was dying surrounded by her family. McKenzie's first thought was this woman should be on Palliative Care where she and her family could be given the care and time they needed. The patient asked for 
something for pain and the nurse left to check with the medication nurse to have this taken care of. Arriving in the medication room McKenzie finds Pharmacy has not completed the unit stocking and the medication nurse went to pharmacy to get the most needed medications. McKenzie began to prepare the pain medication, the floating RN's had numerous questions for McKenzie and it took some time to get back to the terminally ill patient and upon arrival in the room the family were annoyed at the delay in treatment and asked to speak with the head nurse.

McKenzie realized it was only 10 am and already two nurse patient/family encounters resulted in difficulty. McKenzie did not get back to speak with the patient and family encounter that started the day. The entire shift was like this and consequently, staff did not feel good about themselves and patients did not receive the care they believed they needed in a timely fashion.

\section{Summary.}

Despite Mckenzie's best effort, there was not enough time to get to know the patients. Medications were not available to be delivered on time, patients and families did not get the nursing time they believed they needed. Staff did not know each other and were not able to work effectively as a team and staff attempted to control patients or to justify a lack of time by saying the patient should be on a different unit to get the appropriate care. All of this necessitated a great deal of reconciliation on the part of the nurse, yet temporalities were not reconciled.

The participants in this study all valued time. Nursing staff believed that when they had the time they needed that the nurse patient encounter went well and all concerns 
could be reconciled, including time. Patients felt that when they received the care they needed in a timely fashion that all was reconciled.

These findings need to be examined for their contribution to nursing science, how they extend existing work and for the questions they raise. The next chapter will focus on a discussion of their contribution and the implications of these findings for nursing care, nursing education and nursing research. 


\section{Chapter VI}

\section{Discussion}

This chapter presents a review of the substantive explanation followed by a discussion of the major findings that explained the origins of difficulty in the nurse patient encounter. The discussion will include what was known about the phenomenon prior to this study, work this study validated, and contributions this study made. The implications of these findings for nursing education, practice and research are discussed subsequent to the presentation of each salient finding.

\section{A Review of The Substantive Explanation}

Reconciling temporalities was the core category that emerged in this study and was the main concern for both nursing staff and patients. The degree of reconciliation required influenced the degree of difficulty in the nurse patient encounter. Knowing the patient minimized difficulty in the nurse patient encounter and reconciliation of time was inherent in getting to know the patient. When nurses did not have the time, and patients did not feel that care has been delivered in a timely manner, and this resulted in temporal incongruencies. The greater the incongruence the more reconciliation was required in the encounter. The factors that contributed to temporal incongruencies, and necessitated reconciliation were: Families, availability of supplies and equipment, who is working, 
and care space changes. Contextual conditions that influenced the process of reconciliation were: Unit reputation and labor market structure changes. The strategies that nurses used to reconcile temporalities were controlling, working together, managing families, and employing geographies of place/bodies.

Prior to this study little was known about what happened in the nurse patient encounter that resulted in the construction of difficulty. Most nursing research accepted as fact that difficulty resided in the individual and that nurses needed to develop interventions to change the patient's difficult (deviant) behavior. Johnson and Webb (1995) found that the labeling of patients as good or bad was not unilateral and suggested that this phenomenon was the result of a combination of factors in the context of care. As early as 1982, Kelly and May urged researchers to look beyond the individual to the context to find what factors may be at work that resulted in patients being labelled good or bad.

Social scientists on the other hand had been studying deviant behavior for quite some time. Becker $(1966,1973)$, in particular, discovered that deviance (difficulty) was not a trait of the individual but rather a process that arises out of interaction among individuals; a process that is dynamic, varies over time, varies according to who the players are and what is at stake. Kleinman $(1988,1995)$ in his work with patients with chronic illness implored health care providers to get to know the life world of the patient, to pay attention to context, that the meaning of a patient's illness is deeply embedded in that life world and in the context of care.

In this study finding how difficulty was constructed in the nurse patient encounter validated the work of social scientists including that of Kleinman $(1988,1995)$, and 
Johnson and Webb (1995). Finding that knowing the patient led to harmonious nurse patient encounters also confirmed the work already done by many on this topic such as Fisher (1989) and Tanner (1993).

The most important contribution of this work is the substantive explanation of how difficulty was constructed in the nurse patient encounter. During the process of data collection while doing participant observation, the researcher noted that nursing staff began to speak about difficult encounters, not difficult patients. Finding how difficulty was constructed gave nursing staff an alternative way of expressing difficulty. The identification of the factors that made up the substantive explanation provided fertile ground for future research. The most noteworthy of the antecedent factors were knowing the patient and time, of the conditions were families, and of the strategies were employing geographies of place and person.

\section{Knowing the Patient}

Knowing the patient was an important category that emerged from this study. Knowing the patient is a concept well documented in the nursing literature. Tripp-Reimer (1984) proposed a model for viewing the health of individuals whereby the nurse could further understand what illness and disease meant for a person from a cultural perspective. Gaining this understanding involved taking the time to get to know the patient. Fisher (1989), in a study of how nurses came to define patients as dangerous, found mental health nurses evaluated patients as more dangerous when they were unknown, and were more understanding of patients when they knew them. Tanner (1993) found knowing the patient was central to skilled clinical judgement, required involvement, and set up the possibility for patient advocacy and for learning about patient 
populations" (p. 273). Liaschenko (1997) supported the concept of knowing the person based on the complexity of the clinical situation. She maintained this concept is a political one and related directly to the kind of healthcare system a society believes in.

Laskowski (2001) found the degree of meaning established in the nurse patient relationship mediated the degree of difficult behavior expressed by clients. In a study of nursing practice Allen (2001), found nurses expected they should know the patient. Although Physicians, families and the institution expected them to do this, the care setting where nurses found themselves working, often did not foster knowing the patient.

\section{Implications}

The findings of this study offer further support that knowing the person is central to nursing. If the concept of knowing the patient is not embraced beyond the boundaries of nursing, then nursing resources to make this possible will remain elusive. Practicing nurses will continue to struggle to achieve this and become increasingly dissatisfied or settle for knowing what they can in the time they have.

There has been an assumption by nurse administrators and educators that because nurses learn the importance of the nurse patient relationship, this concept is accommodated in the practice setting. In this study, the nurse patient encounter was the focus. Nurses believed when they had the time to know the patient, encounters went well. The restructuring of practice settings is distancing the nurse from the patient and this has been further accentuated by the nursing shortage (Malone, 2003). Nursing's political voices will need to remain strong and gather further momentum in order to have a hand in shaping the kind of healthcare system that fosters harmonious encounters. The nursing research is abundant with respect to improved patient outcomes with lower nurse to 
patient ratios (Aiken, Havens \& Sloane, 2000; Aiken et al., 2001; Aiken et al., 2002). The fewer patients a nurse has, the greater the likelihood of getting to know the patient and of having a harmonious encounter. Nurses from the State of California provided a recent example of the political struggle that nursing faces to establish and maintain ratios that permit the development of the nurse patient relationship. Nurses in this state lobbied successfully for legislation that limited the number of patients per nurse to five as of January 2005. Now the state wants to roll back this legislation because employers maintained they cannot meet the legislated ratio ("Nurses Protest," 2005).

In chapter II, it was pointed out that the interactional nurse theorists viewed the nurse patient relationship as central to nursing but that this theory did not appear in the studies on the difficult patient. One flaw in the nursing research was the unquestioning acceptance of the concept of the difficult patient. Researchers did not examine the nurse patient interaction. The findings suggest that interactional nursing theories need to be broadened to include the macro environment of care as a contributing factor to the nurse patient relationship. This may interrupt the present taken for grantedness that the nurse patient relationship is a given.

Nurse educators must continue to provide evidence to students regarding the importance of knowing their patients. Nurses entering practice with an awareness of the importance of knowing the patient and of the potential disconnect between the time philosophy of the employer and the time nurses need to care for patients will at least be able to understand and articulate this disconnect and work toward more effective reconciliation. 


\section{Temporal Incongruencies}

The concept of time was ubiquitous in the data and findings of this study. Time was such a part of everything and everyone that for the most part any examination of it was not even considered other than for most people to say they did not have enough of it. A number of scholarly works have been written that broaden the traditional linear understanding of time and reveal some thought provoking notions (Adam, 1995; Casey, 2003, Jones, 2001; Malone, 2003).

Most workplaces including hospitals have a linear time orientation. This means activities have a start and an end creating the perception that work and nursing work in the care of patients takes place in a neat linear fashion. In the pre-industrial age the nature of the activity dictated the time. The industrial age comodified time and made it equal capital (Adam, 1995). Since then the perception has been created that time is linear and that any and all activity can and should be quantified.

In the process of carrying out a nursing assignment it is not uncommon that two or three patients need the nurse at the same moment in time. The nature and meaning of nursing work is context dependent and to a great extent not captured by linear time (Jones, 2001). The majority of nurses continue to work in organizations that interpret time as linear. For nurses "tensions can arise between the goal of managing time and the goal of providing quality care to patients" (Waterworth, 2003, p. 45). The core category that emerged from this study was reconciling temporalities. Both nurses and patients were struggling to find the time they needed. The time the nurse needed to get to know the patient was an important factor in mediating the degree of difficulty in the nurse patient encounter. Patients looked for compassion in the nurse patient encounter and 
found it in the moments when nurses sat with them, listened, and provided explanations. Taking this time may be incongruent with the hospital temporal framework of reduced lengths of stay.

\section{Implications}

The importance of time and the philosophies of time held by organizations have important implications for nursing. Nurses currently practicing and those who are beginning to practice need to be aware of the tensions that can arise between the time allotted for care and the time they find they need to deliver care. Nurse educators need to include the concept of time in the curriculum of nursing students. Nurses need to understand that places of employment follow a linear philosophy of time, and that nursing work does not always unfold in a neat linear fashion. When the clinical status of a patient changes all efforts are concentrated on one patient for a period of time, the nurse will fall behind in the care of the other patients. This unpredictability in patient care has time implications for nurses and patients. There is a considerable body of nursing research concerning patient outcomes and nursing skill mix, but there is almost none on the topic of time and nursing. Nursing studies that explore how a linear philosophy of time affects patient care are needed. A linear time approach to patient care parcels out time for patient care tasks and getting to know the patient is not one of those tasks.

Nursing leaders need to be familiar with the evidence of the value of knowing the patient in order to lobby politically for the nursing human resources to achieve this. They also need evidence to defend the hours of patient care needed for staff to get to know the patient, as well as the hours needed to perform a list of tasks. 
The evidence of the importance of nursing staff knowing the patient is good but needs to be strengthened. The current wave of the importance of evidence based practice presents an opportunity to nurse researchers to add to the number and type of studies on this important topic. Nurses spent valuable time travelling to get supplies and to communicate with patients because of the physical layout of the patient ward and the communication technology. Outside of hospitals almost every other person can instantly communicate using their cellular telephone, and this telephone may also have wireless email and internet capacity. The nursing unit in this study had three land based telephones and a centrally located intercom for communicating with patients.

The technology exists for the nurse to be in constant contact with patients yet a nurse could more easily communicate from outside the hospital with a patient using a personal cellular telephone then from room to room on a nursing unit. Finding that nurses and patients are in a constant process of reconciling time suggests that nursing staff need to have improved electronic means of communicating with patients. Portable personal computers may provide a means to increase access to patient records and reduce nurse travel. This would also allow them to document care as it is being delivered, respond to patient questions in a more timely fashion, and reset care priorities as needed. Time motion studies would reveal the factors that consume the most time for nurses and recommend the most appropriate strategies to maximize time.

The factors in the immediate context of care that contributed to temporal incongruencies were: Families, availability of supplies and equipment, who is working, and care space changes. The factors in the macro environment of care were the unit reputation and the labor market structure changes. Finding how factors in the context of 
care contributed to temporal incongruency, leading to strategies that created difficulty in the nurse patient encounter was new and important. These findings revealed that the origins of difficulty in the nurse patient encounter were constructed in the context of care and that the individual was not the sole source. All of these factors were considered important and pointed to the need for nursing research to consider the context of care. For the purposes of this discussion, the two most salient factors were families, and geographies of place and person.

\section{Families}

All nursing staff reported how much time families of patients take, to the point they sometimes felt they must choose between the patient and the family when time was extremely limited yet, the discipline of nursing has not provided nurses with an abundance of knowledge about the care of families. Practicing nurses are acutely aware of the nursing time that families need, yet are ill equipped in the assessment and intervention with families (Hayes, 1997 \& Wright \& Leahey, 2000). Wright and Leahey developed the Calgary Family Assessment model twenty years ago. They noted that historically families cared for patients. Following World War II medicine and hospitals medicalized care. The next wave was restructuring healthcare and shifting care from hospitals to communities and families. Nurses knowing about this model and understanding that the patient and family are a unit is important, however, nurses still need to have the time to get to know patients and families.

\section{Implications}

Acute care nurses are caught between the shifting of care to families and being ill equipped to assess and intervene with families. Some of the consequences of this 
included passive exclusion of families until such time as care providers realized they needed the family to take over some aspect of the care (Levine \& Zuckerman, 2000), dissatisfaction of family members and patients with care (Malacrida et al., 1998), and increased stress for families and patients when they did not get the information they needed (Carter, 2001).

Nursing curricula need to emphasize simultaneously the person as an individual and the person as a member of a family (Wright \& Leahey, 2000). Nursing leadership in institutions of care needs to recognize and support this principle in order to lobby for time for nursing staff to spend with families. Further nursing research on the context of care is necessary to challenge the predominance of studies that measure patient outcomes only and fail to consider family as context.

Geographies of Place and Person

A final and significant finding of this study was that nursing staff and patients employed geographies of place and of bodies as a strategy to reconcile temporal incongruencies. Holloway and Hubbard (2001) carefully described the geographies of place, how social order and discipline are instilled in places, and that all places have expectations. Classic examples of such expectations include: Inner cities as places of crime, and suburbia as a place for families. These authors also described the human body as place and argue that how individuals treat their bodies is a social construction. For example "good complete citizens are generally considered to be those who look after their bodies" (Holloway \& Hubbard, 2001, p. 194). In this study, nursing staff spoke about the frustration they felt in taking care of patients who had abused their bodies and now expected to be healed. This frustration has likely been born from prolonged 
engagement with a system informed by sick role theory. A system that when faced with what it perceives as an incomplete citizen blames the citizen and absolves society (Kleinman, 1995).

The patients interviewed all believed that everyone should have the care they need, however, patients did not expect to be on the same unit as patients with Alzheimer's disease, who were crying and moaning, or with patients who were substance abusers. Patient study participants had expectations that the unit would be a restful place and that other patients would not bother them. This illustrated how patients employed geographies of place and person. The numbers of hospital beds continue to be reduced in an effort to preserve hospital space for medical and technological interventions (Cartier, 2003). For this reason family medicine units will continue to serve the medical needs of an increasing variety of non-clinical specialty patients.

\section{Implications}

These non-clinical specialty patients generally have considerable personal and psychosocial care needs that nursing staff will be challenged to meet. As soon as the medical need is treated then the patient is moved to some other type of sub-acute care facility. In this study, nursing staff generally employed geographies of place by recommending the transfer of patients that required more time than they believed they could provide. For example, palliative care patients need to be on the palliative care unit once they need a certain amount of care because the physical and psychosocial care required will most likely not be allotted on most family medicine units. This finding extends the work of Cartier (2003) who noted not only that lengths of stay have been shortened but that part of this approach to care also limited the care time of providers. 
This notion of the geographies that are applied to person and place is important for nurses. This is also another frontier for nursing research.

\section{Summary}

Studies exploring the factors that contributed to the construction of difficulty in the nurse patient encounter are a place to begin future research. The most pressing factor is in the area of time and nursing. The focus of this study was the nurse patient encounter in what was described in Chapter III as a nursing unit with strong leadership, low staff attrition, and experienced nursing staff. It would be instructive to conduct this study on a nursing unit that does not have these attributes and on nursing units other than family medicine to find out how the factors that contributed to the construction of difficulty would vary.

Additional research frontiers in the context of care are studies that explore the origins of difficulty in nurse to nurse, nurse to physician, and nurse-to-other-health care provider encounters. Of equal importance are studies in the context of care that consider race, gender, class, androcentric, and ethnocentric bias.

The most important contribution of this work is the substantive explanation of how difficulty was constructed in the nurse patient encounter. This discovery added to the knowledge in the discipline of nursing and interrupted the nursing discourse that has located difficulty in the individual. Finding how difficulty was constructed in the nurse patient encounter extended the work of the social scientists mentioned earlier in this chapter and made a case for nursing research that considers the context of care. 
The salient factors that influenced difficulty were: Knowing the patient, time, families, and employing geographies of place and person. The implications of these factors were discussed for nursing practice, education and research.

Research frontiers arising from this study include: Time motion studies that identify factors that consume the most time for nurses in their work, and studies that explore the origins of difficulty in nurse to nurse, nurse to physician and nurse to other provider encounters. Finally, studies that focus on exploring the strategy of employing geographies of place and person in the context of care by both staff and patients, have potential to add to healthcare provider information on how context affects care. 


\section{References}

Adam, B. (1995). Timewatch: The social analysis of time. Cambridge, UK: Polity Press.

Aiken, L. H., Havens, D. S., Sloane, D. (2000). Magnet nursing services recognition programme. Nursing Standard, 14 (25), 41-46.

Aiken, L. H., Clarke, S. P., Sloane, D. M., Sochalski, J. A., Busse, R., Clarke, H., Giovannetti, P., Hunt, J., Rafferty, A. M., \& Shamian, J. (2001). Nurses' reports on hospital care in five countries. Health Affairs, 20 , 43-53.

Aiken, L., H., Clarke, S. P., Sloane, D. M., Sochalski, J., \& Silber, J. H. (2002). Hospital nurse staffing and patient mortality, nurse burnout, and job dissatisfaction. Journal of The American Medical Association, 288, 1987-1993.

Allen, D. (2004). Ethnomethodological insights into insider-outsider relationships in nursing ethnographies of healthcare settings. Nursing Inquiry, $11,14-24$.

Baumgart, A. J., \& Larsen, J. (19920. Canadian nursing faces the future. Toronto: Mosby

Beck, K. L., \& Larrabee, J. H. (1996). Measuring patients perceptions of nursing care. Nursing Management, 27(9), 32B, 32D

Becker, H. S. (1966). The other side: Perspectives on deviance. New York: The Free Press.

Becker, H. S. (1973). Outsiders: Studies in the sociology of deviance. New York: The Free Press.

Becker, H. S. (1998). Tricks of the trade: How to think about your research while you are doing it. Chicago: The University of Chicago Press.

Blegen, M. A. (1993). Nurses' job satisfaction a meta-analysis of related variables. Nursing Research, 42, 36-41 
Blumer, H. (1969). Symbolic Interactionism. Englewood Cliffs, NJ: Prentice-Hall, Inc.

Brandi, C. L. (2000). Relationships between nurse executives and physicians: The gender paradox in healthcare. Journal of Nursing Administration, 30 (7/8), 373-378.

Breeze, J. A., \& Repper, J. (1998). Struggling for control: The care experiences of difficult patients in mental health services. Journal of Advanced Nursing, 28, 1301-1311.

Bunting, S., \& Campbell, J. C. (1990). Feminism and nursing: Historical perspectives. Advances in Nursing Science, 12(4), 11-24.

Carper, B. (1978). Fundamental pattern of knowing in nursing. Advances in Nursing Science, 1 (1), 13-23.

Carter, P. A. (2001). A not so silent cry for help: Older female caregivers' need for information. Journal of Holistic Nursing, 19, 271-284.

Cartier, C. (2003). From home to hospital and back again: Economic restructuring, end of life, and the gendered problems of place-switching health services. Social Science and Medicine, 56, 2289-2301.

Carveth, J. A. (1995). Perceived patient deviance and avoidance by nurses. Nursing Research, 44, 173-178.

Carveth Trexler, J.A. (1996). Reformulation of deviance and labeling theory for nursing. Image: Journal of Nursing Scholarship, 28, 131-135.

Casey, E. (2003). From space to place in contemporary health care. Social Science and Medicine, 56, 2245-2247.

Chambliss, D. (1996). Beyond caring: Hospitals, nurses, and the social organization of ethics. Chicago: University of Chicago Press. 
Charmaz, K. (2000). Grounded theory: Objectivist and constructivist methods. In N. K. Denzin \& Y. S. Lincoln (Eds.), Handbook of qualitative research. $\left(2^{\text {nd }} \mathrm{ed} ., \mathrm{pp}\right.$. 509-535). Thousand Oaks, Ca: Sage.

Charon, J. M. (1998). Symbolic Interactionism (6th ed.). Upper Saddle River, NJ: Prentice Hall.

Chenitz, C. W., \& Swanson, J. M. (1986). From practice to grounded theory. Menlo Park, CA: Addison-Wesley Publishing Company.

Cleland, V. (1971). Sex discrimination: Nursing's most pervasive problem. American Journal of Nursing, 71 (8), 1542-1547.

Cook, D. M. (2000). Difficult patient: Building a bridge to Angie. Nursing 2000, 30 (6), $42-43$

Cowin, L. (2002). The effects of nurses' job satisfaction on retention: An Australian perspective. Journal of Nursing Administration, 32 (5), 283-291.

Davies, K. (2001). Responsibility and daily life: Reflections over timespace. In J. May \& N. Thrift (Eds.), Timespace: Geographies of temporality. (pp. 133-148). London:Routledge.

Davis, F. (1972). Uncertainty in medical prognosis, clinical and functional. In E. Freidson \& J. Lorber (Eds.), Medical men and their work. (pp. 239-248). New York: Atherton

Denzin, N. K., \& Lincoln, Y. S. (2000). Handbook of qualitative research $\left(2^{\text {nd }}\right.$ ed.). Thousand Oaks, CA: Sage

English, J., \& Morse, J. M. (1988). The difficult elderly patient: Adjustment or maladjustment? International Journal of Nursing Studies, 25, 23-39. 
Erlandson, D. A., Harris, E. L., Skipper, B. L., \& Allen, S. D. (1993). Doing naturalistic inquiry. A guide to methods. London: Sage Publications.

Fadiman, A. (1997). The spirit catches you and you fall down. New York, NY: Farrar, Straus and Giroux.

Fee, C. (2001). Death of a difficult patient. Annals of Emergency Medicine, 37, 354-355

Fineman, N. (1991). The social construction of noncompliance: A study of health care and social service providers in everyday practice. Sociology of Health and Illness, $13,355-374$.

Fineman, N. (1997). The making and meanings of difficult patients: Doctors' and Nurses' subjective understandings and experience of difficulty. Dissertation Abstracts International, 58, 07A. (UMI No. 9738395)

Finlay, L. (2002). "Outing" the researcher: The provenance, process, and practice of reflexivity. Qualitative Health Research, 12, 531-545.

Fisher, A. (1989). The process of definition and action: The case of dangerousness. Dissertation Abstracts International, (UMI No. 8917915)

Foley, B. J., Kee, C. C., Minick, P., Harvey, S. S., \& Jennings, B. (2002). Characteristics of nurses and hospital work environments that foster satisfaction and clinical expertise. Journal of Nursing Administration, 32 (5), 273-282.

Freidson, E. \& Lorber, J. (1972). Medical men and their work. Chicago: Aldine.

Gallagher, E. B. (1979). Lines of reconstruction and extension in the Parsonian sociology of illness. In E. Jaco (Eds.), Patients, physicians and illness: A sourcebook in behavioral science and health. ( $3^{\text {rd }}$ ed., pp. 162-183). New York: The Free Press. 
George, V., \& Dundes, A. (1978). The gomer. Journal of American Folklore, 91, 568581.

Glaser, B. G., \& Strauss, A. L. (1970). The discovery of grounded theory: Strategies of grounded theory. Chicago: Aldine Publishing Company.

Goffman, E. (1963). Stigma: Notes on the management of spoiled identity. New York: Simon \& Schuster.

Gorman, M. (1996). Culture clash: Working with a difficult patient. American Journal of Nursing, 96 (11), 58.

Hagerstrand, T. (1985b). Lecture, Geographic Days in Uppsala, 1 June 1985.

Hayes, V. (1997). Searching for family nursing practice knowledge. In S. E. Thorne \& V. E. Hayes (Eds.), Nursing praxis: Knowledge and action (pp. 54 -68). Thousand Oaks, CA: Sage.

Haynes, R. B. (1979). Introduction. In R. B. Haynes, D. W. Taylor, and D. L. Sackett (Eds.), Compliance in healthcare (pp. 1 - 7). Baltimore: Johns Hopkins University Press.

Hayward, K., \& Colman, R. (2003). The tides of change: Addressing inequity and chronic disease in Atlantic Canada. Ottawa: Health Canada. Retrieved October 9, 2004 from

http://www.phacaspc.gc.ca/canada/regions/atlantic/pdf/Tides_Inequity and_Chro nic Disease.pdf 
Health and Wellness New Brunswick (2004). Healthy futures: Securing New

Brunswick's Health Care System. The provincial health plan 2004-2008.

Retrieved September 20, 2004, from

http://www.gnb.ca/0051/pdf/healthplan-2004-2008_e.pdf

Hirst, S. P. (1983). Understanding the difficult patient. Nursing Management, 14(2), 6870.

Holloway, L., \& Hubbard, P. (2001). People and place: The extraordinary geographies of everyday life. New York: Prentice Hall.

Inglis, D., \& Holmes, M. (2004). Toiletry Time: Defecation, temporal strategies and the dilemmas of modernity. Time and Society, 9 (2/3), 223-245.

Ingersoll, G. L., Olsan, T., Drew-Cates, J., DeVinney, B. C., \& Davies, J. (2002). Nurses job satisfaction, organizational commitment, and career intent. Journal of Nursing Administration, 32 (5), 250-263.

Jacox, A. K., Bausell, B. R., \& Mahrenholz, D. M. (1997). Patient satisfaction with nursing care in hospitals. Outcomes Management in Nursing Practice, 1(1), 2028.

Johnson, M., \& Webb, C. (1995). Rediscovering unpopular patients: The concept of social judgement. Journal of Advanced Nursing, 21, 466-475.

Jones, A. R. (2001). Time to think: Temporal considerations in nursing practice and research. Journal of Advanced Nursing, 33, 150-158. 
Juliana, C. A., Orehowsky, S., Smith-Regojo, P., Sikora, S. M., Smith, P. A., Stein, D. K., Wagner, D. O., \& Wolf, Z. R. (1997). Interventions used by staff nurses to manage difficult patients. Holistic Nursing Practice, 11(4), 1-26.

Kangas, S., Kee, C. C., \& McKee-Waddle, R. (1999). Organizational factors, nurses, job satisfaction, and patient satisfaction with nursing care. Journal of Nursing Administration, 29 (1), 32-42

Kelly, M. P., \& May, D. (1982). Good and bad patients: A review of the literature and a theoretical critique. Journal of Advanced Nursing, 7, 147-156.

Kincheloe, J. C., \& McLaren, P. (2000). Rethinking critical theory. In N. K. Denzin \& Y. S. Lincoln (Eds.), Handbook of qualitative research. (2nd ed., pp. 279-313). Thousand Oaks, Ca: Sage.

King, I. M. (1971). Toward a theory for nursing. New York: John Wiley and Sons Inc.

Kleffel. D. (1994). The environment: Alive, whole, interconnected and interacting. Dissertation Abstracts International, 55, 08B. (UMI No. 9500795)

Kleinman, A. (1988). The illness narratives: Suffering, healing and the human condition. New York: Basic Books

Kleinman, A. (1995). Writing at the margin. Los Angeles: The University of California Press.

Kus, R. J. (1990). Nurses and unpopular patients. American Journal of Nursing, 90 (6), $62-66$.

Laghi, B., Clark, C., \& Fagan, D. (2004, September 16). PM pulls out a deal. The Globe and Mail, pp. A1, A9-11. 
Laskowski, C. (2001). The mental health clinical nurse specialist and the difficult patient: Evolving Meaning. Issues in Mental Health Nursing, 22, 5-22.

Levine, C., \& Zuckerman, C. (2000). Hands on/hands off: Why health care professionals depend on families but keep them at arm's length. Journal of Law, Medicine and Ethics, 28, 5-18.

Leiderman, D. B., \& Grisso, J. A. (1985). The gomer phenomenon. Journal of Health and Social Behavior, 26, 222-232.

Liaschenko, J. (1997). Knowing the patient? S. E. Thorne \& V. E. Hayes (Eds.), Nursing praxis: Knowledge and action (pp. 23-37). Thousand Oaks, CA: Sage.

Lincoln, Y. S., \& Guba, E. G. (1985). Naturalistic Inquiry. Newbury Park: Sage.

Lofland, J., \& Lofland, L. H. (1995). Analyzing social settings: A guide to qualitative observation and analysis ( $3^{\text {rd }}$ ed.). San Francisco, Ca: Wadsworth Publishing Company.

Lorber, J. (1979). Good patients and problem patients: Conformity and deviance in a general hospital. In E. Jaco (Eds.), Patients, physicians and illness: A sourcebook in behavioural science and health. ( $3^{\text {rd }}$ ed., pp. 202-217). New York: The Free Press.

Macdonald, M. T. (2003). Seeing the cage: Stigma and its potential to inform the phenomenon of the difficult patient. Clinical Nurse Specialist, 17, 305-310.

Malacrida, R., Bettelini, C. M., Degrate, A., Martinez, M., Badia, F., Piazza, J., Vizzardi, N., Wullschleger, R., \& Rapin, C. H. (1998). Reasons for dissatisfaction: A survey of relatives of intensive care patients who died. Critical Care medicine, $26,1187-1193$. 
Malone, R. E. (2003). Distal Nursing. Social Science and Medicine, 56, 2317-2326.

Meleis, A. I. (1997). Theoretical nursing: Development and progress (3rd Ed.). New York: Lippincott Co.

Merriam Webster. Retrieved October 21, 2004 from http://www.m-w.com/cgi-bin/dictionary?book=Dictionary\&va

Mizrahi, T. (1984). Coping with patients: Subcultural adjustments to the conditions of work among internists in training. Social Problems, 32, 156-165.

Morrison, E. F., Ramsey, A., \& Synder, B. A. (2000). Managing the care of complex, difficult patients in the medical surgical setting. Medsurg Nursing, 9, 21-26.

Mystakidou, K., \& Tsilika, E. (2000). Team dynamics and the difficult patient. European Journal of Palliative Care, 7, 56-59.

Neuwirth, Z. E. (1999). The difficult patient--- myth or reality? Hospital Medicine, 35 (4), 48-55.

Nield-Anderson, L., Minarik, P. A., Dilworth, J. M., Jones, J., Nash, P. K., O'Donnell, K. L., \& Steinmiller, E. A. (1999). Responding to difficult patients. American Journal of Nursing, 99 (12), 26-34.

Nurses protest Governor's proposal. (2005, January 18). San Diego Union Tribune.

Retrieved January 25, 2005, from

http://www.nbcsandiego.com/health/4106206/detail.html

O’Brien-Pallas, L., Baumann, A., Donner, G., Lochhaas-Gerlach, J., Luba, M., \& Tomblin-Murphy, G. (2001). Forecasting models for human resources in health care. Journal of Advanced Nursing, 33, 120-129. 
Olsen, D. P. (1997). When the patient causes the problem: The effect of patient responsibility on the nurse-patient relationship. Journal of Advanced Nursing, 26, $515-522$

Olshansky, E. F. (1996). Theoretical issues in building a grounded theory: Application of an example of a program of research on infertility. Qualitative Health Research, $6,394-405$.

Parsons, T. (1979). Definitions of health and illness in the light of American values and social structure. In E. G. Jaco (Eds.), Patients, physicians and illness: $A$ sourcebook in behavioural science and health. ( $3^{\text {rd }}$ ed., pp. 120-144). New York: The Free Press.

Peplau, H. (1952). Interpersonal relations in nursing. New York: G. P. Putnam's Sons.

Platt, F. W., \& Gordon, G. H. (1999). Field guide to the difficult patient interview. Philadelphia, PA: Lippincott Williams \& Wilkins.

Podrasky, D. L., \& Sexton, D. L. (1988). Nurses' reactions to difficult patients. Image: Journal of Nursing Scholarship, 20, 16-21.

Quan, J. (2000). Difficult patient. American Journal of Nursing, 30 (7), 46.

Quint, J. C. (1972). Institutionalized practices of information control. In E. Freidson \& J. Lorber (Eds.), Medical men and their work. (pp. 220-238). New York: Atherton.

Roberts, S. J. (1983). Oppressed group behavior: Implications for nursing. Advances in Nursing Science, 5 (3), 21-30.

Santamaria, N. (1996). The difficult patient stress scale: A new instrument to measure interpersonal stress in nursing. Australian Journal of Advanced Nursing, 13 (2), 22-29. 
Santamaria, N. (2000). The relationship between nurses' personality and stress levels reported when caring for interpersonally difficult patients. Australian Journal of Advanced Nursing, 18 (2), 20-26.

Schatzman, L. (1979). Voluntarism and professional practice in the health professions. In J. R. Folta \& E. S. Deck (Eds.) A sociological framework for patient care (pp. 181-193). New York: John Wiley and Sons.

Schatzman, L., \& Strauss, A. L. (1973). Field research: Strategies for a natural sociology. New Jersey: Prentice-Hall, Inc.

Schwartz, R. D., \& Skolnick, J. H. (1966). Two studies of legal stigma. In H. S. Becker (Eds.) The other side: Perspectives on deviance (pp. 103-117). New York: The Free Press.

Shiloh, A. (1972). Equalitarian and hierarchical patients: An investigation among Hadassah hospital patients. In E. Freidson \& J. Lorber (Eds.) Medical men and their work. (pp. 249-266). New York: Atherton.

Stevens, P. E., \& Hall, J. M. (1992). Applying critical theories to nursing in communities. Public Health Nursing, 9, 2-9.

Steinbrook, R. (2002). Nursing in the crossfire: Health policy report. The New England Journal of Medicine, 346, 1757-1766

Sohr, E. (1996). The difficult patient. Miami, Fl: MedMaster Inc.

Stake, R. E. (2000). Case studies. In N. K. Denzin \& Y. S. Lincoln (Eds.), Handbook of Qualitative Research (2 ${ }^{\text {nd }}$ Ed.). Thousand Oaks: Sage.

Stockwell, F. (1972). The unpopular patient. Kent, UK: Croom Helm-Beckenham. 
Strauss, A. L. (1987). Qualitative analysis for social scientists. UK: Cambridge University Press.

Strauss, A., \& Corbin, J. (1998). Basics of qualitative research $\left(2^{\text {nd }}\right.$ Ed.). Thousand Oaks: Sage.

Tagliacozzo, D. L., \& Mauksch, H. O. (1979). The patient's view of the patient's role. In E.G. Jaco (Eds.), Patients, physicians and illness: A sourcebook in behavioural science and health. $\left(3^{\text {rd }}\right.$ ed., pp. 185-201). New York: The Free Press.

Tanner, C. A., Benner, P., Chesla, C., \& Gordon, D. R. (1993). The phenomenology of knowing the patient. Image: Journal of Nursing Scholarship, 25, 273-280.

Tripp-Reimer, T. (1984). Reconceptualizing the construct of health: Integrating emic and etic perspectives. Research in Nursing and Health, 7, 101-109.

Ujhely, G. (1963). The nurse and her problem patients. New York: Springer Publishing Company Inc.

Walsh, J. L., \& Elling, R. H. (1972). Professionalism and the poor, structural effects and professional behavior. In E. Freidson \& J. Lorber (Eds.) Medical men and their work. (pp. 267-283). New York: Atherton.

Waterworth, S. (2003). Temporal reference frameworks and nurses' work organization. Time and Society, $12(1), 41-54$.

Wiedenbach, E. (1964). Clinical nursing: A helping art. New York: Springer.

Winick, C. (1966). Physician narcotic addicts. In H. S. Becker (Eds.) The other side: Perspectives on deviance (pp. 261-279). New York: The Free Press Worldwatch Institute. (2003). Vital Signs 2003. New York, NY: W. W. Norton \& Company. 
Wright, L. M., \& Leahey, M. (2000). Nurses and families: A guide to family assessment and intervention ( $3^{\text {rd }}$ Ed.). Philadelphia, PA: F. A. Davis Company.

Wuest, J. (1993). Removing the shackles: A feminist critique of non-compliance. Nursing Outlook, 41, 217-224.

Wuest, J. (1994). A feminist approach to concept analysis. Western Journal of Nursing Research, 16, 577-586.

Wuest, J. (1995). Feminist grounded theory: An exploration of the congruency and tensions between two traditions in knowledge discovery. Qualitative Health Research, 5, 125-138.

Zussman, R. (1992). Intensive care: Medical ethics and the medical profession. Chicago: University of Chicago Press. 
Appendix A

\section{Consent (Participant Observation)}

Purpose: The purpose of this research study is to find out what happens in the care encounters between nurses/nursing personnel and patients that sometimes results in nurses/nursing personnel not being happy with patients or patients not being happy with nurses/nursing personnel.

Procedure: For this study Marilyn Macdonald will observe nursing personnel interacting at work. The researcher will attend change of shift reports, discharge planning rounds, and take written notes on communication patterns used by nurses/nursing personnel. The researcher will at no time record any names and will use code numbers or pseudonyms in all written records. All written records will be kept in a locked location with access only by the researcher. Participant observation in the hospital will take place four days a month, four to six hours a day, over a six month period.

Risks: $\quad$ No risks are anticipated.

Rights: There is no obligation to participate in the study. You have the right to withdraw from this study at any time. Your participation, non-participation or refusal to answer certain questions is your decision. A presentation of the results of this study to the nurses is planned.

Use of Data: The information obtained will be shared with the researcher's committee members. The data will be coded so that your identity will not be revealed. Written reports of this study will not identify you. All these materials will be destroyed in five years.

Benefits: There will be no direct benefit to you for your participation. This study will help develop a better understanding of what happens in the nurse-patient encounter.

I have read and understand this form, and consent to be part of this study. If I have any further questions about the study or about my rights as a study participant I may contact either Marilyn Macdonald at (506) 857-5428 or Diane Hatton, Professor, Research Supervisor, University of San Diego at (619) 260-7481. If I have questions or concerns about my participation in a research study, I may contact someone not involved in the study, by calling the patient Representative, Nancy Chedore at (506) 648- 6714. 
Appendix B

\section{Consent Form for Former Patients}

Purpose: The purpose of this research study is to find out what happens in the care encounters between nurses and patients that sometimes results in patients not being happy with nurses or the nurses are not happy with the patients.

Procedure: You will be interviewed by the researcher for about 60 to 90 minutes, scheduled at a date, time and place convenient to you. You will be asked to recall your most recent hospital experience and to tell the researcher what it was like. The interview will be tape recorded. The tape from the interview will be listened to by the researcher and written out. Your name will never be used and everything you say will be kept confidential. If the researcher needs to, she may telephone you after the interview to ask you to clarify anything she does not understand.

Risks: There is a risk in discussing past events, in that they may cause emotional distress. If this happens you may wish to stop the interview. You may stop the interview at any time and either continue later or, or decide not to be in the study. A telephone number for psychological counselling will be given to you if you would like to talk to someone about your emotional distress.

Rights: There is no obligation to participate in the study. You have the right to withdraw from this study at any time. Your participation, non-participation or refusal to answer certain questions will have no effect on health services that you or any member of your family may receive. The results of this study will be made available to you if you request them from the researcher.

Use of Data: Everything in the interview will be kept confidential. Your name will not be used and either a code number or a made-up name (pseudonym) will be assigned to you. The tapes and all written materials used in this study will be kept in a locked place with access only by the researcher. All these materials will be destroyed in five years.

Benefits: There will be no direct benefit to you for your participation. This study will help us develop a better understanding of what happens in the nurse-patient encounter.

I have read and understand this form, and consent to be interviewed. If I have any further questions about the study or about my rights as a study participant I may contact either Marilyn Macdonald at (506) 857-5428 or Diane Hatton, Professor, Research Supervisor, University of San Diego at (619) 260-7481. If I have questions or concerns about my participation in a research study, I may contact someone not involved in the study, by calling the patient Representative, Nancy Chedore at (506) 648- 6714.

$\overline{\text { Date }} \quad$ Name of Participant (Print) $\quad$ Participant's Signature

Interviewer's Signature 


\section{Appendix C}

\section{Consent Form for Nurses}

Purpose: The purpose of this research study is to focus on finding out what happens in the care encounters between nurses and patients that sometimes results in nurses not being happy with patients or patients not being happy with nurses.

Procedure: You will be interviewed by the researcher for about 60 to 90 minutes, scheduled at a date, time and place convenient to you. You will be asked to recall a typical encounter you had with a patient that went well, and an encounter that did not go so well and discuss how you think these situations arise. The interview will be tape recorded. The tape from the interview will be listened to by the researcher and written out. Your name will never be used and everything you say will be kept confidential. If the researcher needs to, she may telephone you after the interview to ask you to clarify anything she does not understand.

Risks: There is a risk in discussing past events, in that they may cause emotional distress. If this happens you may wish to stop the interview. You may stop the interview at any time and either continue later, or decide not to be in the study. A telephone number for psychological counselling will be given to you if you would like to talk to someone about your emotional distress.

Rights: There is no obligation to participate in the study. You have the right to withdraw from this study at any time. Your participation, non-participation or refusal to answer certain questions will have no effect on your job status. The results of this study will be made available to you if you request them from the researcher.

Use of Data: Everything in the interview will be kept confidential. Your name will not be used and either a code number or made-up name (pseudonym) will be assigned to you. The tapes and all written materials used in this study will be kept in a locked place with access only by the researcher. All these materials will be destroyed in five years.

Benefits: There will be no direct benefit to you for your participation. This study will help us develop a better understanding of what happens in the nurse-patient encounter.

I have read and understand this form, and consent to be interviewed. If I have any further questions about the study or about my rights as a study participant I may contact either Marilyn Macdonald at (506) 857-5428 or Diane Hatton, Professor, Research Supervisor, University of San Diego at (619) 260-7481. If I have questions or concerns about my participation in a research study, I may contact someone not involved in the study, by calling the Patient Representative, Nancy Chedore at (506) 648-6714.

Date Name of Participant (Print) Participant's Signature

Interviewer's Signature 


\section{Appendix D}

\section{Patient Participant Letter}

Dear Participant,

I am a New Brunswick nurse and a student at The University of San Diego. Doing research is part of my program of study. I know that as a nurse there are times when the nurse is not happy with a patient and there are times when the patient is not very happy with the nurse. I want to know more about what makes this happen. In order to find out I am doing research with patients and nurses.

You are about to be discharged from the hospital. I would like to know if you are interested in helping with this research project. If you are, you can let the nurse who gave you this letter know. When you have been home for a week or so I will contact you by telephone to ask you if you are still interested. If so, I will set up a date, time and place to interview you at your convenience.

I will send you a written consent form in the mail for you to read before the interview. This will give you a chance to make a note of any questions you may have for me. I will call you the day of the interview to make sure the date and time are still convenient for you.

Sincerely,

Marilyn Macdonald

(506) 857-5428 


\section{Appendix E}

\section{Nurse Participant Flyer}

Dear Nurses,

I am a New Brunswick nurse and a graduate student at The University of San Diego. Doing research is part of my program of study. I know that as a nurse there are times when the nurse is not happy with a patient and there are times when the patient is not very happy with the nurse. I want to know more about what makes this happen. In order to find out, I am doing research with patients and nurses.

If you are a nurse with at least one year of full-time experience on an adult family practice or general medical surgical nursing unit, I would like to know if you are interested in helping with this research project. If you are, please take note of the phone number below and give me a call. I will be happy to tell you more about the study. If you decide to participate, I will set up a date, time and place convenient for us to meet and conduct a private interview that will last about 60 to 90 minutes.

I will send you a written consent form in the mail for you to read before the interview. This will give you a chance to make a note of any questions you may have for me. I will call you the day of the interview to make sure the date and time are still convenient for you.

Sincerely,

Marilyn Macdonald

(506)857-5428 


\section{Appendix F \\ Interview Questions}

Questions for former patient participants:

1. Tell me about your recent hospital experience

2. What makes patients happy with their care?

3. What makes patients unhappy with their care?

4. Describe for me what you think a patient's hospital experience should be like?

5. How do you think a hospital stay can be made better?

6. How do you feel about the future possibility of having to return to hospital?

Questions for nursing participants:

1. Tell me about a typical encounter you had with a patient that went well. Tell me about an encounter you had that did not go so well.

2. How do such situations come about?

3. Describe for me what you do in these situations

4. Describe for me what you think the nurse-patient relationship should be like

5. Describe for me how you think patients should act while in hospital 
Appendix G

\section{Patient Guide}

Family medicine 


\section{Hospital Mission}

Our mission is to deliver the highest possible quality of health care, while respecting the dignity and individuality of our patients, co-workers and the public we serve.

We are committed to continuous improvement in the delivery of patient care, in the promotion of wellness and in the effective communication of health care issues. We face the future with optimism.

\section{Values}

- Respect for the individual

- Medical ethics and community standards

- Equal and fair access to appropriate services

- Fiscal responsibility and accountability

- Teamwork plus respect and appreciation of our people

- Adaptability in the pursuit of excellence

- Enhanced patient care and services through stakeholder partnerships

\section{Welcome to our Hospital}

\section{Family Medicine}

Family medicine is a 36-bed nursing unit. This unit cares for patients who are in need of medical attention. The daily care is provided by the nursing staff; however, a Patient Care Team meets weekly to discuss each patient and go over the plan of care. The planning and participation in this care by patient and family are encouraged. This can be 
done by telling the charge nurse at the nursing station (or a team member) any concerns or questions about the care (e. g. tests, medications, treatments, diet, discharge problems). Health promotion and education are also important in patient care. Please ask a nurse or team member about the teaching available on the unit (e.g. Lung Education, Congestive heart Failure videos, Stress Reduction, Stop Smoking, Diabetic Teaching).

\section{Team Members}

Nurse Manager will visit throughout the week and is available Monday - Friday, 7:30 am $-3: 30 \mathrm{pm}$ if there are any questions or concerns.

Charge Nurse is at the nurse's station and can contact the doctor or a team member for patients/family.

Nursing Staff (Registered Nurses \& Licensed Practical Nurses) plan and provide daily care and can also contact the doctor or another team member.

Doctor (family doctor, doctor on call or hospitalist) gives direction in planning care and treatment.

Dietitian helps with questions or concerns about nutrition and food services.

Discharge Planning Nurse or Care Coordinator helps with making plans for continuing care and discharge from hospital.

Extra-Mural Nurse helps with any discharge needs at home (i.e. Dressings, intravenous therapy, physio).

Pastoral Care clergy are available to visit patients.

Pharmacist helps with questions or concerns about medications.

Physiotherapist helps with questions or concerns about activity (i.e. walker, exercise, chest physio). 
Respiratory Therapist helps with any breathing problems e.g. puffers.

Social Worker helps with personal, family, social concerns, and emotional support in hospital as well as discharge plans.

Patient Service Workers clean rooms, make beds, deliver food trays.

Ward Clerks complete secretarial duties.

Other team members available: Occupational Therapy who can help with special aids/needs for daily living. Speech Therapist who can help with speech or swallowing problems. These team members are available to speak with patients and families by asking the nurse to contact them.

Patient/Family Information

\section{Call Board}

This is a clipboard at the nurse's station. Any questions or concerns about patient care are written here by the charge nurse for the doctors to see when they come to the unit. If there is an urgent concern, the doctor is called. Please feel free to tell a team member if you would like a question or concern written on the clipboard. This is confidential.

Doctors are usually in contact with the unit on a daily basis.

\section{Assignment Board}

Located in front of nurse's station. This lists the room numbers and nurses' assignments. Visit Hours 3:00 pm to 8:30 pm

Maximum of two visitors for each patient at any one time. Family may only stay with patients who need extra support (e.g. confused, upset, seriously ill).

\section{Rest Period}

Patients need rest to heal. Rest period is 1:30 pm to 3:00 pm. Do not visit at this time. 


\section{No Smoking}

This hospital is a NON SMOKING building.

\section{Perfumes/Scents}

This hospital is a scent free environment. Many patients have respiratory problems and are bothered by perfumes, fresh flowers, etc. It may be necessary at times to send flowers home. Please do not wear scented products as a patient or when visiting.

\section{Medications}

DO NOT keep medications at your bedside. Please send medications home unless asked by the nurse to do otherwise. There are times when it may be necessary for the patient to take their own medication because the pharmacy cannot supply them. These medications will not be replaced.

\section{Valuables}

The hospital staff are not responsible for valuables such as glasses, jewelry, cash, dentures, etc. If you cannot send valuables or money home, please have the nurse take it to the Cashier for safekeeping.

\section{Personal Effects}

Patients are responsible for bringing their own toothbrush, toothpaste, comb, deodorant, lotions, etc. These are not supplied by the hospital.

\section{Tests and Procedures}

Nursing staff try to keep you informed. Please ask questions of the nursing staff, patient care team, and the doctors about tests and procedures being done. Most tests and procedures are scheduled and have a preparation such as nothing to eat or drink. 


\section{Meals}

Meal trays arrive on this unit at 8:15 am; 12:10pm; and 5:10pm (times may vary). If family are present at these times, they are encouraged to help with feeding. Please check with the nurse.

\section{Kitchen}

There are limited drinks available for patient use. Items from home may be kept in the kitchen. Have patients put a label on them. We can not be responsible for these items.

\section{Quiet Room}

A quiet area for families of very ill patients is available. A daybed is available if a family member needs to stay overnight. Please check with the charge nurse. Only one family member overnight.

\section{Visitors Bathroom}

Located in the hallway across from room 21.

\section{Report Times}

Shift reports for staff are 7:30 am to $8: 00 \mathrm{am} ; 3: 30 \mathrm{pm}$ to $4: 00 \mathrm{pm} ; 7 ; 30 \mathrm{pm}$ to $8: 00 \mathrm{pm}$; and 11:30 pm to $12: 00 \mathrm{am}$. Please try not to call the unit during these times if possible. Phone Calls/Patient Inquiries

There is a phone at each bedside. If you connect your phone, please be considerate of other patients in your room. Late night incoming calls are discouraged (after 10:00 pm). Phone calls to the nursing station are welcome but should be limited to one family member who shares the information with the rest of the family. Every time you call the nurse to the phone, time is taken away from patient care. Best time to call is after 10:00 am. 


\section{Discharge}

When your care and treatment is completed, the doctor will write your discharge order. To be ready for this, we discuss your needs early. You may not require assistance or you may require follow up care after you leave us for help with meals, homemakers, etc. The Patient Care Team will assist you in preparing for discharge. To make this process easier, discharge time is to be by 11:00 am or within two hours of being told you may go home.

\section{Confidentiality}

When patients are ill it is difficult to move them from a ward or semi-private room to talk about their condition. Any information is confidential. All patients have the right to have information kept confidential. It is also the patient's responsibility to keep any information about another patient confidential.

\section{Patients Have Rights and Responsibilities}

There is a pamphlet available to read on this subject. A Patient Representative is available at request.

\section{Flu Season}

Our patients are at risk for being infected with the flu. DO NOT VISIT if you have symptoms of the flu or cold. Patients and visitors please consider asking your physician about your flu shot. Visitors, even though you may not be ill, you can still carry the flu virus. Protect our patients and your loved one.

If you have any questions about this information, please ask your nurse or any member of the Patient Care Team. 